\title{
Neurophysiological Correlates of Hand Preference in Primary Motor Cortex of Adult Squirrel Monkeys
}

\author{
R. J. Nudo,' W. M. Jenkins, ${ }^{2}$ M. M. Merzenich, ${ }^{2}$ T. Prejean, ${ }^{1}$ and R. Grenda ${ }^{1}$ \\ 'Department of Neurobiology and Anatomy, University of Texas Medical School at Houston, Houston, Texas, 77030 and \\ ${ }^{2}$ Coleman Laboratory and Keck Center for Integrative Neuroscience, and Departments of Physiology and Otolaryngology, \\ University of California at San Francisco, San Francisco, California 94143
}

\begin{abstract}
Variability in the functional topography of area 4 was examined in adult squirrel monkeys. Conventional intracortical microstimulation techniques were used to derive detailed maps (250 $\mu \mathrm{m}$ interpenetration distances) of distal forelimb movement representations in both hemispheres of six monkeys. Spatial features of these representational maps were then compared to the hand preferred by the individual animals during a motor task requiring skilled digit use.

Beyond a few broad generalizations common to all area 4 motor maps, the local mosaic-like topography of individual distal forelimb representations was highly idiosyncratic. Using statistical procedures to determine the independent contributions of individual, side, and movement category to the total variation in motor maps, the results demonstrate statistically significant variation in representational topography among individuals as well as between hemispheres of the same individuals. In the dominant hemisphere (i.e., the hemisphere opposite the preferred hand), the distal forelimb representations generally were greater in number and larger in total area, and displayed a longer total boundary length and a greater index of spatial complexity.

Because of the direct relationship between interhemispheric asymmetry and behavioral asymmetry, these studies suggest that a large source of variability found in the topography of motor maps in this and other studies derives from differences in the way particular movements and/or movement combinations are performed by individual animals.
\end{abstract}

Asymmetries in hand preference are well documented in humans. About $90 \%$ of humans are right-handed; right handedness is associated with a left hemisphere specialization for manual function (Broca, 1865; Oldfield, 1971; Kimura, 1977; Springer and Deutsch, 1989).

Evidence for comparable asymmetries in nonhuman primates is mixed, and conclusions are still controversial (e.g., Beck and Barton, 1972; Warren, 1977; MacNeilage et al., 1987; Fagot and Vauclair, 1991). Given the significant role of manual skill in

Received Oct. 7, 1991; revised Feb. 10, 1992; accepted Mar. 9, 1992.

We thank B. Keith Patricio and Casey Patricio for their help with the illustrations. This work was supported by Grants NS-27974 (to R.J.N.) and NS-10414 (to M.M.M.) from the National Institutes of Health, and the Whitehall Foundation (to R.J.N.)

Correspondence should be addressed to Randolph J. Nudo, Department of Neurobiology and Anatomy, University of Texas Medical School at Houston, Houston, TX 77030.

Copyright (C) 1992 Society for Neuroscience $0270-6474 / 92 / 122918-30 \$ 05.00 / 0$ theories of human evolution (e.g., Corballis, 1989), it is important to understand whether manual laterality is prevalent among nonhuman primates, and, if so, whether neurophysiological correlates of these behavioral specializations can be found. Such studies should provide new insights into the ontogenetic as well as the phylogenetic origins of hand "dominance" in humans.

It is generally assumed that some relationship must exist between functional and structural asymmetries in the two hemispheres (e.g., Semmes, 1968; Webster and Webster, 1975; Diamond et al., 1981; Kolb et al., 1982; Sherman and Galaburda 1984; Denenberg and Yutzey, 1985; Geschwind and Galaburda, 1985, 1987; Greenough et al., 1985; Galaburda et al., 1986). Still, only a few studies have attempted to find a relationship between functional hemispheric asymmetry and hand preference in individual animals. Many studies that have been reported employed ablation-behavior techniques to examine asymmetrics in bchavioral deficits following unilateral lesions. For example, in a series of experiments by Ettlinger and colleagues, unilateral removal of the second somatosensory area (SII) contralateral to a monkey's preferred hand resulted in bilateral deficits on a tactile discrimination task, while removal of SII ipsilateral to the preferred hand resulted in little or no impairment (Garcha et al., 1982; Hörster and Ettlinger, 1985; see also Robinson, 1979). These studies suggest that hemispheric differences may exist in somatic sensorimotor cortex in several mammalian species, and that such differences may be related to lateralization of certain sensorimotor skills.

In the present study, we used intracortical microstimulation techniques to derive detailed maps of distal forelimb movement representations in both hemispheres of adult squirrel monkeys. Spatial features of these representational maps were then compared to the hand preference of individual animals as defined by a motor task requiring skilled digit usc. The results show that in the dominant hemisphere (i.e., the hemisphere opposite the preferred hand), distal forelimb representations are larger, contain a larger number of discrete regions, and are more spatially complex.

\section{Materials and Methods}

Six adult, experimentally naive male squirrel monkeys (Saimiri sciureus) were used in the present study. This species was chosen mainly because the primary motor distal forelimb representation in squirrel monkeys is located within a relatively flat, unfissured sector of cortex, enabling derivation of highly detailed, two-dimensional evoked-movement maps. Although the precise ages of these animals were unknown, based on body weight and dentition, each was estimated to be a young adult, between 2 and 5 years of age. Each was free of any obvious physical or 
neurological deficit, and each was judged to be healthy both prior to and following behavioral testing and electrophysiological mapping sessions.

The gencral procedure adopted for each animal was as follows. First, limited hand preference testing was conducted on a task requiring skilled use of the digits (see below). Several days later, an electrophysiological map of the distal forelimb representation within primary motor cortex was derived, first in one hemisphere, and then, at least 5 weeks later, in the other. The experimenters conducting electrophysiological procedures were blind to the outcome of the behavioral procedures. The order of mapping in the two hemispheres was random.

In four animals, following a recovery period of several weeks after the final electrophysiological mapping session, additional behaviora] testing was conducted to determine the stability of hand preferences over time. In the other two animals, follow-up behavioral testing was not conducted since the final mapping session was performed as an acute procedure.

Iland preference testing procedure. Hand preference tcsting was conducted using a modified "Klüver board" (Glees, 1961; Lawrence and Kuypers, 1968). This device consisted of a rectangular Plexiglas board, $24 \mathrm{~cm}$ by $7.6 \mathrm{~cm}$ by $1.8 \mathrm{~cm}$ thick, containing four food wells of different diameters: $25 \mathrm{~mm}, 19.5 \mathrm{~mm}, 13 \mathrm{~mm}$, and $9.5 \mathrm{~mm}$ (Fig. 1).

Each animal was food restricted for $18 \mathrm{hr}$ prior to each testing session. Hand preference was measured for 100 trials over a period of 2-3 d. The Klüver board was attached to the front of the animal's home cage, approximately 12 inches above the height of the cage floor. The animal was required to support itself with one hand while reaching through the cage bars to retrieve pellets with the other. Each trial was recorded on videotape for later analysis. A single, banana-flavored, $45 \mathrm{mg}$ food pellet (BioServe) was placed randomly into one of the four wells, and the animal allowed to retrieve it. If the pellet was not successfully retrieved within $1 \mathrm{~min}$, the pellet was removed from the well, and the next trial begun. Thus, a trial was defined as the period beginning with the placement of a pellet into a well, and ending with a successful retrieval or a lapse of $1 \mathrm{~min}$. The time limit was imposed to minimize training effects. Hand preference was measured for 100 trials over a period of 2-3 d. Later, the videotape was reviewed, and for each trial we recorded (1) the hand used on the initial reach for that trial, (2) the hand used on subsequent reaches, and (3) the hand used to dislodge or retrieve the pellet. A reach was defined as the passing of the hand completely through the plane of the cage bars. A subsequent reach occurred only after the hand was withdrawn back through the plane of the cage bars into the interior of the cage. The percentage of initial reaches, subsequent reaches, and retrievals made with each hand on each well and summed across all wells was calculated. Since these three measures were highly correlated, for each animal we derived a "preference score": the average of the percentage of left-hand initial reaches and percentage of left-hand retrievals, for all wells.

In addition to the preference score, a handedness index was derived to provide an index of the degree of hand preference, irrespective of side. The handedness index was computed as follows:

$$
\mathrm{HI}=(P-50) * 2 \text {, }
$$

where $\mathrm{HI}$ is the handedness index, and $P$ is the average percentage of responses (average of initial reaches and retrievals) made with the preferred hand. Thus, the handedness index ranged from 0 for no hand preference (50\% responses made with each hand) to 100 for exclusive use of one hand.

Electrophysiological mapping procedure. The animal was initially lightly anesthetized with ketamine hydrochloride $(20 \mathrm{mg} / \mathrm{kg}$, i.m.). Following tracheal intubation, the animal was administered halothane (1-2\%) and nitrous oxide $(75 \%)$ and placed in a stereotaxic frame. Core temperature was measured using a rectal probe, and a homeothermic blanket maintained body temperature to within $36.5-38.0^{\circ} \mathrm{C}$ for the entire procedure (typically $15-19 \mathrm{hr}$ ). Core temperature only rarely fell below $37.0^{\circ} \mathrm{C}$ or rose above $37.5^{\circ} \mathrm{C}$. Heart and respiration rates were periodically monitored. An indwelling cannula was inserted into the saphenous vein for delivery of intravenous fluids. Mannitol $(8 \mathrm{cc} / \mathrm{kg})$ was slowly administered to reduce the likelihood of brain edema. Antibiotics (crysticillin, approximately $60,000 \mathrm{U}$ ) were administered prior to surgery and then every $12 \mathrm{hr}$ thereafter for $5 \mathrm{~d}$. Under sterile conditions, a limited craniotomy (approximately $1.5 \mathrm{~cm}$ diameter) was made over the primary motor cortex. A small, plastic chamber was affixed with dental acrylic to the skull around the opening. After reflection of the dura, the chamber was filled with silicone oil ( $30 \mathrm{k}$ centistoke, dimethylpolysiloxane, Dow 200 fluid).

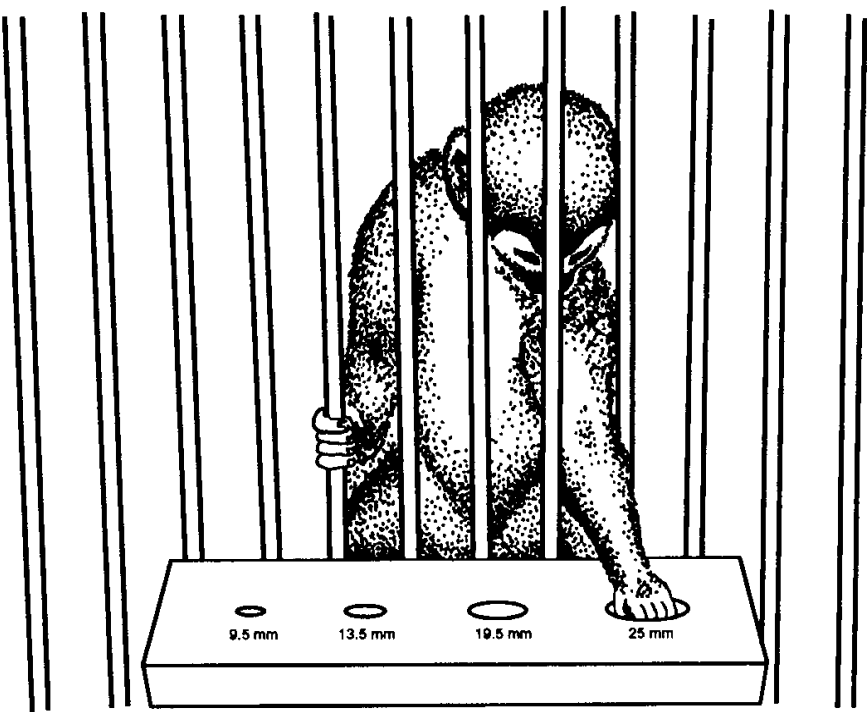

Figure 1. Schematic drawing of squirrel monkey during retrieval of a food pellet from the apparatus used to determine hand preference. A Plexiglas board (Klüver board) containing four small food wells was mounted on the front of the animal's cage. The wells ranged in size from $9.5 \mathrm{~mm}$ to $25 \mathrm{~mm}$. A single, small, banana-flavored pellet $(45 \mathrm{mg})$ was placed in one well until successfully retrieved. Videotape recordings of these sessions were later reviewed, and several measures of hand preference were quantified. Scc Matcrials and Methods for further details.

The halothane and nitrous oxide were then withdrawn, and the animal administered ketamine hydrochloride (diluted to $10 \mathrm{mg} / \mathrm{cc}$ with saline) intravenously at the rate of $15 \mathrm{mg} / \mathrm{kg} / \mathrm{hr}$. In addition, acepromazine (diluted to $0.1 \mathrm{mg} / \mathrm{cc}$ with saline) was administered at the rate of 0.01 $\mathrm{mg} / \mathrm{kg} / \mathrm{hr}$. The rate of ketamine infusion was occasionally adjusted to maintain a relatively stable anesthetic state. Intracortical microstimulation (ICMS) mapping was conducted only during periods of stable anesthesia; it was halted during occasional periods of shallow anesthesia marked by excessive muscle tone in forelimb muscles combined with rapid heart rate, or during occasional periods of deeper anesthesia marked hy unusually high thresholds.

A magnified photograph of the cortical surface vasculature was obtained using a video frame grabber. Stimulating microelectrodes consisted of glass micropipettes, $15-20 \mu \mathrm{m}$ in diameter at the tip, less than $100 \mu \mathrm{m}$ at $2 \mathrm{~mm}$ from the tip, and beveled to a sharp point. Micropipettes were filled with $3.5 \mathrm{M} \mathrm{NaCl}$. Impedances varied from $750 \mathrm{k} \Omega$ to $1 \mathrm{M} \Omega$. Microelectrodes were introduced on a fine grid pattern $(250 \mu \mathrm{m}$ interpenetration distances) sited with reference to the surface vasculature (Fig. 2). At each electrode penetration site, conventional intracortical microstimulation techniques were used to define evokable movements. Briefly, the micropipette was advanced perpendicular to the cortical surface to a depth of $1700-1800 \mu \mathrm{m}$ using a hydraulic microdrive. Our preliminary data, as well as previously published data by others (e.g., Strick and Preston, 1982a; Gould et al., 1986), suggested that thresholds for evoking movements are lowest at these depths. The stimulus consisted of $40 \mathrm{msec}$ current trains of 200 - $\mu \mathrm{sec}$-duration monophasic cathodal pulses delivered at $350 \mathrm{pulses} / \mathrm{sec}$ from an electrically isolatcd, charge-balanced (capacitivcly coupled) stimulation circuit. Trains were delivered at the rate of $1 / \mathrm{sec}$. Current was monitored by observing the voltage drop across a $10 \mathrm{k} \Omega$ resistor in series with the stimulation circuit.

In the derivation of all maps, monkeys were maintained in a standard prone position. The contralateral forelimb was supported below the elbow in the same slightly flexed position throughout each experiment. The forelimb was manipulated only when it was necessary to stabilize the wrist in order to distinguish between wrist extension and digit extension.

At each site, the movement evoked by stimulation at near-threshold 


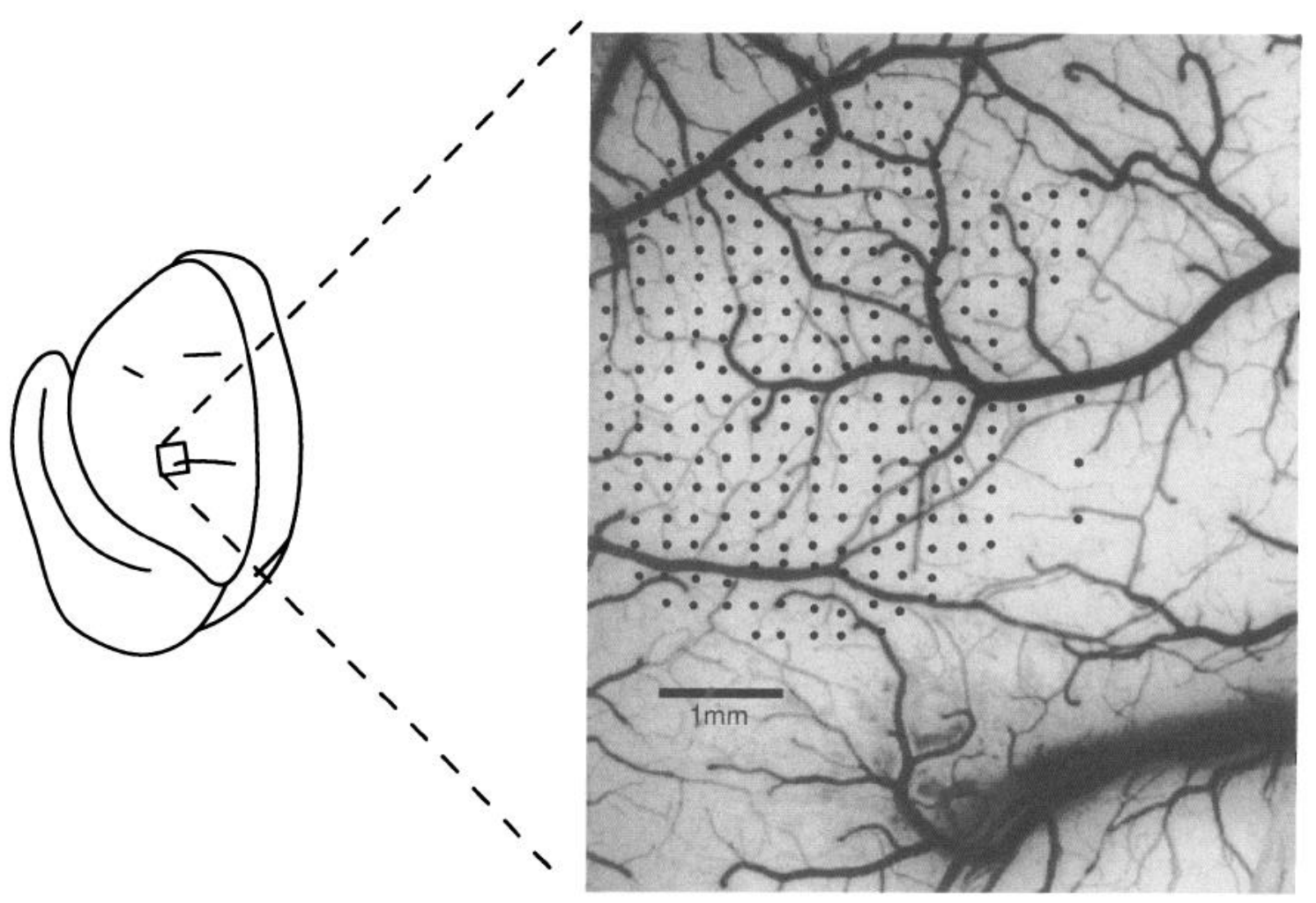

Figure 2. ICMS techniques used to derive representation of distal forelimb movements in primary motor cortex of squirrel monkey. Left, Dorsolateral view of squirrel monkey neocortex (left hemisphere), outlining the cortical territory explored in a typical motor mapping procedure. Right, Enlarged video image of cortical surface in monkey 8911 showing blood vessels used as landmarks for microelectrode insertion. Microelectrode penetration sites are indicated by dots. At each site, the microelectrode was advanced perpendicular to the surface vasculature to a depth of 1700 $1800 \mu \mathrm{m}$. Using standard ICMS stimulation parameters, the movement evoked by stimulation at near-threshold and at suprathreshold current levels was determined at each penetration site. See Materials and Methods for further details.

current levels was determined by the following procedure. Current was gradually increased from zero until a response was just visible. When the evoked movement was defined, the current was decreased until the movement disappeared, and then gradually increased again to determine the current level required for evoking the movement by at least $50 \%$ of the train bursts. This current was defined as the threshold current. The response evoked at threshold current level was called the threshold or primary response. In each experiment, in a sample of approximately $10 \%$ of electrode penetration sites, a second observer independently determined the primary response and threshold current. If a response was not evoked at $30 \mu \mathrm{A}$, stimulation was halted and the site was designated as nonresponsive. Sites at which the threshold current level was $\leq 18 \mu \mathrm{A}$ were called low-threshold sites. In a limited number of sites, the response evoked by stimulation at various depths from 1500 $2000 \mu \mathrm{m}$ was determined using identical procedures.

At low-threshold sites in four animals, the response evoked at a fixed suprathreshold current level of $20 \mu \mathrm{A}$ was also recorded. When an additional response (or responses) was evoked at this suprathreshold current level, it was called the suprathreshold or secondary response.

The territorial extent of the area 4 distal forelimb representation was explored as completely as possible using the following criteria. Penetrations were made at each coordinate of a $250 \mu \mathrm{m}$ grid pattern until the distal forelimb area was circumscribed by sites evoking either proximal movements or no visible response. When nonresponsive sites were encountered, their response to stimulation was verified later in the same mapping procedure.

Movements were described using conventional terminology identical to that used by Gould et al. (1986) in the owl monkey. For clarity, common terminology was used where appropriate. For example, movements of digit 1 are called "thumb" movements, and movements of digits 2-5 are called "finger" movements. A more complete description movement categories is provided in Results.

Description of spatial characteristics of distal forelimb representations. In order to define unambiguous boundaries between various movement regions and thus derive reliable perimetry information, we used the following procedure. First, $x-y$-coordinates of each penetration site were determined from their locations as indicated on the enlarged digital photograph of the surface vasculature. Next, a computer program delineated discrete regions encompassing sites whose stimulation evoked identical movements. Briefly, this algorithm gradually increased the size of designated (e.g., colored) circles whose origins were at each penetration site. A different color was used for each movement category. When a circle encountered another color, these two circles no longer increased in size along their common border, but continued to grow in other directions until the entire distal forelimb area was filled. The result was a two-dimensional map comprising colored regions whose borders were located halfway between sites representing different movement categories. In this way, we were able to assign movement categories objectively for a variety of classification schemes, and quickly redefine unambiguous borders.

Finally, these colored representational maps were analyzed using an image analysis program (IMAGE, version 1.35 ) that measured spatial parameters of regions representing different movement categories, coded by different colors. Using this program, we derived the following spatial parameters for each movement category: total area, total perimeter, total number of discrete regions, size of the largest region, and percentage of total distal forelimb area. In addition, a complexity index was derived for each movement category. The complexity index was a relative measure of total perimeter independent of area, and was defined as follows:

$$
\text { index }=p / 2 \cdot(\sqrt{\pi \cdot a}) \text {, }
$$

where $p$ is the total perimeter and $a$ is the total area. Therefore, a circle, a spatially simple region, has a complexity index of 1 . For more spatially complex regions, the perimeter per unit area, and thus the complexity index, is $>1$.

Finally, thresholds for evoking each movement were analyzed.

Histological analysis. Following completion of these experiments, each animal was anesthetized, the primary motor cortex exposed, and boundaries of the distal forelimb representations marked either by small, electrolytic lesions or by injection of fluorescent latex microspheres. The 


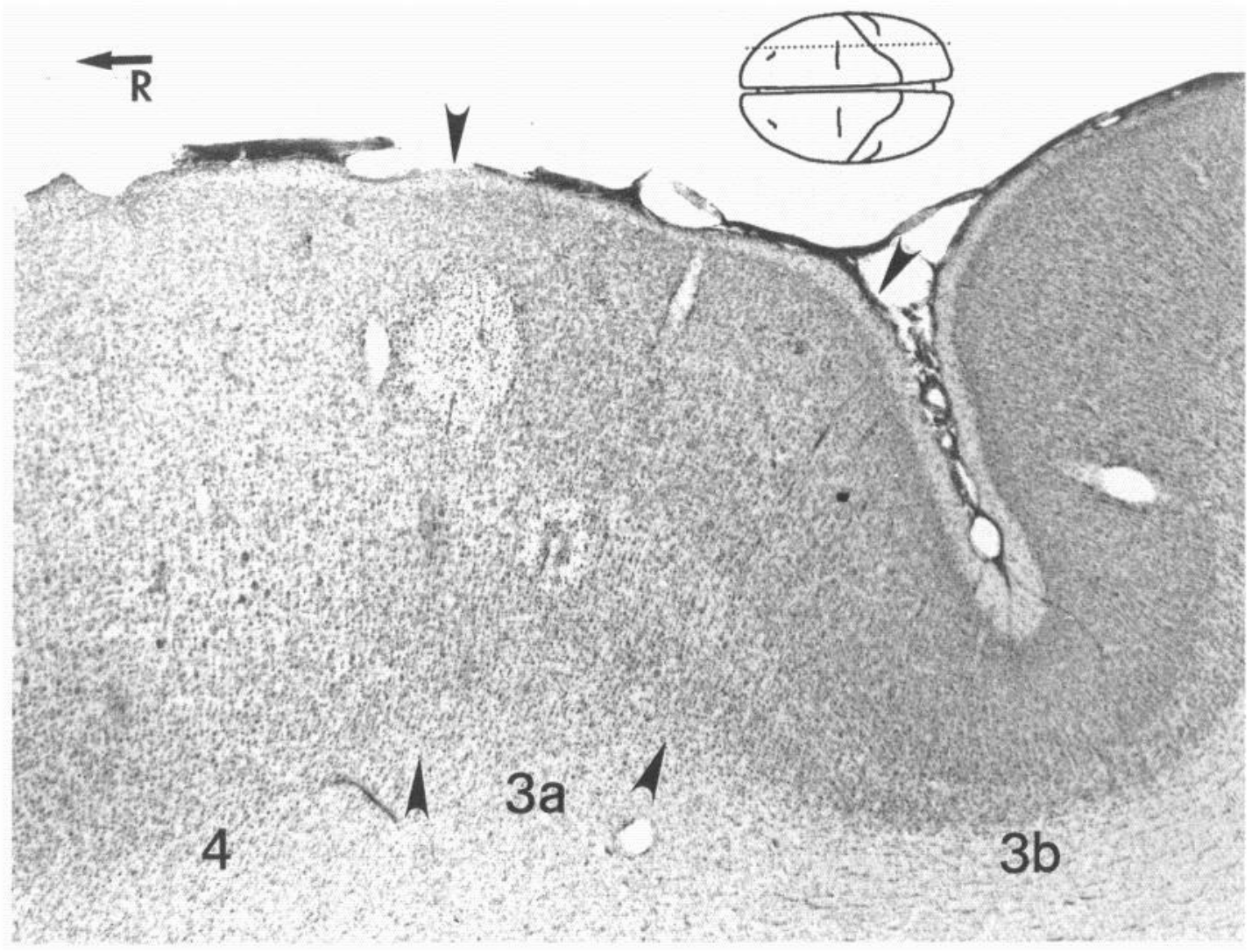

Figure 3. Photomicrograph of cresyl violet-stained parasagittal section through the left hemisphere of monkey 8734 . Inset at top shows histological section in dorsal view of brain. Larger lesion on left was made at $800 \mu \mathrm{m}$ while the smaller lesion on right was made at $1500 \mu \mathrm{m}$. ICMS at these sites evoked no visible movement at $\leq 30 \mu \mathrm{A}$ at depths from $1500 \mu \mathrm{m}$ to $2000 \mu \mathrm{m}$. ICMS at sites rostral to lesions evoked distal forelimb movements at low current levels. Cytoarchitectonically defined boundaries are indicated by arrowheads. $R$, Rostral. Magnification, $37 \times$.

animal was then injected with a lethal dose of pentobarbital $(100 \mathrm{mg} /$ $\mathrm{kg}$ ) and perfused, first with $0.9 \%$ saline, $0.2 \%$ lidocaine hydrochloride, $1 \%$ heparin, and then with $1.25 \%$ glutaraldehye, $1 \%$ paraformaldehyde or with $10 \%$ formalin. The brain was subsequently removed and immersed in $30 \%$ sucrose for $1-2 \mathrm{~d}$. It was cut in $50 \mu \mathrm{m}$ frontal sections. Every other section was mounted and stained with cresyl violet for cytoarchitectonic analysis. This sampling frequency was sufficient to locate each penetration site indicating the boundaries of distal forelimb representation (electrolytic lesions or fluorescent microspheres). Electrode tracks produced by the glass micropipettes used for recording stimulus-evoked movements were not detectable using these techniques.

\section{Results}

\section{Hand preference}

As described in Materials and Methods, hand preference was estimated for each animal using a modified Klüver board in a task requiring retrieval of small food pellets from a set of four wells graded in diameter. For each of 100 trials, (1) the hand used on the initial attempt on each trial, (2) the hand used on subsequent attempts on each trial, and (3) the hand used to retrieve food pellets successfully on each trial were recorded and analyzed.

During a typical trial, the animal grasped the cage bars with one hand while reaching through the plane of the bars with the other hand (Fig. 1). Once the well was reached, the pellet was retrieved by making successive flexions and extensions of digits $1-5$ or digits $2-5$, often with the palm on the surface of the board and the wrist dorsiflexed until the pellet was dislodged. Upon withdrawal from the well, the pellet was typically held between the flexed fingers and the palm in a power grip (Napier and Napier, 1985; Costello and Fragaszy, 1988). Successful retrieval usually required a single reach and a single flexion on the larger wells, but required multiple flexions and often multiple reaches on the smallest well. When multiple reaches were made, the animal occasionally varied the hand used on subsequent attempts.

While a clear preference was not always apparent on the first 20-30 trials, most animals consistently used the same hand after approximately 40-50 trials. Since hand preference scores for initial attempts and subsequent attempts were nearly identical, only initial attempts and retrievals are reported here. Once established, hand preference scores were stable over a studied

\begin{tabular}{lllll}
\hline Table 1. & $\begin{array}{c}\text { Hand preference scores and handedness index } \\
\text { Initial } \\
\text { Case }\end{array}$ & $\begin{array}{l}\text { Retrievals } \\
(\% \mathrm{~L})\end{array}$ & $\begin{array}{l}\text { Preference } \\
\text { score }(\% \mathrm{~L})\end{array}$ & $\begin{array}{l}\text { Hand- } \\
\text { edness } \\
\text { index }\end{array}$ \\
\hline 8727 & 18 & 10 & 14 & 72 \\
8734 & 98.3 & 98.3 & 98.3 & 96.6 \\
8905 & 98.6 & 100 & 99.3 & 98.6 \\
8909 & 80 & 76 & 78 & 56 \\
8910 & 84 & 84.7 & 84.35 & 68.7 \\
8911 & 59 & 51.6 & 55.3 & 10.6 \\
\hline
\end{tabular}




\section{1}
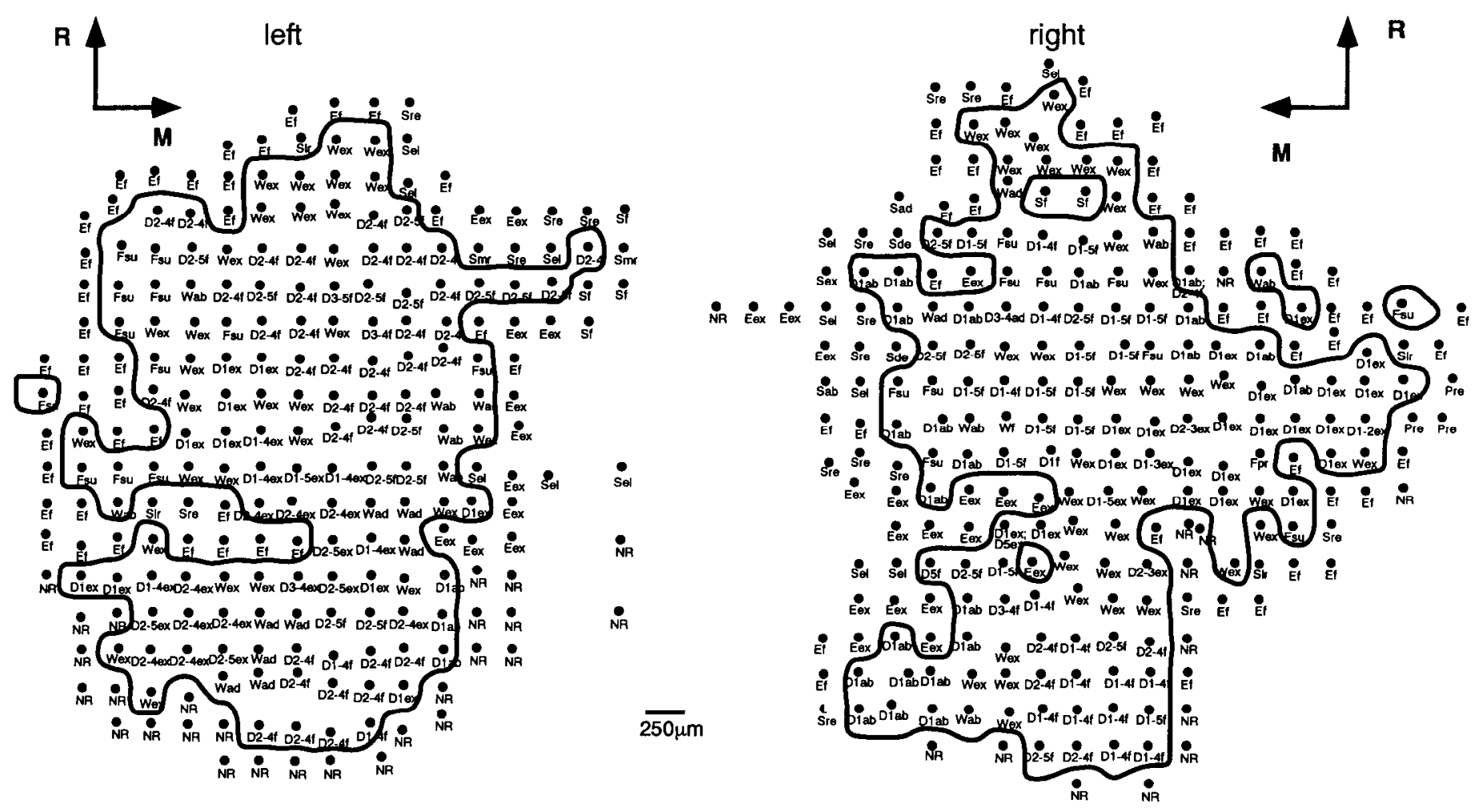

Figure 4. Left, Movements evoked at near-threshold current levels from each site shown in Figure 2 (monkey 8911 , left hemisphere). Right, Movements evoked at near-threshold current levels from sites in the right hemisphere of monkey 8911 . The distal forelimb is outlined to illustrate its total areal extent within primary motor cortex. Note that individual movements were represented at multiple locations within the primary motor distal forelimb representation. Abbreviations: $D$, digit; $W$, wrist; $F$, forearm; $S$, shoulder; $E$, elbow; $P$, pinna; $J$, jaw; $N R$, no response; $f$, flexion; $e x$, extension; $a d$, adduction; $a b$, abduction; $m r$, medial rotation; $s u$, supination; pro, pronation; $e l$, elevation; $r e$, retraction; $u$, ulnar; $M$, medial; $R$, rostral. Numbers indicate specific digits involved in movement.

period of scveral months. In four of the animals in this series, hand preference was again obtained 4 months after recovery from the final mapping session. The results of each animal were nearly identical to those obtained prior to mapping studies. Hand preference scores and handedness indices derived from 100 trials for each of the six monkeys are recorded in Table 1.

Five of the six monkeys preferred the left hand on more than $50 \%$ of trials on both initial attempts and retrievals, and were considered left-handed. The sixth monkey (subject 8727 ) preferred the right hand on more than $50 \%$ of trials, and was considered right-handed. Four of the five left-handed monkeys were strongly left-handed, with preference scores of $78 \%$ left or higher, and handedness indices of 56 or higher. The fifth monkey was weakly left-handed, with a preference score of $55.3 \%$ left and a handedness index of 10.6. Finally, the single right-handed monkey was strongly right-handed, with a preference score of $86 \%$ right and a handedness index of 72 .

\section{General organization of distal forelimb representation in primary motor cortex}

The caudal boundary of the area 4 distal forelimb representation was located approximately $1-2 \mathrm{~mm}$ rostral to the central sulcus, usually near its lateral edge (Figs. 2, 3). The distal forelimb representation was bounded medially, rostrally, and laterally by more proximal movement representations, primarily those of the elbow and shoulder (Figs. 4,5 ), and caudally by a nonresponsive zone $(\leq 30 \mu \mathrm{A})$.

Examination of lesions and fluorescent markers revealed that the entire distal forelimb representation, as defined by ICMSevoked movements at current levels $\leq 30 \mu \mathrm{A}$, was contained within cytoarchitectonic area 4 . Figure 3 depicts an example of the material upon which this conclusion was based. This parasagittal section through the right hemisphere of monkey 8734 shows two lesions placed immediately caudal to the caudalmost responsive site in this experiment. The lesion on the left was placed at $800 \mu \mathrm{m}$ while the lesion on the right was placed at $1500 \mu \mathrm{m}$. At both of these sites, ICMS evoked no visible movement at any depth from 1500 to $2000 \mu \mathrm{m}$. At a site $250 \mu \mathrm{m}$ rostral to the site marked by the left lesion, ICMS at $1800 \mu \mathrm{m}$ evoked thumb extension at $18 \mu \mathrm{A}$. The physiologically defined border between responsive and nonresponsive cortex approximately coincided with an attcnuation of the internal granular layer (layer IV) and a decrease in the number of large layer $\mathrm{V}$ pyramidal cells, indicative of the area 4-area 3a border (Sanides, 1968; Jones, 1975; Jones and Porter, 1980; Strick and Preston, 1982a).

The distal forelimb representation was explored in detail in each animal. Although the exact placement of microelectrodes was sometimes locally constrained by the location of surface blood vessels, the interelectrode penetration distance was as 


\section{0}

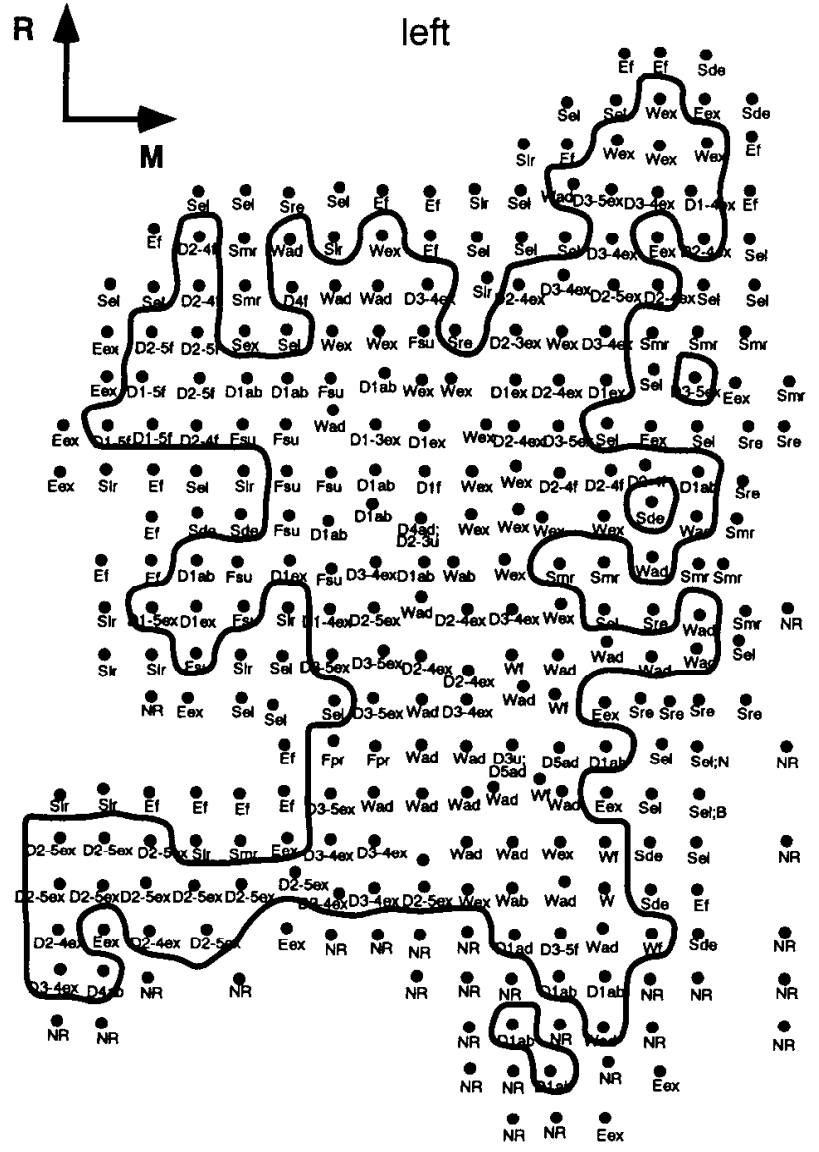

right

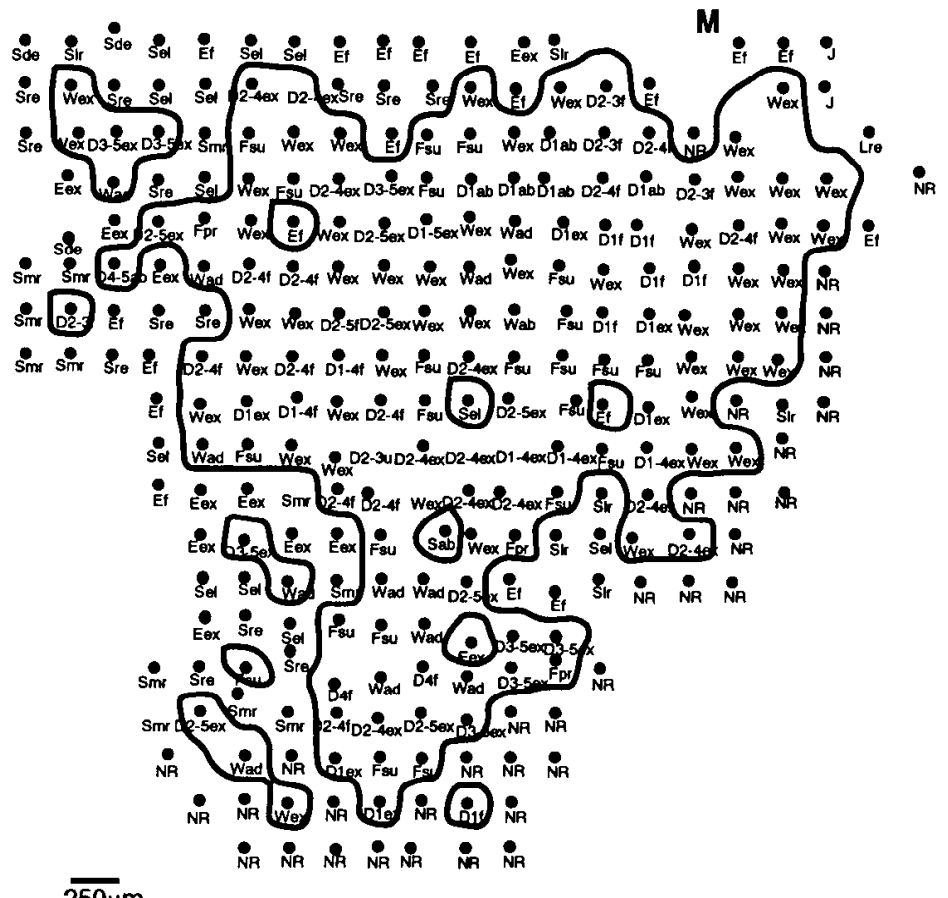

Figure 5. Movements evoked at near-threshold current levels from stimulation of sites in monkcy 8910 . The distal forelimb field is outlined to illustrate its total areal extent within primary motor cortex. Abbreviations are as in Figure 3.

close as possible to $250 \mu \mathrm{m}$, in all maps. We attempted to explore the entire territorial extent of the area 4 distal forelimb representation. Because of limitations imposed by the size of the craniotomy, sectors of the distal forelimb boundary were occasionally not mapped completely, leaving some boundaries undefined. Since the distal forelimb representation was well circumscribed on three sides by more proximal movement representations and on the remaining side by an unresponsive region, we estimate that for the six animals included in the present analysis, the undefined boundary averaged less than $6 \%$ of the total distal forelimb boundary (maximum, 16\%). Primary responses independently defined by two experimenters were identical on $>90 \%$ of the sites that were compared. Differences were typically limited to definition of the exact digits whose movement was evoked by stimulation, such as digits $2-4$ flexion versus digits $2-5$ flexion. Differences in movement category were rare. Representation of movements in two representative cases are shown in Figures 4 and 5.

The total distal forelimb area was highly varible in extent, both among individuals and between hemispheres within individuals. The mean areal extent for the 12 maps in six individuals was $9.69 \mathrm{~mm}^{2}$, and ranged from 5.86 to $14.26 \mathrm{~mm}^{2}$ in animals with approximately equal body weights. No significant correlation was found between distal forelimb representational area and body weight. Interhemispheric disparities in total area ranged from 0.070 to $3.64 \mathrm{~mm}^{2}$, or $0.7 \%$ to $37.6 \%$ of the mean area, for all 12 maps. Since the total area was so variable, the total number of penetrations required to explore the entire distal forelimb representation also varied. The mean number of penetrations per hemisphere was 295.25 (range, 214-450). Histological analysis in each animal verified that the entire distal forelimb representation was contained within cytoarchitectonic area 4.

Observed distal forelimb movements evoked by ICMS may be described at different levels of specificity. For example, with respect to the specific body part(s) involved in the movement, flexion of the thumb may be described as "thumb flexion," or the more generic "thumb" or the even more generic "digit." Because the division of distal forelimb movements into digit and wrist/forearm categories forms a second level of a movement hierarchy, we refer to movements in this classification schemc as "digit-wrist/forearm categories." Similarly, with respect to agonist movement groups, the same movement may be described as belonging to the "thumb flexion group" (i.e., thumb flexion and/or thumb adduction), "digit flexion group" (i.e., thumb flexion group and/or finger flexion group), or simply "flexion group" (i.e., digit flexion group and/or wrist/forearm flexion group). Because the division of distal forelimb move- 


\section{DIGIT-WRIST/FOREARM CATEGORIES}

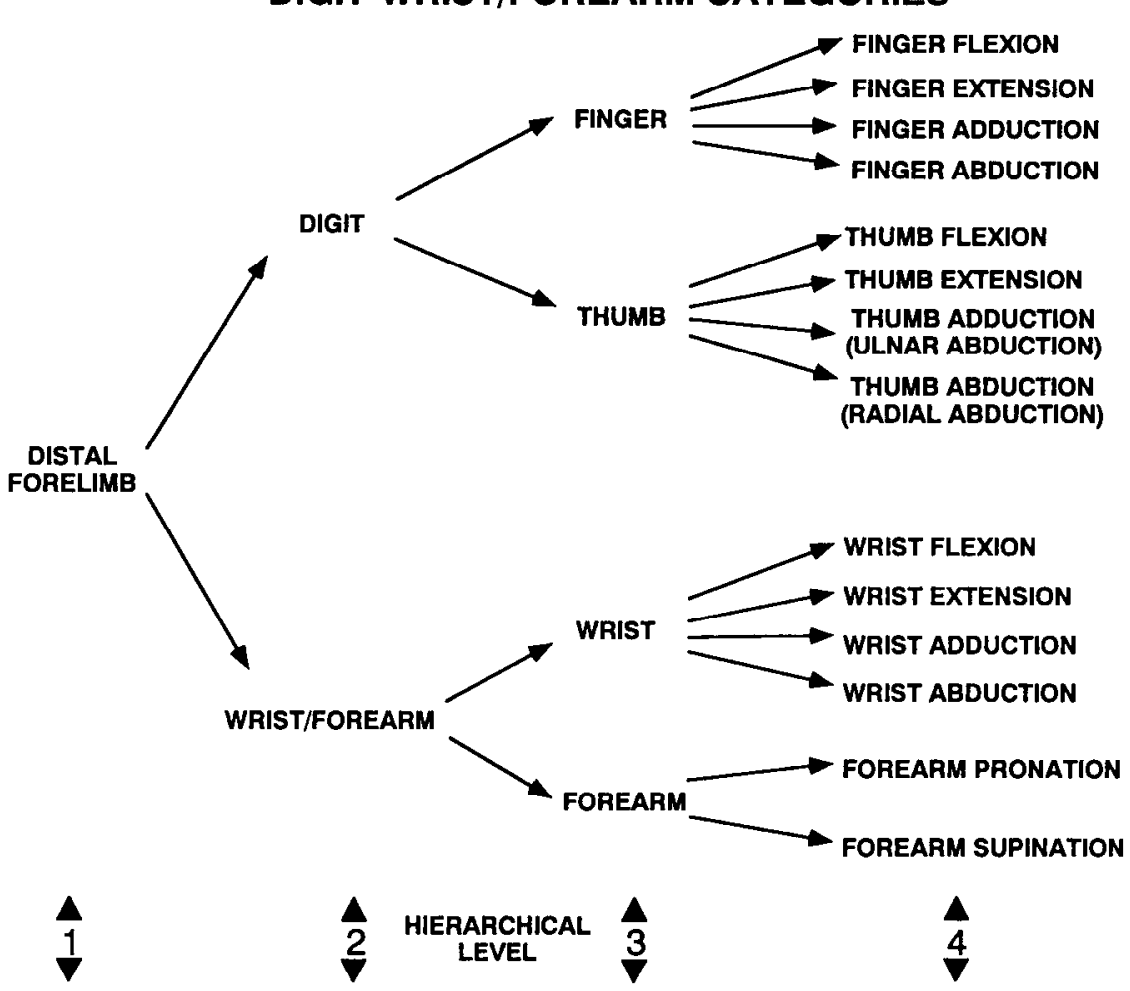

Figure 6. Hierarchical classification of distal forelimb movements. For statistical purposes, differences between dominant and nondominant hemispheres were examined at each of four hierarchical levels of movement classification. Further, two different classification schemes were used, one broadly dividing distal forelimb movements into digit and wrist/forearm categories (top), and the second broadly dividing distal forelimb movements into flexion and extension categories (bottom).

\section{FLEXION-EXTENSION CATEGORIES}

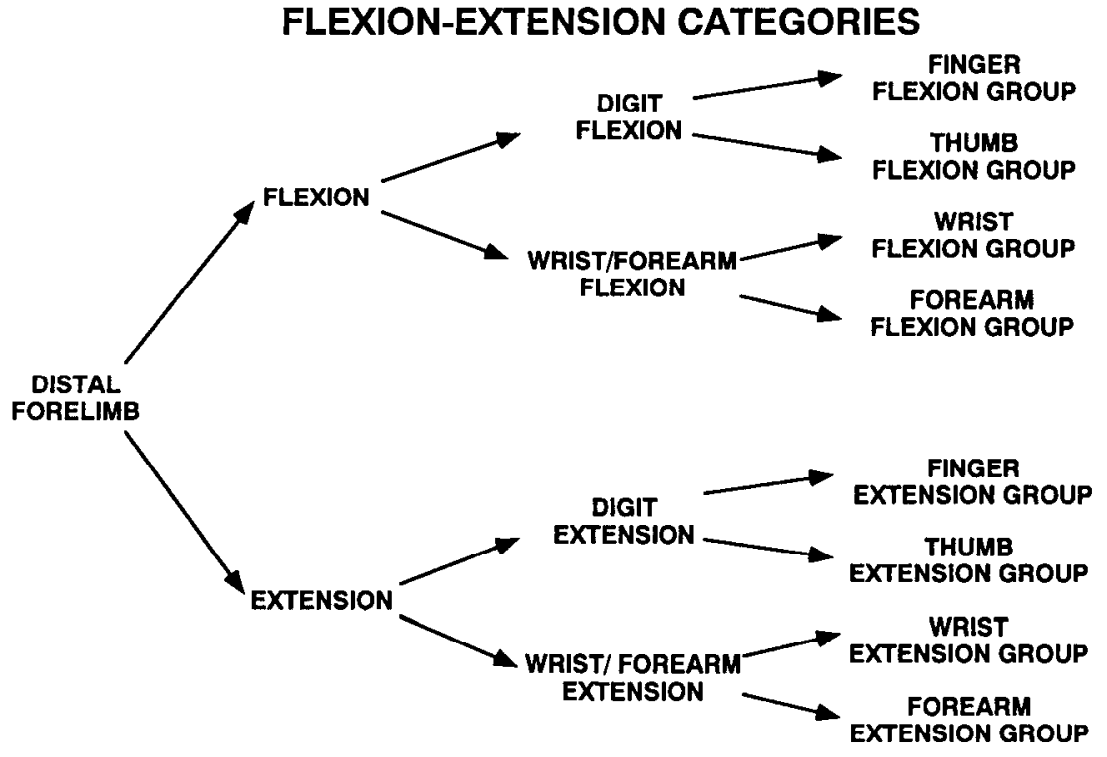

ments into flexion and extension categories forms a second level of a second movement hierarchy, we refer to movements in this classification scheme as "flexion-extension categories."

The spatial characteristics of motor maps were examined at each of four hierarchical levels of both classification schemes, for two reasons: (1) It was not clear a priori which description would be most appropriate for drawing relationships to behavioral asymmetries. (2) We wanted to determine the robustness of the results in the face of different, somewhat arbitrary movement classifications. Hierarchical classification of the 21 digitwrist/forearm categories and the 15 flexion-extension categories is shown in Figure 6.

For each movement category, the following statistics were calculated: total representational area, total boundary length or perimeter, size of the largest discrete representational region, total number of discrete regions, complexity index (see Materials and Methods), percentage of total distal forelimb area, and mean threshold current.

In the descriptions of results that follow, the hemisphere contralateral to the preferred hand will be referred to as the dominant hemisphere, and the hemisphere ipsilateral to the preferred hand as the nondominant hemisphere. These terms are used here only for heuristic purposes, and are not intended to generalize to dominance related to other motor tasks.

A summary of the distal forelimb representation in both hemispheres of each of the six animals is illustrated in Figure 7. For 


\section{DIGIT-WRIST/FOREARM}

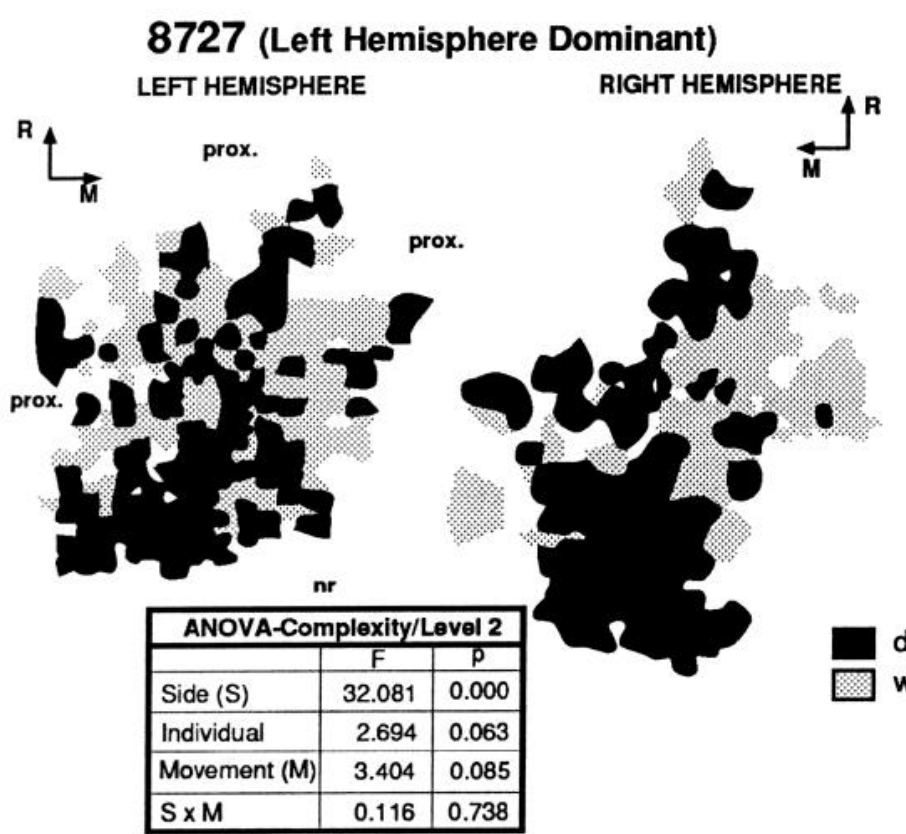

8905 (Right Hemisphere Dominant)

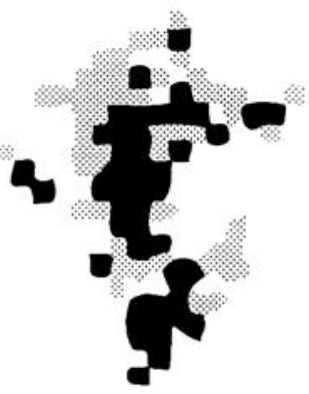

\begin{tabular}{|l|r|c|}
\hline \multicolumn{3}{|c|}{ t- tests-Digit } \\
\hline & d-nd & $p$ \\
\hline perimeter & 10.377 & 0.015 \\
\hline complexity & 1.124 & 0.003 \\
\hline
\end{tabular}

8910 (Right Hemisphere Dominant)

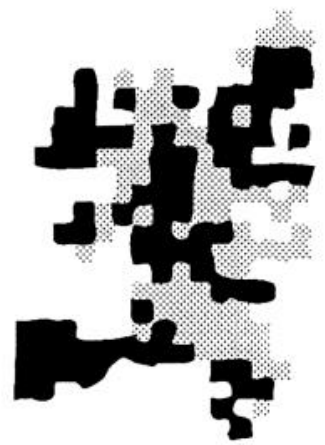

\section{4 (Right Hemisphere Dominant)}

digit

wrist/forearm
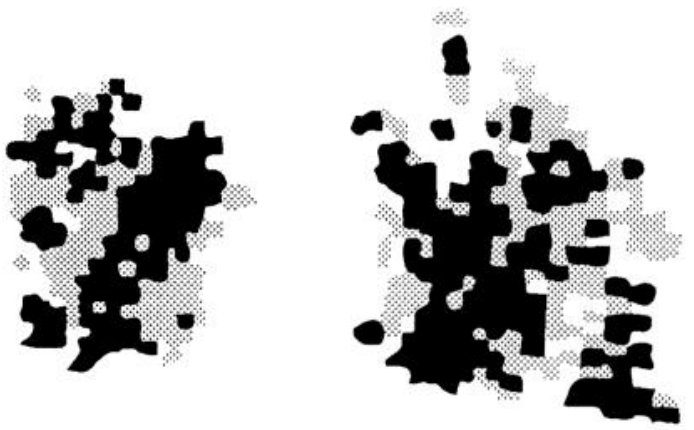

\begin{tabular}{|l|r|c|}
\hline \multicolumn{3}{|c|}{ ANOVA-Perimeter/Level 2 } \\
\hline & \multicolumn{1}{|c|}{$\mathrm{F}$} & $\mathrm{P}$ \\
\hline Side (S) & 33.942 & 0.000 \\
\hline Individual & 7.466 & 0.001 \\
\hline Movement (M) & 0.280 & 0.604 \\
\hline $\mathrm{S} \times \mathrm{M}$ & 0.809 & 0.383 \\
\hline
\end{tabular}

\section{9 (Right Hemisphere Dominant)}
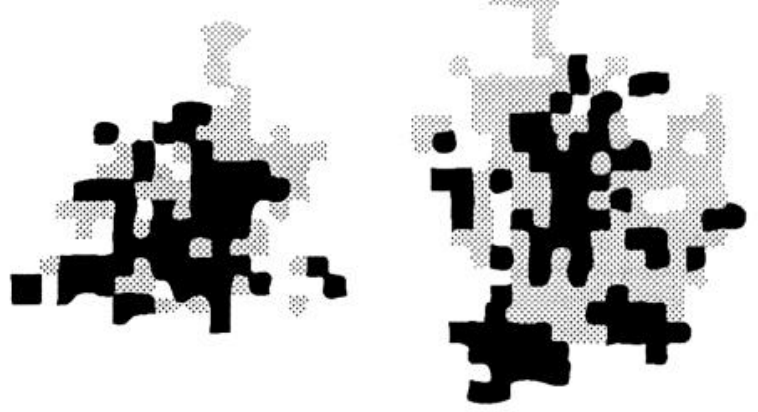

\begin{tabular}{|l|r|c|}
\hline \multicolumn{3}{|c|}{ t-tests-Wrist/forearm } \\
\hline & d-nd & $p$ \\
\hline perimeter & 14.167 & 0.006 \\
\hline complexity & 0.997 & 0.019 \\
\hline largest reg. & 1.525 & 0.018 \\
\hline
\end{tabular}

8911 (Right Hemisphere Dominant)
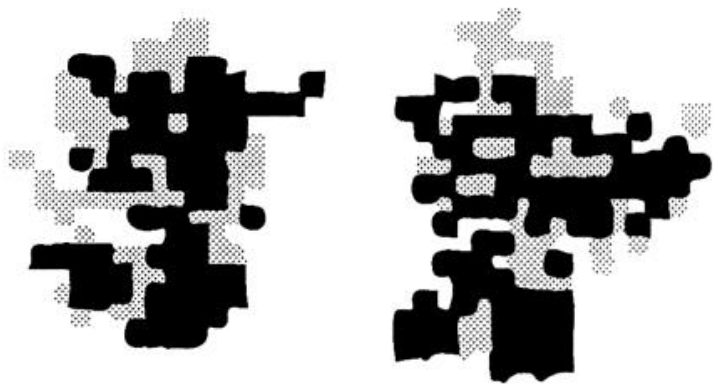

Figure 7. Representation of the distal forelimb in cortical area 4 in left and right hemispheres of all six squirrel monkeys used in this study. In this illustration, distal forelimb movements have been broadly categorized as digit (black) or wrist/forearm (shaded) movements (hierarchical level 2 of Fig. 6). Magnification in this and Figures 8-10 is the same for all 12 maps. Note that a larger cortical territory, stimulation of the remainder of which did not evoke digit or wrist/forearm movements, was actually explored in every case. Sites evoking proximal movements (prox.) were usually located rostral, medial, and lateral to the distal forelimb area. Nonresponsive sites $(n r)$ were usually located caudal to distal forelimb area. Selected statistical results are shown in insets. $d$-nd, dominant minus nondominant. 
clarity, movements are grouped into two broad classes forming level 2 of the digit-wrist/forearm hierarchy. It can be seen that the arrangement of these broad movement classes was extremely variable. Digit representation areas were interdigitated with wrist/ forearm representation areas in mosaic-like patterns. Using unambiguous criteria to subdivide regions (i.e., the computer algorithm; see Materials and Methods), a mean of 10.92 discrete digit regions ranging from a minimum of 5 to a maximum of 20 could be observed in any one map. Likewise, wrist/forearm regions were also highly variable. An average of 10.58 discrete wrist/forearm regions, ranging from a minimum of 5 to a maximum of 13 , could be observed in a single map.

Representations of other movement classes (finger flexion, wrist extension, and thumb extension) at level 4 of the digitwrist/forcarm heirarchy are shown for each of the six animals in Figures 8-10.

Statistical analyses were performed in order to examine quantitative differences in each of the spatial characteristics of movement categories. Three-way ANOVAs were performed to determine the independent effects of (1) individual, (2) side (hemisphere), and (3) movement category, on each of seven dependent variables: area, perimeter, number of regions, largest region, complexity index, percentage of total distal forelimb area, and threshold. A separate ANOVA was performed at each level of each of the two movement hierarchies. Interaction effects were determined only for side and movement category (fixed effects), but not for individual (random effect). An $\alpha$-level of 0.05 was used throughout as the criterion level for statistically significant effects.

These analyses resulted in several statistically significant main effects of individual, side, and movement category. Descriptive statistics and specific results of individual analyses are listed in Tables 2 and 3.

\section{Interindividual comparisons of motor map topography}

When representations of movement categories were examined, large differences among animals were observed. These differences were reflected in the shape of the distal forelimb representational zone within area 4 , the topographic location of a particular movement relative to the remainder of the distal forelimb representation, as well as total area, perimeter, number of regions, and measures of complexity (Figs. 7-10). Topological neighborhood relationships of different movements were also highly variable among individuals, but will not be described further in the present report. Few generalizations could be made regarding the specific locations of any movement representation, though there was some tendency for thumb movements to be represented more in the lateral half of the distal forelimb area (Fig. 10). A clear distinction between rostral and caudal digit and wrist/forearm representations was not observed.

ANOVAs revealed several statistically significant differences among individuals at hierarchical levels 2,3 , and 4 . These included differences in area, perimeter, number of regions, largest region, complexity index, and threshold, but not percentage of total distal forelimb area (Table 3). For example, averaging across the two hemispheres of each individual, the mean areal extent of the wrist abduction representation ranged from $0.09 \mathrm{~mm}^{2}$ in monkey 8910 to $0.62 \mathrm{~mm}^{2}$ in monkey 8909 , nearly a sevenfold difference; the mean perimeter of the thumb flexion representation ranged from $0.515 \mathrm{~mm}$ in monkey 8911 to $7.125 \mathrm{~mm}$ in monkey 8727 , nearly a 14 -fold difference; the mean number of thumb extension regions ranged from 2.5 in monkey 8905 to 10 in monkey 8734 , a fourfold difference.

\section{Interhemispheric comparisons of motor map topography}

The topography of specific movement representations was more similar between hemispheres of the same individual than among individuals. For example, the locations of finger flexion regions in the left hemisphere of monkey 8910 very roughly mirrored those in the right hemisphere (Fig. 8). Likewise, the locations of finger flexion regions in the left hemisphere of monkey 8911 roughly paralleled those in the right hemisphere. On the other hand, finger flexion locations were quite different between the two cases. While rough mirror images of certain movement representations were observed in some monkeys, striking exceptions were also noted, such as the finger flexion locations of monkey 8905 (Fig. 8) or the wrist extension locations of monkey 8910 (Fig. 9).

Despite the large variation in motor map topography contributed by the individual monkeys, several statistically significant interhemispheric differences were found at each of the hierarchical levels and for each of the seven spatial parameters. 'Figures 11 and 12 summarize independent main effects of side and side-by-movement interactions for each of the seven dependent variables.

Effects of side on spatial characteristics of digit-wrist/forearm categories. When digit-wrist/forearm categories were examined, each of the seven variables displayed either a significant effect of side, a significant side-by-movement interaction, or both (Fig. 11, Table 3). There was a significant effect of side for at least one hierarchical level for five of the seven variables. The differences in perimeter and complexity index were due to significant effects of side at each of levels 2, 3, and 4 of the hierarchy. The differences in number of regions were due to effects of side at hierarchical levels 3 and 4 , the differences in area were due to effects of side only at hierarchical level 3 , and the differences in threshold were due to effects of side only at level 4 .

Effects of side on spatial characteristics of flexion/extension categories. When flexion/extension categories were examined, five of the seven variables displayed either a significant effect of side, a significant side-by-movement interaction, or both (Fig. 12). There was a significant effect of side for at least one hierarchical level for three of the seven variables. The differences in perimeter and complexity index were due to significant effects of side at each of levels 2,3 , and 4 of the hierarchy, identical to the analyses for digit/wrist-forearm categories; the differences in number of regions were due to effects of side at hierarchical levels 3 and 4 . The differences in the size of the largest region and threshold were not due to either side or side-by-movement interactions at any hierarchical level.

Differences in spatial characteristics for individual movement categories. Since ANOVA demonstrated significant differences between the dominant and nondominant hemispheres using several of the dependent variables at various hierarchical levels, we next determined whether effects of side were due to interhemispheric differences in the representations of specific movement categories using post hoc analyses. Paired $t$ tests were performed only within hierarchical levels in which the main effect of side or side-by-movement interactions was significant.

These analyses resulted in 22 significant $t$ tests for digit-wrist/ forearm categories, and 19 significant $t$ tests for flexion/extension categories (Figs. 11, 12; Table 2). Significant differences were most numerous for complexity index and perimeter. For 


\section{FINGER FLEXION}

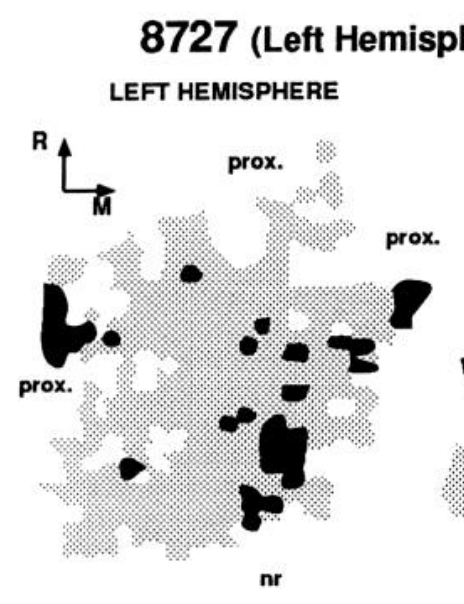

8727 (Left Hemisphere Dominant)

RIGHT HEMISPHERE

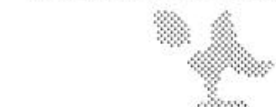

$\stackrel{\sim}{M}^{R}$

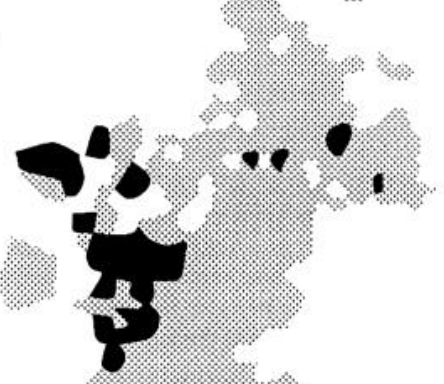

finger flexion

other distal forelimb

\section{4 (Right Hemisphere Dominant)}
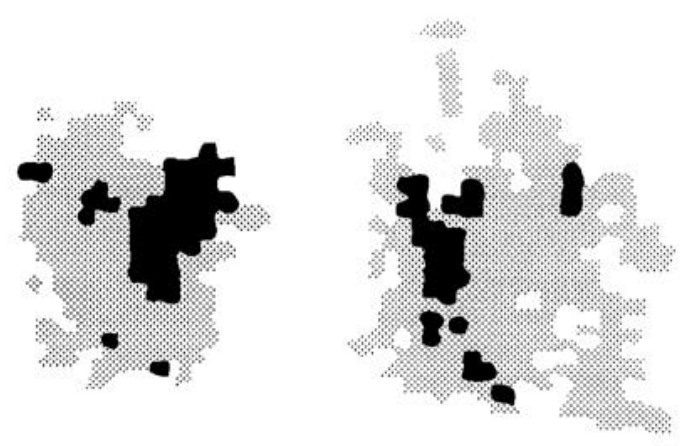

8905 (Right Hemisphere Dominant)
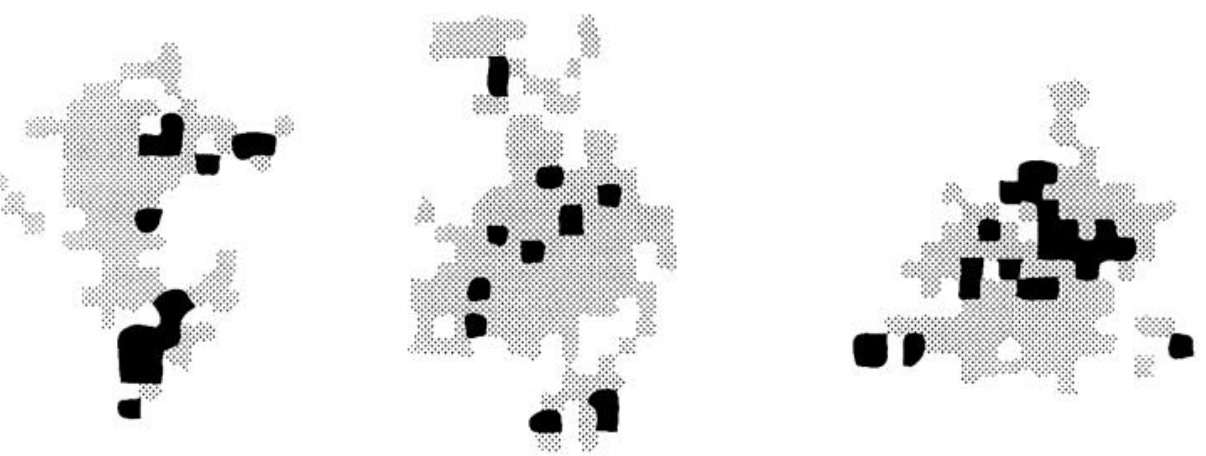

8909 (Right Hemisphere Dominant)

\begin{tabular}{|l|l|c|}
\hline \multicolumn{3}{|c|}{ t-tests-Finger flexion } \\
\hline & d-nd & $P$ \\
\hline complexity & 0.570 & 0.046 \\
\hline
\end{tabular}

\section{0 (Right Hemisphere Dominant)}
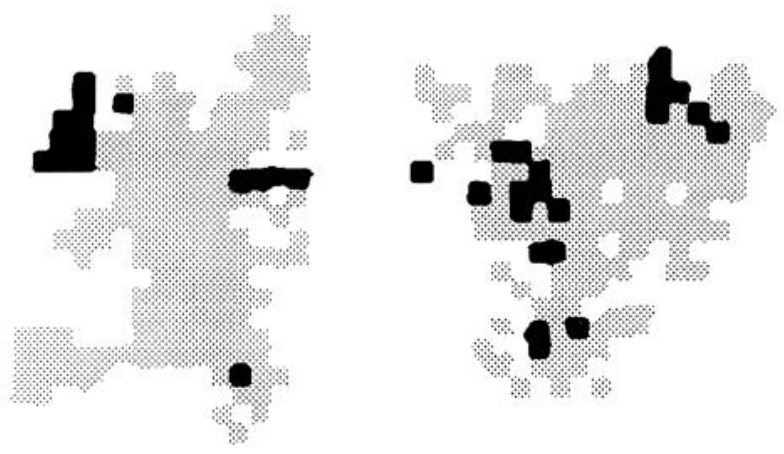

8911 (Right Hemisphere Dominant)
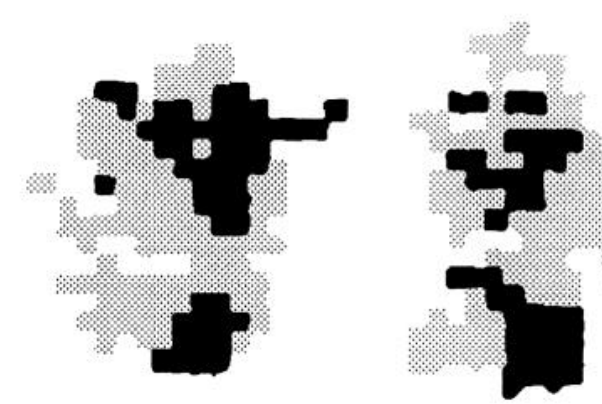

Figure 8. Representation of finger flexion fields in cortical area 4 in left and right hemispheres of all six squirrel monkeys used in this study. Finger flexion fields are displayed in black; other distal forelimb fields are displayed in shaded areas. Proximal fields and nonresponsive fields are not shown. Selected statistical results are shown in the inset. 


\begin{tabular}{|c|c|c|c|c|c|c|c|c|c|}
\hline Movement & $\overline{\mathrm{D}}$ & $\mathrm{SD}$ & $\overline{\mathrm{ND}}$ & $\mathrm{SD}$ & $\overline{\mathrm{D}}-\overline{\mathrm{ND}}$ & $\mathrm{SD}$ & $t$ & df & $p$ \\
\hline \multicolumn{10}{|c|}{ A. Digit/wrist-forearm categories } \\
\hline \multicolumn{10}{|c|}{ Area } \\
\hline Distal forelimb & 10.59 & 1.78 & 8.79 & 3.06 & $\mathrm{n} / \mathrm{a}$ & $\mathrm{n} / \mathrm{a}$ & $\mathrm{n} / \mathbf{a}$ & $\mathrm{n} / \mathrm{a}$ & $\mathrm{n} / \mathbf{a}$ \\
\hline Digit & 5.22 & 1.31 & 4.75 & 1.94 & $\mathrm{n} / \mathrm{a}$ & $\mathrm{n} / \mathrm{a}$ & $\mathrm{n} / \mathrm{a}$ & $\mathrm{n} / \mathrm{a}$ & $\mathrm{n} / \mathbf{a}$ \\
\hline Wrist/forearm & 5.39 & 1.25 & 4.17 & 1.24 & $\mathrm{n} / \mathrm{a}$ & $\mathrm{n} / \mathrm{a}$ & $\mathrm{n} / \mathrm{a}$ & $\mathrm{n} / \mathrm{a}$ & $\mathrm{n} / \mathrm{a}$ \\
\hline Fingers & 3.34 & 0.89 & 3.88 & 1.79 & -0.54 & 1.18 & -1.11 & 5 & 0.318 \\
\hline Thumb & 2.11 & 1.14 & 1.02 & 0.35 & 1.09 & 1.33 & 2.01 & 5 & 0.101 \\
\hline Wrist & 3.84 & 1.00 & 2.51 & 1.01 & 1.33 & 1.13 & 2.89 & 5 & 0.034 \\
\hline Forearm & 1.52 & 0.42 & 1.22 & 0.42 & 0.30 & 0.44 & 1.64 & 5 & 0.162 \\
\hline Finger flexion & 1.54 & 0.63 & 1.66 & 0.79 & -0.12 & 0.40 & -0.74 & 5 & 0.494 \\
\hline Finger ext. & 1.45 & 0.89 & 2.02 & 1.64 & -0.58 & 1.01 & -1.39 & 5 & 0.223 \\
\hline Finger add. & 0.08 & 0.07 & 0.05 & 0.05 & 0.03 & 0.06 & 1.06 & 5 & 0.337 \\
\hline Finger abd. & 0.04 & 0.04 & 0.03 & 0.06 & 0.00 & 0.04 & 0.10 & 5 & 0.925 \\
\hline Thumb flexion & 0.27 & 0.17 & 0.17 & 0.17 & 0.11 & 0.19 & 1.37 & 5 & 0.228 \\
\hline Thumb ext. & 1.08 & 0.81 & 0.42 & 0.15 & 0.65 & 0.78 & 2.06 & 5 & 0.095 \\
\hline Thumb add. & 0.02 & 0.06 & 0.21 & 0.26 & -0.19 & 0.25 & -1.81 & 5 & 0.130 \\
\hline Thumb abd. & 0.61 & 0.58 & 0.22 & 0.32 & 0.39 & 0.69 & 1.38 & 5 & 0.225 \\
\hline Wrist flexion & 0.06 & 0.06 & 0.09 & 0.11 & -0.03 & 0.15 & -0.41 & 5 & 0.700 \\
\hline Wrist ext. & 2.64 & 1.05 & 1.28 & 0.87 & 1.36 & 0.95 & 3.50 & 5 & 0.017 \\
\hline Wrist add. & 0.66 & 0.56 & 0.87 & 0.44 & -0.20 & 0.55 & -0.90 & 5 & 0.407 \\
\hline Wrist abd. & 0.46 & 0.34 & 0.27 & 0.14 & 0.19 & 0.31 & 1.49 & 5 & 0.197 \\
\hline Forearm pron. & 0.23 & 0.12 & 0.22 & 0.14 & 0.04 & 0.11 & 0.83 & 5 & 0.445 \\
\hline Forearm sup. & 1.26 & 0.34 & 1.05 & 0.44 & 0.21 & 0.53 & 0.98 & 5 & 0.374 \\
\hline \multicolumn{10}{|l|}{ Number of regions } \\
\hline Distal forelimb & 4.00 & 1.41 & 3.33 & 1.21 & $n / a$ & $n / a$ & $\mathrm{n} / \mathrm{a}$ & $\mathrm{n} / \mathbf{a}$ & $n / a$ \\
\hline Digit & 13.33 & 4.80 & 8.50 & 3.21 & $\mathrm{n} / \mathrm{a}$ & $\mathrm{n} / \mathrm{a}$ & $\mathrm{n} / \mathbf{a}$ & $\mathrm{n} / \mathrm{a}$ & $\mathrm{n} / \mathbf{a}$ \\
\hline Wrist/forearm & 10.50 & 3.08 & 10.67 & 1.75 & $\mathrm{n} / \mathrm{a}$ & $\mathrm{n} / \mathrm{a}$ & $\mathrm{n} / \mathrm{a}$ & $\mathrm{n} / \mathrm{a}$ & $\mathrm{n} / \mathbf{a}$ \\
\hline Fingers & 13.67 & 3.56 & 8.83 & 2.79 & 4.83 & 2.04 & 5.80 & 5 & 0.002 \\
\hline Thumb & 12.83 & 6.97 & 7.67 & 2.25 & 5.17 & 6.31 & 2.01 & 5 & 0.101 \\
\hline Wrist & 16.17 & 5.35 & 11.50 & 1.98 & 4.67 & 5.85 & 1.95 & 5 & 0.108 \\
\hline Forearm & 10.67 & 2.94 & 9.33 & 2.81 & 1.33 & 2.34 & 1.40 & 5 & 0.221 \\
\hline Finger flexion & 8.17 & 3.49 & 6.00 & 2.10 & 2.17 & 2.71 & 1.96 & 5 & 0.108 \\
\hline Finger ext. & 9.17 & 2.56 & 5.33 & 1.97 & 3.83 & 1.94 & 4.84 & 5 & 0.005 \\
\hline Finger add. & 1.17 & 0.98 & 0.83 & 0.75 & 0.33 & 0.52 & 1.58 & 5 & 0.175 \\
\hline Finger abd. & 0.67 & 0.82 & 0.67 & 1.21 & 0.00 & 0.63 & 0.00 & 5 & 1.000 \\
\hline Thumb flexion & 3.50 & 2.17 & 2.00 & 2.10 & 1.50 & 1.05 & 3.50 & 5 & 0.017 \\
\hline Thumb ext. & 7.83 & 4.54 & 4.00 & 1.67 & 3.83 & 3.31 & 2.84 & 5 & 0.036 \\
\hline Thumb add. & 0.17 & 0.41 & 1.50 & 1.64 & -1.33 & 1.37 & -2.39 & 5 & 0.062 \\
\hline Thumb abd. & 5.33 & 4.72 & 2.33 & 3.14 & 3.00 & 6.13 & 1.20 & 5 & 0.284 \\
\hline Wrist flexion & 0.83 & 0.75 & 1.50 & 1.87 & -0.67 & 2.42 & -0.67 & 5 & 0.530 \\
\hline Wrist ext. & 12.50 & 4.18 & 9.00 & 2.19 & 3.50 & 5.24 & 1.64 & 5 & 0.163 \\
\hline Wrist add. & 6.33 & 4.68 & 5.83 & 2.40 & 0.50 & 3.15 & 0.39 & 5 & 0.713 \\
\hline Wrist abd. & 4.50 & 2.43 & 3.67 & 1.51 & 0.83 & 1.17 & 1.75 & 5 & 0.141 \\
\hline Forearm pron. & 3.80 & 1.48 & 2.50 & 1.76 & 0.83 & 1.47 & 1.39 & 5 & 0.224 \\
\hline Forearm sup. & 7.83 & 1.84 & 7.17 & 2.32 & 0.67 & 1.86 & 0.88 & 5 & 0.421 \\
\hline \multicolumn{10}{|l|}{ Perimeter } \\
\hline Distal forelimb & 40.42 & 6.21 & 35.10 & 9.67 & $\mathrm{n} / \mathbf{a}$ & $\mathrm{n} / \mathrm{a}$ & $\mathbf{n} / \mathbf{a}$ & $\mathrm{n} / \mathbf{a}$ & $\mathbf{n} / \mathbf{a}$ \\
\hline Digit & 45.87 & 8.82 & 35.50 & 10.15 & 10.38 & 7.00 & 3.63 & 5 & 0.015 \\
\hline Wrist/forearm & 48.88 & 8.57 & 34.72 & 4.94 & 14.17 & 7.57 & 4.59 & 5 & 0.006 \\
\hline Fingers & 31.72 & 7.61 & 31.27 & 10.27 & 0.45 & 6.00 & 0.18 & 5 & 0.861 \\
\hline Thumb & 23.53 & 11.82 & 12.39 & 4.15 & 11.15 & 12.81 & 2.13 & 5 & 0.086 \\
\hline Wrist & 42.22 & 9.26 & 26.97 & 5.69 & 15.25 & 9.31 & 4.01 & 5 & 0.010 \\
\hline Forearm & 19.52 & 4.91 & 15.68 & 5.03 & 3.84 & 4.95 & 1.90 & 5 & 0.116 \\
\hline Finger flexion & 16.40 & 3.29 & 14.61 & 4.19 & 1.79 & 2.60 & 1.69 & 5 & 0.152 \\
\hline Finger ext. & 15.92 & 7.01 & 17.53 & 10.40 & -1.62 & 6.61 & -0.60 & 5 & 0.575 \\
\hline Finger add. & 1.31 & 1.16 & 0.85 & 0.72 & 0.47 & 0.91 & 1.26 & 5 & 0.264 \\
\hline Finger abd. & 0.63 & 0.72 & 0.63 & 1.11 & 0.00 & 0.73 & -0.01 & 5 & 0.996 \\
\hline Thumb flexion & 4.50 & 2.74 & 2.48 & 2.48 & 2.02 & 2.28 & 2.17 & 5 & 0.082 \\
\hline
\end{tabular}




\begin{tabular}{|c|c|c|c|c|c|c|c|c|c|}
\hline Movement & $\overline{\mathrm{D}}$ & SD & $\overline{\mathrm{ND}}$ & $\mathrm{SD}$ & $\overline{\mathrm{D}}-\overline{\mathrm{ND}}$ & SD & $t$ & $\mathrm{df}$ & $p$ \\
\hline Thumb ext. & 13.09 & 9.12 & 5.87 & 1.88 & 7.22 & 7.82 & 2.26 & 5 & 0.073 \\
\hline Thumb add. & 0.30 & 0.72 & 2.42 & 2.65 & -2.12 & 2.38 & -2.19 & 5 & 0.080 \\
\hline Thumb abd. & 8.28 & 7.43 & 3.31 & 4.73 & 4.97 & 9.49 & 1.28 & 5 & 0.256 \\
\hline Wrist flexion & 1.01 & 0.92 & 1.49 & 1.87 & -0.47 & 2.55 & -0.46 & 5 & 0.668 \\
\hline Wrist ext. & 29.85 & 9.18 & 15.59 & 7.02 & 14.26 & 8.07 & 4.33 & 5 & 0.008 \\
\hline Wrist add. & 9.67 & 7.47 & 10.64 & 5.41 & -0.97 & 6.72 & -0.35 & 5 & 0.738 \\
\hline Wrist abd. & 6.32 & 3.92 & 4.33 & 1.80 & 1.98 & 2.94 & 1.65 & 5 & 0.159 \\
\hline Forearm pron. & 3.75 & 2.07 & 3.04 & 2.41 & 0.71 & 1.70 & 1.03 & 5 & 0.352 \\
\hline Forearm sup. & 15.69 & 3.41 & 12.77 & 4.34 & 2.92 & 5.07 & 1.41 & 5 & 0.217 \\
\hline \multicolumn{10}{|l|}{ Largest region } \\
\hline Distal forelimb & 10.05 & 2.13 & 8.42 & 2.70 & $\mathrm{n} / \mathrm{a}$ & $\mathrm{n} / \mathrm{a}$ & $\mathrm{n} / \mathrm{a}$ & $n / a$ & $\mathrm{n} / \mathrm{a}$ \\
\hline Digit & 2.53 & 1.41 & 2.98 & 1.37 & -0.46 & 1.00 & -1.12 & 5 & 0.315 \\
\hline Wrist/forearm & 3.39 & 1.25 & 1.86 & 1.25 & 1.53 & 1.08 & 3.47 & 5 & 0.018 \\
\hline Fingers & 1.34 & 0.44 & 2.25 & 1.33 & -0.91 & 0.96 & -2.32 & 5 & 0.068 \\
\hline Thumb & 0.74 & 0.25 & 0.41 & 0.23 & 0.33 & 0.44 & 1.81 & 5 & 0.130 \\
\hline Wrist & 1.33 & 0.98 & 0.75 & 0.37 & 0.58 & 0.85 & 1.67 & 5 & 0.156 \\
\hline Forearm & 0.57 & 0.30 & 0.38 & 0.12 & 0.20 & 0.34 & 1.41 & 5 & 0.219 \\
\hline Finger flexion & 0.72 & 0.50 & 1.07 & 0.56 & $\mathrm{n} / \mathrm{a}$ & $\mathrm{n} / \mathrm{a}$ & $\mathrm{n} / \mathrm{a}$ & $\mathrm{n} / \mathrm{a}$ & $\mathrm{n} / \mathbf{a}$ \\
\hline Finger ext. & 0.63 & 0.55 & 1.04 & 0.89 & $\mathrm{n} / \mathrm{a}$ & $\mathrm{n} / \mathrm{a}$ & $\mathrm{n} / \mathrm{a}$ & $\mathrm{n} / \mathrm{a}$ & $\mathrm{n} / \mathbf{a}$ \\
\hline Finger add. & 0.05 & 0.04 & 0.04 & 0.05 & $\mathrm{n} / \mathrm{a}$ & $\mathrm{n} / \mathrm{a}$ & $\mathrm{n} / \mathbf{a}$ & $\mathrm{n} / \mathrm{a}$ & $\mathrm{n} / \mathrm{a}$ \\
\hline Finger abd. & 0.03 & 0.04 & 0.02 & 0.03 & $\mathrm{n} / \mathrm{a}$ & $\mathrm{n} / \mathrm{a}$ & $\mathrm{n} / \mathrm{a}$ & $\mathrm{n} / \mathrm{a}$ & $\mathrm{n} / \mathrm{a}$ \\
\hline Thumb flexion & 0.17 & 0.12 & 0.11 & 0.11 & $\mathrm{n} / \mathrm{a}$ & $\mathrm{n} / \mathrm{a}$ & $\mathbf{n} / \mathbf{a}$ & $\mathrm{n} / \mathrm{a}$ & $\mathrm{n} / \mathrm{a}$ \\
\hline Thumb ext. & 0.44 & 0.32 & 0.22 & 0.16 & $\mathrm{n} / \mathrm{a}$ & $\mathrm{n} / \mathrm{a}$ & $\mathbf{n} / \mathbf{a}$ & $\mathrm{n} / \mathrm{a}$ & $\mathrm{n} / \mathrm{a}$ \\
\hline Thumb add. & 0.02 & 0.06 & 0.12 & 0.12 & $\mathbf{n} / \mathbf{a}$ & $\mathrm{n} / \mathbf{a}$ & $\mathbf{n} / \mathbf{a}$ & $\mathrm{n} / \mathrm{a}$ & $\mathrm{n} / \mathrm{a}$ \\
\hline Thumb abd. & 0.23 & 0.22 & 0.09 & 0.10 & $\mathrm{n} / \mathbf{a}$ & $\mathrm{n} / \mathrm{a}$ & $\mathbf{n} / \mathbf{a}$ & $\mathrm{n} / \mathbf{a}$ & $\mathrm{n} / \mathrm{a}$ \\
\hline Wrist flexion & 0.06 & 0.05 & 0.04 & 0.03 & $\mathrm{n} / \mathrm{a}$ & $\mathrm{n} / \mathbf{a}$ & $\mathrm{n} / \mathrm{a}$ & $\mathbf{n} / \mathbf{a}$ & $\mathrm{n} / \mathrm{a}$ \\
\hline Wrist ext. & 0.90 & 0.56 & 0.46 & 0.39 & $\mathrm{n} / \mathbf{a}$ & $\mathrm{n} / \mathrm{a}$ & $\mathrm{n} / \mathrm{a}$ & $\mathbf{n} / \mathbf{a}$ & $\mathrm{n} / \mathrm{a}$ \\
\hline Wrist add. & 0.20 & 0.19 & 0.42 & 0.20 & $\mathbf{n} / \mathbf{a}$ & $\mathrm{n} / \mathrm{a}$ & $\mathrm{n} / \mathrm{a}$ & $\mathrm{n} / \mathrm{a}$ & $\mathrm{n} / \mathrm{a}$ \\
\hline Wrist abd. & 0.18 & 0.14 & 0.13 & 0.07 & $\mathrm{n} / \mathbf{a}$ & $\mathbf{n} / \mathbf{a}$ & $\mathrm{n} / \mathrm{a}$ & $\mathrm{n} / \mathrm{a}$ & $\mathrm{n} / \mathrm{a}$ \\
\hline Forearm pron. & 0.11 & 0.04 & 0.10 & 0.03 & $\mathrm{n} / \mathrm{a}$ & $\mathrm{n} / \mathbf{a}$ & $\mathrm{n} / \mathrm{a}$ & $\mathrm{n} / \mathrm{a}$ & $\mathrm{n} / \mathrm{a}$ \\
\hline Forearm sup. & 0.56 & 0.30 & 0.37 & 0.13 & $\mathbf{n} / \mathbf{a}$ & $\mathrm{n} / \mathbf{a}$ & $\mathbf{n} / \mathbf{a}$ & $\mathbf{n} / \mathbf{a}$ & $\mathrm{n} / \mathrm{a}$ \\
\hline \multicolumn{10}{|l|}{ Complexity index } \\
\hline Distal forelimb & 3.52 & 0.46 & 3.36 & 0.53 & $\mathrm{n} / \mathrm{a}$ & $\mathrm{n} / \mathrm{a}$ & $\mathrm{n} / \mathrm{a}$ & $\mathbf{n} / \mathbf{a}$ & $\mathrm{n} / \mathrm{a}$ \\
\hline Digit & 5.68 & 0.52 & 4.55 & 0.71 & 1.12 & 0.52 & 5.32 & 5 & 0.003 \\
\hline Wrist/forearm & 5.96 & 0.63 & 4.96 & 0.17 & 1.00 & 0.72 & 3.39 & 5 & 0.019 \\
\hline Fingers & 4.96 & 0.74 & 4.52 & 0.63 & 0.44 & 0.46 & 2.35 & 5 & 0.066 \\
\hline Thumb & 4.48 & 1.12 & 3.44 & 0.67 & 1.04 & 1.21 & 2.11 & 5 & 0.089 \\
\hline Wrist & 6.08 & 0.90 & 4.87 & 0.12 & 1.21 & 0.87 & 3.40 & 5 & 0.019 \\
\hline Forearm & 4.45 & 0.61 & 3.96 & 0.65 & 0.49 & 0.57 & 2.13 & 5 & 0.086 \\
\hline Finger flexion & 3.82 & 0.44 & 3.25 & 0.50 & 0.57 & 0.53 & 2.64 & 5 & 0.046 \\
\hline Finger ext. & 3.75 & 0.67 & 3.51 & 0.89 & 0.25 & 0.58 & 1.04 & 5 & 0.348 \\
\hline Finger add. & 1.63 & 0.35 & 1.36 & 0.19 & 0.28 & 0.43 & 1.27 & 3 & 0.292 \\
\hline Finger abd. & 1.33 & 0.24 & 1.63 & 0.61 & -0.27 & 0.28 & -1.36 & 1 & 0.403 \\
\hline Thumb flexion & 2.35 & 0.78 & 2.03 & 0.68 & 0.64 & 0.42 & 3.06 & 3 & 0.055 \\
\hline Thumb ext. & 3.44 & 1.12 & 2.54 & 0.58 & 0.90 & 0.71 & 3.07 & 5 & 0.028 \\
\hline Thumb add. & 1.33 & $\mathrm{n} / \mathrm{a}$ & 1.81 & 0.57 & $\mathrm{n} / \mathrm{a}$ & $\mathrm{n} / \mathrm{a}$ & $\mathrm{n} / \mathrm{a}$ & $\mathrm{n} / \mathrm{a}$ & $n / a$ \\
\hline Thumb abd. & 3.13 & 1.24 & 2.23 & 1.18 & 0.60 & 1.88 & 0.64 & 3 & 0.568 \\
\hline Wrist flexion & 1.40 & 0.31 & 1.67 & 0.67 & 0.44 & 0.38 & 1.65 & 1 & 0.347 \\
\hline Wrist ext. & 5.21 & 0.84 & 3.96 & 0.62 & 1.25 & 0.67 & 4.56 & 5 & 0.006 \\
\hline Wrist add. & 3.55 & 1.17 & 3.17 & 0.87 & 0.30 & 0.88 & 0.76 & 4 & 0.487 \\
\hline Wrist abd. & 2.55 & 0.82 & 2.33 & 0.41 & 0.22 & 0.48 & 1.11 & 5 & 0.320 \\
\hline Forearm pron. & 2.16 & 0.68 & 2.12 & 0.57 & 0.24 & 0.59 & 0.90 & 4 & 0.418 \\
\hline Forearm sup. & 3.94 & 0.39 & 3.47 & 0.41 & 0.47 & 0.45 & 2.57 & 5 & 0.050 \\
\hline \multicolumn{10}{|l|}{ Threshold } \\
\hline Distal forelimb & 14.39 & 1.84 & 14.76 & 4.19 & $\mathrm{n} / \mathrm{a}$ & $\mathbf{n} / \mathbf{a}$ & $\mathbf{n} / \mathbf{a}$ & $\mathbf{n} / \mathbf{a}$ & $\mathbf{n} / \mathbf{a}$ \\
\hline Digit & 13.69 & 2.35 & 13.74 & 5.19 & $\mathrm{n} / \mathrm{a}$ & $n / a$ & $\mathbf{n} / \mathbf{a}$ & $\mathrm{n} / \mathrm{a}$ & $\mathbf{n} / \mathbf{a}$ \\
\hline Wrist/forearm & 14.50 & 2.12 & 15.09 & 4.11 & $n / a$ & $n / a$ & $\mathbf{n} / \mathbf{a}$ & $\mathbf{n} / \mathbf{a}$ & $\mathbf{n} / \mathbf{a}$ \\
\hline Fingers & 13.99 & 1.57 & 14.85 & 4.21 & $\mathrm{n} / \mathrm{a}$ & $\mathrm{n} / \mathrm{a}$ & $n / a$ & $\mathrm{n} / \mathrm{a}$ & $\mathrm{n} / \mathrm{a}$ \\
\hline
\end{tabular}




\begin{tabular}{|c|c|c|c|c|c|c|c|c|c|}
\hline Movement & $\overline{\mathrm{D}}$ & $\mathrm{SD}$ & $\overline{\mathrm{ND}}$ & $\mathrm{SD}$ & $\overline{\mathrm{D}}-\overline{\mathrm{ND}}$ & $\mathrm{SD}$ & $t$ & $\mathrm{df}$ & $p$ \\
\hline Thumb & 13.05 & 3.56 & 13.36 & 5.45 & $\mathrm{n} / \mathrm{a}$ & $\mathbf{n} / \mathbf{a}$ & $\mathrm{n} / \mathrm{a}$ & $\mathrm{n} / \mathrm{a}$ & $\mathrm{n} / \mathrm{a}$ \\
\hline Wrist & 15.55 & 2.17 & 16.52 & 3.52 & $\mathrm{n} / \mathrm{a}$ & $\mathbf{n} / \mathbf{a}$ & $\mathbf{n} / \mathbf{a}$ & $\mathrm{n} / \mathrm{a}$ & $\mathrm{n} / \mathrm{a}$ \\
\hline Forearm & 12.76 & 1.29 & 12.84 & 5.19 & $\mathbf{n} / \mathbf{a}$ & $\mathrm{n} / \mathrm{a}$ & $\mathrm{n} / \mathrm{a}$ & $\mathrm{n} / \mathrm{a}$ & $\mathrm{n} / \mathrm{a}$ \\
\hline Finger flexion & 12.27 & 1.17 & 13.56 & 4.49 & -1.29 & 4.76 & -0.66 & 5 & 0.536 \\
\hline Finger ext. & 15.32 & 4.12 & 15.36 & 4.81 & -0.04 & 4.73 & -0.02 & 5 & 0.984 \\
\hline Finger add. & 11.79 & 7.12 & 17.38 & 8.35 & -5.59 & 10.78 & -1.04 & 3 & 0.376 \\
\hline Finger abd. & 12.11 & 8.57 & 23.40 & 3.68 & -6.74 & 1.04 & -9.16 & 1 & 0.069 \\
\hline Thumb flexion & 12.25 & 4.01 & 11.42 & 8.69 & 0.82 & 9.35 & 0.18 & 3 & 0.872 \\
\hline Thumb ext. & 13.92 & 5.14 & 11.33 & 5.59 & 2.59 & 1.66 & 3.84 & 5 & 0.012 \\
\hline Thumb add. & 3.67 & $\mathrm{n} / \mathrm{a}$ & 13.25 & 6.67 & $\mathrm{n} / \mathrm{a}$ & $\mathbf{n} / \mathbf{a}$ & $\mathbf{n} / \mathbf{a}$ & $\mathrm{n} / \mathrm{a}$ & $\mathbf{n} / \mathbf{a}$ \\
\hline Thumb abd. & 12.80 & 4.18 & 19.09 & 8.44 & -7.46 & 10.37 & 1.44 & 3 & 0.246 \\
\hline Wrist flexion & 8.00 & 5.16 & 20.63 & 9.72 & -16.00 & 2.83 & -8.00 & 1 & 0.079 \\
\hline Wrist ext. & 15.75 & 2.91 & 14.81 & 4.14 & 0.95 & 4.77 & 0.49 & 5 & 0.648 \\
\hline Wrist add. & 14.94 & 1.66 & 17.19 & 5.64 & -2.96 & 5.29 & -1.25 & 4 & 0.280 \\
\hline Wrist abd. & 13.38 & 3.36 & 13.25 & 6.84 & 0.13 & 7.54 & 0.04 & 5 & 0.968 \\
\hline Forearm pron. & 13.66 & 5.46 & 14.50 & 3.81 & 0.90 & 5.81 & 0.35 & 4 & 0.746 \\
\hline Forearm sup. & 12.44 & 1.57 & 12.30 & 6.27 & 0.14 & 5.76 & 0.06 & 5 & 0.954 \\
\hline \multicolumn{10}{|c|}{ Percentage total distal forelimb area } \\
\hline Distal forelimb & 1.00 & $\mathrm{n} / \mathrm{a}$ & 1.00 & $\mathrm{n} / \mathbf{a}$ & $\mathbf{n} / \mathbf{a}$ & $\mathbf{n} / \mathbf{a}$ & $\mathrm{n} / \mathbf{a}$ & $\mathrm{n} / \mathbf{a}$ & $\mathrm{n} / \mathrm{a}$ \\
\hline Digit & 0.49 & 0.08 & 0.53 & 0.04 & $\mathbf{n} / \mathbf{a}$ & $\mathbf{n} / \mathbf{a}$ & $\mathbf{n} / \mathbf{a}$ & $\mathbf{n} / \mathbf{a}$ & $\mathrm{n} / \mathrm{a}$ \\
\hline Wrist/forearm & 0.51 & 0.08 & 0.48 & 0.06 & $\mathbf{n} / \mathbf{a}$ & $\mathbf{n} / \mathbf{a}$ & $\mathrm{n} / \mathrm{a}$ & $\mathrm{n} / \mathrm{a}$ & $\mathrm{n} / \mathrm{a}$ \\
\hline Fingers & 0.31 & 0.05 & 0.43 & 0.07 & -0.12 & 0.07 & -4.02 & 5 & 0.010 \\
\hline Thumb & 0.20 & 0.11 & 0.12 & 0.05 & 0.08 & 0.14 & 1.41 & 5 & 0.219 \\
\hline Wrist & 0.36 & 0.06 & 0.28 & 0.04 & 0.08 & 0.07 & 2.87 & 5 & 0.035 \\
\hline Forearm & 0.15 & 0.05 & 0.15 & 0.06 & 0.00 & 0.04 & -0.16 & 5 & 0.881 \\
\hline Finger flexion & 0.15 & 0.07 & 0.20 & 0.09 & -0.05 & 0.06 & -2.25 & 5 & 0.074 \\
\hline Finger ext. & 0.13 & 0.07 & 0.21 & 0.10 & -0.07 & 0.08 & -2.33 & 5 & 0.067 \\
\hline Finger add. & 0.01 & 0.01 & 0.01 & 0.01 & 0.00 & 0.01 & 0.57 & 5 & 0.592 \\
\hline Finger abd. & 0.00 & 0.00 & 0.00 & 0.01 & 0.00 & 0.01 & -0.30 & 5 & 0.775 \\
\hline Thumb flexion & 0.03 & 0.01 & 0.02 & 0.02 & 0.00 & 0.03 & 0.39 & 5 & 0.715 \\
\hline Thumb ext. & 0.10 & 0.07 & 0.05 & 0.03 & 0.05 & 0.08 & 1.55 & 5 & 0.182 \\
\hline Thumb add. & 0.00 & 0.01 & 0.02 & 0.03 & -0.02 & 0.02 & -2.32 & 5 & 0.068 \\
\hline Thumb abd. & 0.06 & 0.06 & 0.02 & 0.03 & 0.04 & 0.07 & 1.26 & 5 & 0.263 \\
\hline Wrist flexion & 0.01 & 0.01 & 0.01 & 0.01 & 0.00 & 0.02 & -0.57 & 5 & 0.594 \\
\hline Wrist ext. & 0.24 & 0.07 & 0.13 & 0.05 & 0.11 & 0.08 & 3.51 & 5 & 0.017 \\
\hline Wrist add. & 0.07 & 0.06 & 0.10 & 0.05 & -0.04 & 0.05 & -1.81 & 5 & 0.131 \\
\hline Wrist abd. & 0.04 & 0.03 & 0.04 & 0.03 & 0.01 & 0.02 & 0.81 & 5 & 0.453 \\
\hline Forearm pron. & 0.02 & 0.01 & 0.03 & 0.02 & 0.00 & 0.02 & -0.41 & 5 & 0.696 \\
\hline Forearm sup. & 0.12 & 0.04 & 0.13 & 0.05 & 0.00 & 0.04 & -0.20 & 5 & 0.848 \\
\hline \multicolumn{10}{|c|}{ B. Flexion-extension categories } \\
\hline \multicolumn{10}{|l|}{ Area } \\
\hline Distal forelimb & 10.59 & 1.78 & 8.79 & 3.06 & $\mathrm{n} / \mathbf{a}$ & $\mathrm{n} / \mathbf{a}$ & $\mathrm{n} / \mathrm{a}$ & $\mathrm{n} / \mathrm{a}$ & $\mathrm{n} / \mathrm{a}$ \\
\hline Flexion & 3.00 & 0.48 & 3.35 & 0.53 & -0.35 & 0.57 & -1.47 & 5 & 0.201 \\
\hline Extension & 7.37 & 1.45 & 5.36 & 2.66 & 2.02 & 1.90 & 2.60 & 5 & 0.048 \\
\hline Digit flexion & 1.99 & 0.50 & 2.15 & 0.75 & $\mathrm{n} / \mathrm{a}$ & $\mathbf{n} / \mathbf{a}$ & $\mathbf{n} / \mathbf{a}$ & $\mathbf{n} / \mathbf{a}$ & $\mathrm{n} / \mathbf{a}$ \\
\hline $\mathrm{W} /$ forearm $\mathrm{fl}$ & 3.31 & 1.04 & 2.80 & 1.79 & $\mathrm{n} / \mathrm{a}$ & $\mathrm{n} / \mathrm{a}$ & $\mathrm{n} / \mathrm{a}$ & $\mathbf{n} / \mathbf{a}$ & $\mathrm{n} / \mathrm{a}$ \\
\hline Digit ext. & 1.04 & 0.69 & 1.21 & 0.58 & $\mathrm{n} / \mathrm{a}$ & $\mathrm{n} / \mathrm{a}$ & $\mathrm{n} / \mathrm{a}$ & $\mathrm{n} / \mathrm{a}$ & $\mathrm{n} / \mathrm{a}$ \\
\hline $\mathrm{W} /$ forearm ext. & 4.39 & 1.21 & 2.74 & 1.27 & $\mathrm{n} / \mathrm{a}$ & $\mathrm{n} / \mathrm{a}$ & $\mathrm{n} / \mathrm{a}$ & $n / a$ & $\mathrm{n} / \mathrm{a}$ \\
\hline Finger flexion & 1.70 & 0.61 & 1.79 & 0.80 & -0.09 & 0.41 & -0.52 & 5 & 0.623 \\
\hline Thumb flexion & 0.33 & 0.15 & 0.21 & 0.22 & 0.12 & 0.19 & 1.53 & 5 & 0.187 \\
\hline Wrist flexion & 0.78 & 0.65 & 1.01 & 0.54 & -0.23 & 0.75 & -0.76 & 5 & 0.484 \\
\hline Forearm flex. & 0.23 & 0.12 & 0.19 & 0.15 & 0.04 & 0.11 & 0.83 & 5 & 0.445 \\
\hline Finger ext. & 1.54 & 0.90 & 2.15 & 1.74 & -0.61 & 1.11 & -1.35 & 5 & 0.235 \\
\hline Thumb ext. & 2.04 & 1.13 & 0.78 & 0.37 & 1.25 & 1.13 & 2.71 & 5 & 0.042 \\
\hline Wrist ext. & 3.16 & 1.18 & 1.71 & 0.89 & 1.44 & 1.30 & 2.72 & 5 & 0.042 \\
\hline Forearm ext. & 1.26 & 0.34 & 1.05 & 0.44 & 0.21 & 0.53 & 0.98 & 5 & 0.374 \\
\hline
\end{tabular}




\begin{tabular}{|c|c|c|c|c|c|c|c|c|c|}
\hline Movement & $\overline{\mathrm{D}}$ & SD & $\overline{\mathrm{ND}}$ & SD & $\overline{\mathrm{D}}-\overline{\mathrm{ND}}$ & SD & $t$ & df & $p$ \\
\hline \multicolumn{10}{|l|}{ Number of regions } \\
\hline Distal forclimb & 4.00 & 1.41 & 3.33 & 1.21 & $\mathbf{n} / \mathbf{a}$ & $\mathbf{n} / \mathbf{a}$ & $\mathbf{n} / \mathbf{a}$ & $\mathrm{n} / \mathrm{a}$ & $\mathbf{n} / \mathbf{a}$ \\
\hline Flexion & 10.83 & 3.37 & 9.17 & 3.06 & $\mathrm{n} / \mathrm{a}$ & $\mathrm{n} / \mathrm{a}$ & $\mathrm{n} / \mathrm{a}$ & $\mathrm{n} / \mathbf{a}$ & $\mathrm{n} / \mathrm{a}$ \\
\hline Extension & 8.17 & 3.55 & 6.67 & 1.37 & $\mathrm{n} / \mathrm{a}$ & $\mathrm{n} / \mathrm{a}$ & $\mathbf{n} / \mathbf{a}$ & $\mathrm{n} / \mathrm{a}$ & $\mathrm{n} / \mathrm{a}$ \\
\hline Digit flexion & 8.50 & 3.21 & 6.33 & 1.63 & 2.17 & 2.14 & 2.48 & 5 & 0.056 \\
\hline $\mathrm{W} /$ forearm $\mathrm{fl}$ & 7.67 & 3.83 & 7.50 & 3.02 & 0.17 & 3.31 & 0.12 & 5 & 0.907 \\
\hline Digit ext. & 15.33 & 2.94 & 6.83 & 2.48 & 8.50 & 3.02 & 6.90 & 5 & 0.001 \\
\hline W/forearm ext. & 12.67 & 3.62 & 9.50 & 2.07 & 3.17 & 3.82 & 2.03 & 5 & 0.098 \\
\hline Finger flexion & 7.67 & 2.73 & 6.50 & 2.17 & 1.17 & 3.13 & 0.91 & 5 & 0.402 \\
\hline Thumb flexion & 5.17 & 4.88 & 2.33 & 2.25 & 2.83 & 4.40 & 1.58 & 5 & 0.176 \\
\hline Wrist flexion & 5.83 & 3.87 & 6.00 & 2.53 & -0.17 & 3.37 & -0.12 & 5 & 0.908 \\
\hline Forearm flex. & 3.33 & 1.75 & 2.50 & 1.76 & 0.83 & 1.47 & 1.39 & 5 & 0.224 \\
\hline Finger ext. & 10.17 & 3.19 & 5.50 & 2.07 & 4.67 & 2.34 & 4.89 & 5 & 0.005 \\
\hline Thumb ext. & 10.50 & 5.79 & 5.83 & 2.79 & 4.67 & 5.85 & 1.95 & 5 & 0.108 \\
\hline Wrist ext. & 14.17 & 3.82 & 10.83 & 2.71 & 3.33 & 4.08 & 2.00 & 5 & 0.102 \\
\hline Forearm ext. & 7.83 & 1.84 & 7.17 & 2.32 & 0.67 & 1.86 & 0.88 & 5 & 0.421 \\
\hline \multicolumn{10}{|l|}{ Perimeter } \\
\hline Distal forelimb & 40.42 & 6.21 & 35.10 & $9.67^{\circ}$ & $\mathbf{n} / \mathbf{a}$ & $n / a$ & $\mathbf{n} / \mathbf{a}$ & $\mathbf{n} / \mathbf{a}$ & $\mathrm{n} / \mathbf{a}$ \\
\hline Flexion & 29.13 & 6.55 & 27.04 & 3.08 & 2.09 & 4.76 & 1.07 & 5 & 0.333 \\
\hline Extension & 48.53 & 8.26 & 36.89 & 10.57 & 11.64 & 8.35 & 3.42 & 5 & 0.019 \\
\hline Digit flexion & 19.06 & 2.64 & 16.69 & 1.44 & 2.88 & 1.91 & 3.69 & 5 & 0.014 \\
\hline $\mathrm{W} /$ forearm $\mathrm{fl}$ & 12.90 & 7.42 & 13.72 & 5.90 & 0.82 & 6.97 & -0.29 & 5 & 0.786 \\
\hline Digit ext. & 29.03 & 4.94 & 23.25 & 10.81 & 5.79 & 8.40 & 1.69 & 5 & 0.153 \\
\hline W/forearm ext. & 43.00 & 9.47 & 25.43 & 3.92 & 17.57 & 8.61 & 5.00 & 5 & 0.004 \\
\hline Finger flexion & 15.36 & 3.46 & 15.38 & 3.86 & -0.03 & 5.26 & -0.01 & 5 & 0.991 \\
\hline Thumb flexion & 7.39 & 7.73 & 3.04 & 3.08 & 4.36 & 7.20 & 1.48 & 5 & 0.198 \\
\hline Wrist flexion & 9.89 & 7.31 & 11.42 & 5.64 & -1.53 & 7.54 & -0.50 & 5 & 0.641 \\
\hline Forearm flex. & 3.75 & 2.07 & 3.04 & 2.41 & 0.71 & 1.70 & 1.03 & 5 & 0.352 \\
\hline Finger ext. & 16.55 & 6.85 & 18.07 & 10.64 & -1.52 & 7.03 & -0.53 & 5 & 0.618 \\
\hline Thumb ext. & 22.64 & 11.66 & 9.72 & 4.68 & 12.91 & 11.30 & 2.80 & 5 & 0.038 \\
\hline Wrist ext. & 34.23 & 9.47 & 19.49 & 5.67 & 14.75 & 9.77 & 3.70 & 5 & 0.014 \\
\hline Forearm ext. & 15.69 & 3.41 & 12.77 & 4.34 & 2.92 & 5.07 & 1.41 & 5 & 0.217 \\
\hline \multicolumn{10}{|l|}{ Largest region } \\
\hline Distal forelimb & 10.05 & 2.13 & 8.42 & 2.70 & $\mathbf{n} / \mathbf{a}$ & $\mathrm{n} / \mathrm{a}$ & $n / a$ & $\mathbf{n} / \mathbf{a}$ & $\mathbf{n} / \mathbf{a}$ \\
\hline Flexion & 1.55 & 0.50 & 1.93 & 0.53 & $\mathrm{n} / \mathrm{a}$ & $\mathrm{n} / \mathrm{a}$ & $\mathrm{n} / \mathrm{a}$ & $\mathrm{n} / \mathrm{a}$ & $\mathrm{n} / \mathrm{a}$ \\
\hline Extension & 5.93 & 2.25 & 4.30 & 2.60 & $\mathbf{n} / \mathbf{a}$ & $\mathrm{n} / \mathrm{a}$ & $\mathbf{n} / \mathbf{a}$ & $\mathrm{n} / \mathrm{a}$ & $\mathrm{n} / \mathbf{a}$ \\
\hline Digit flexion & 1.30 & 0.80 & 1.39 & 0.90 & $\mathrm{n} / \mathrm{a}$ & $\mathrm{n} / \mathrm{a}$ & $\mathrm{n} / \mathrm{a}$ & $\mathbf{n} / \mathbf{a}$ & $\mathrm{n} / \mathrm{a}$ \\
\hline $\mathrm{W} /$ forearm $\mathrm{fl}$ & 2.20 & 1.09 & 1.51 & 1.44 & $\mathrm{n} / \mathrm{a}$ & $\mathrm{n} / \mathbf{a}$ & $\mathbf{n} / \mathbf{a}$ & $\mathbf{n} / \mathbf{a}$ & $\mathrm{n} / \mathrm{a}$ \\
\hline Digit ext. & 0.85 & 0.44 & 1.35 & 0.61 & $\mathrm{n} / \mathrm{a}$ & $\mathrm{n} / \mathbf{a}$ & $\mathbf{n} / \mathbf{a}$ & $\mathbf{n} / \mathbf{a}$ & $\mathrm{n} / \mathrm{a}$ \\
\hline $\mathrm{W} /$ forearm ext. & 0.44 & 0.53 & 0.52 & 0.26 & $\mathrm{n} / \mathrm{a}$ & $\mathrm{n} / \mathbf{a}$ & $\mathrm{n} / \mathbf{a}$ & $\mathrm{n} / \mathrm{a}$ & $\mathbf{n} / \mathbf{a}$ \\
\hline Finger flexion & 0.78 & 0.51 & 1.14 & 0.60 & $\mathrm{n} / \mathrm{a}$ & $\mathbf{n} / \mathbf{a}$ & $\mathrm{n} / \mathbf{a}$ & $\mathrm{n} / \mathrm{a}$ & $\mathrm{n} / \mathrm{a}$ \\
\hline Thumb flexion & 0.18 & 0.11 & 0.10 & 0.08 & $\mathrm{n} / \mathrm{a}$ & $\mathrm{n} / \mathrm{a}$ & $\mathbf{n} / \mathbf{a}$ & $\mathrm{n} / \mathrm{a}$ & $\mathrm{n} / \mathrm{a}$ \\
\hline Wrist flexion & 0.33 & 0.32 & 0.45 & 0.23 & $\mathrm{n} / \mathrm{a}$ & $\mathrm{n} / \mathrm{a}$ & $\mathbf{n} / \mathbf{a}$ & $\mathrm{n} / \mathrm{a}$ & $\mathbf{n} / \mathbf{a}$ \\
\hline Forearm flex. & 0.11 & 0.04 & 0.08 & 0.05 & $\mathrm{n} / \mathrm{a}$ & $\mathrm{n} / \mathrm{a}$ & $\mathrm{n} / \mathrm{a}$ & $\mathrm{n} / \mathrm{a}$ & $\mathrm{n} / \mathrm{a}$ \\
\hline Finger ext. & 0.67 & 0.59 & 1.14 & 1.00 & $\mathrm{n} / \mathbf{a}$ & $\mathrm{n} / \mathbf{a}$ & $\mathbf{n} / \mathbf{a}$ & $\mathrm{n} / \mathrm{a}$ & $\mathrm{n} / \mathrm{a}$ \\
\hline Thumb ext. & 0.64 & 0.27 & 0.32 & 0.12 & $\mathrm{n} / \mathrm{a}$ & $\mathrm{n} / \mathrm{a}$ & $\mathrm{n} / \mathrm{a}$ & $\mathrm{n} / \mathrm{a}$ & $\mathbf{n} / \mathbf{a}$ \\
\hline Wrist ext. & 1.05 & 0.62 & 0.56 & 0.39 & $\mathrm{n} / \mathrm{a}$ & $\mathrm{n} / \mathrm{a}$ & $\mathrm{n} / \mathbf{a}$ & $\mathrm{n} / \mathrm{a}$ & $\mathbf{n} / \mathbf{a}$ \\
\hline Forearm ext. & 0.50 & 0.34 & 0.35 & 0.14 & $\mathrm{n} / \mathrm{a}$ & $\mathrm{n} / \mathrm{a}$ & $\mathrm{n} / \mathrm{a}$ & $\mathrm{n} / \mathrm{a}$ & $\mathbf{n} / \mathbf{a}$ \\
\hline \multicolumn{10}{|l|}{ Complexity index } \\
\hline Distal forelimb & 3.52 & 0.46 & 3.36 & 0.53 & $\mathrm{n} / \mathbf{a}$ & $\mathrm{n} / \mathrm{a}$ & $\mathrm{n} / \mathrm{a}$ & $\mathbf{n} / \mathbf{a}$ & $\mathbf{n} / \mathbf{a}$ \\
\hline Flexion & 4.73 & 0.87 & 4.21 & 0.63 & 0.52 & 0.79 & 1.63 & 5 & 0.164 \\
\hline Extension & 5.05 & 0.56 & 4.57 & 0.35 & 0.48 & 0.42 & 2.82 & 5 & 0.037 \\
\hline Digit flexion & 4.00 & 0.63 & 3.38 & 0.26 & 0.62 & 0.46 & 3.28 & 5 & 0.022 \\
\hline $\mathrm{W} /$ forearm $\mathrm{fl}$ & 3.48 & 1.05 & 3.47 & 0.84 & 0.01 & 0.83 & 0.03 & 5 & 0.977 \\
\hline Digit ext. & 5.20 & 0.62 & 4.06 & 0.81 & 1.13 & 0.67 & 4.13 & 5 & 0.009 \\
\hline W/forearm ext. & 5.80 & 0.69 & 4.45 & 0.27 & 1.35 & 0.78 & 4.21 & 5 & 0.008 \\
\hline
\end{tabular}




\begin{tabular}{|c|c|c|c|c|c|c|c|c|c|}
\hline Movement & $\overline{\mathrm{D}}$ & SD & $\overline{\mathrm{ND}}$ & SD & $\overline{\mathrm{D}} \cdot \overline{\mathrm{ND}}$ & $\mathrm{SD}$ & $t$ & $\mathrm{df}$ & $p$ \\
\hline Finger flexion & 3.90 & 0.51 & 3.30 & 0.44 & 0.60 & 0.50 & 2.95 & 5 & 0.032 \\
\hline Thumb flexion & 2.50 & 0.49 & 1.98 & 0.80 & 0.57 & 0.60 & 2.12 & 4 & 0.102 \\
\hline Wrist flexion & 3.42 & 0.86 & 3.17 & 0.79 & 0.25 & 0.65 & 0.86 & 4 & 0.436 \\
\hline Forearm flex. & 2.15 & 0.69 & 2.12 & 0.57 & 0.22 & 0.59 & 0.83 & 4 & 0.453 \\
\hline Finger ext. & 3.76 & 0.59 & 3.49 & 0.87 & 0.27 & 0.64 & 1.04 & 5 & 0.346 \\
\hline Thumb ext. & 4.42 & 1.13 & 3.05 & 0.78 & 1.37 & 0.99 & 3.39 & 5 & 0.019 \\
\hline Wrist ext. & 5.46 & 0.77 & 4.29 & 0.53 & 1.17 & 0.78 & 3.67 & 5 & 0.014 \\
\hline Forearm ext. & 3.91 & 0.38 & 3.54 & 0.55 & 0.37 & 0.55 & 1.65 & 5 & 0.161 \\
\hline \multicolumn{10}{|l|}{ Threshold } \\
\hline Distal forelimb & 14.39 & 1.84 & 14.76 & 4.19 & $n / a$ & $\mathrm{n} / \mathrm{a}$ & $n / a$ & $\mathrm{n} / \mathrm{a}$ & $\mathrm{n} / \mathrm{a}$ \\
\hline Flexion & 12.88 & 1.00 & 15.31 & 3.62 & $\mathrm{n} / \mathrm{a}$ & $\mathrm{n} / \mathrm{a}$ & $\mathrm{n} / \mathrm{a}$ & $\mathrm{n} / \mathrm{a}$ & $\mathrm{n} / \mathrm{a}$ \\
\hline Extension & 14.87 & 2.38 & 14.35 & 4.89 & $\mathrm{n} / \mathrm{a}$ & $\mathrm{n} / \mathrm{a}$ & $n / a$ & $\mathrm{n} / \mathrm{a}$ & $\mathrm{n} / \mathrm{a}$ \\
\hline Digit flexion & 15.10 & 3.02 & 14.65 & 5.51 & $\mathbf{n} / \mathbf{a}$ & $\mathrm{n} / \mathrm{a}$ & $n / a$ & $\mathrm{n} / \mathrm{a}$ & $n / a$ \\
\hline $\mathrm{W} /$ forearm $\mathrm{fl}$ & 14.73 & 1.94 & 13.71 & 5.41 & $n / a$ & $\mathrm{n} / \mathrm{a}$ & $\mathrm{n} / \mathrm{a}$ & $\mathrm{n} / \mathbf{a}$ & $\mathrm{n} / \mathrm{a}$ \\
\hline Digit ext. & 12.14 & 0.87 & 13.40 & 4.62 & $\mathrm{n} / \mathrm{a}$ & $\mathrm{n} / \mathrm{a}$ & $\mathrm{n} / \mathrm{a}$ & $\mathrm{n} / \mathrm{a}$ & $\mathrm{n} / \mathrm{a}$ \\
\hline $\mathrm{W} /$ forearm ext. & 14.89 & 4.07 & 18.17 & 2.86 & $\mathrm{n} / \mathrm{a}$ & $\mathrm{n} / \mathrm{a}$ & $\mathrm{n} / \mathbf{a}$ & $\mathbf{n} / \mathbf{a}$ & $\mathrm{n} / \mathrm{a}$ \\
\hline Finger flexion & 12.39 & 1.10 & 13.73 & 4.32 & $\mathrm{n} / \mathrm{a}$ & $\mathrm{n} / \mathbf{a}$ & $\mathrm{n} / \mathrm{a}$ & $\mathbf{n} / \mathbf{a}$ & $\mathrm{n} / \mathbf{a}$ \\
\hline Thumb flexion & 11.60 & 4.12 & 11.94 & 7.58 & $\mathrm{n} / \mathrm{a}$ & $\mathrm{n} / \mathrm{a}$ & $\mathrm{n} / \mathrm{a}$ & $\mathrm{n} / \mathbf{a}$ & $\mathrm{n} / \mathrm{a}$ \\
\hline Wrist flexion & 15.58 & 4.96 & 19.85 & 1.94 & $\mathrm{n} / \mathrm{a}$ & $n / a$ & $\mathrm{n} / \mathrm{a}$ & $\mathrm{n} / \mathbf{a}$ & $\mathrm{n} / \mathrm{a}$ \\
\hline Forearm flex. & 15.82 & 2.17 & 14.70 & 4.71 & $\mathrm{n} / \mathrm{a}$ & $\mathrm{n} / \mathrm{a}$ & $\mathrm{n} / \mathrm{a}$ & $\mathrm{n} / \mathrm{a}$ & $\mathbf{n} / \mathbf{a}$ \\
\hline Finger ext. & 15.33 & 4.42 & 15.53 & 4.79 & $\mathrm{n} / \mathrm{a}$ & $\mathrm{n} / \mathrm{a}$ & $\mathrm{n} / \mathrm{a}$ & $\mathrm{n} / \mathbf{a}$ & $\mathrm{n} / \mathrm{a}$ \\
\hline Thumb ext. & 13.28 & 4.88 & 12.62 & 5.86 & $\mathrm{n} / \mathrm{a}$ & $\mathrm{n} / \mathrm{a}$ & $\mathrm{n} / \mathrm{a}$ & $\mathbf{n} / \mathbf{a}$ & $\mathbf{n} / \mathbf{a}$ \\
\hline Wrist ext. & 15.82 & 2.17 & 14.70 & 4.71 & $\mathrm{n} / \mathrm{a}$ & $\mathrm{n} / \mathrm{a}$ & $\mathrm{n} / \mathbf{a}$ & $\mathrm{n} / \mathrm{a}$ & $\mathrm{n} / \mathrm{a}$ \\
\hline Forearm ext. & 12.44 & 1.57 & 12.30 & 6.27 & $\mathrm{n} / \mathrm{a}$ & $\mathrm{n} / \mathrm{a}$ & $\mathbf{n} / \mathbf{a}$ & $\mathbf{n} / \mathbf{a}$ & $\mathbf{n} / \mathbf{a}$ \\
\hline \multicolumn{10}{|c|}{ Percentage total distal forelimb area } \\
\hline Distal forelimb & $\mathrm{n} / \mathrm{a}$ & $\mathrm{n} / \mathrm{a}$ & $\mathrm{n} / \mathrm{a}$ & $\mathrm{n} / \mathrm{a}$ & $\mathrm{n} / \mathrm{a}$ & $\mathrm{n} / \mathrm{a}$ & $\mathbf{n} / \mathbf{a}$ & $\mathrm{n} / \mathrm{a}$ & $\mathbf{n} / \mathbf{a}$ \\
\hline Flexion & 0.29 & 0.07 & 0.39 & 0.10 & -0.10 & 0.10 & -2.56 & 5 & 0.050 \\
\hline Extension & 0.71 & 0.07 & 0.60 & 0.10 & 0.11 & 0.11 & 2.57 & 5 & 0.050 \\
\hline Digit flexion & 0.31 & 0.07 & 0.30 & 0.10 & $\mathrm{n} / \mathrm{a}$ & $\mathrm{n} / \mathbf{a}$ & $\mathrm{n} / \mathrm{a}$ & $\mathrm{n} / \mathrm{a}$ & $\mathrm{n} / \mathrm{a}$ \\
\hline W/forearm fl. & 0.41 & 0.07 & 0.31 & 0.06 & $\mathrm{n} / \mathrm{a}$ & $\mathrm{n} / \mathrm{a}$ & $\mathrm{n} / \mathrm{a}$ & $\mathrm{n} / \mathrm{a}$ & $\mathrm{n} / \mathrm{a}$ \\
\hline Digit ext. & 0.19 & 0.05 & 0.26 & 0.09 & $\mathrm{n} / \mathrm{a}$ & $\mathrm{n} / \mathrm{a}$ & $\mathbf{n} / \mathbf{a}$ & $\mathrm{n} / \mathrm{a}$ & $\mathrm{n} / \mathrm{a}$ \\
\hline W/forearm ext. & 0.10 & 0.08 & 0.15 & 0.07 & $\mathbf{n} / \mathbf{a}$ & $\mathrm{n} / \mathrm{a}$ & $\mathrm{n} / \mathrm{a}$ & $\mathrm{n} / \mathrm{a}$ & $\mathrm{n} / \mathrm{a}$ \\
\hline Finger flexion & 0.16 & 0.07 & 0.22 & 0.10 & -0.05 & 0.06 & -2.05 & 5 & 0.095 \\
\hline Thumb flexion & 0.03 & 0.01 & 0.03 & 0.04 & 0.00 & 0.03 & 0.21 & 5 & 0.839 \\
\hline Wrist flexion & 0.08 & 0.07 & 0.12 & 0.05 & -0.04 & 0.07 & -1.43 & 5 & 0.211 \\
\hline Forearm flex. & 0.29 & 0.08 & 0.19 & 0.04 & 0.00 & 0.02 & -0.41 & 5 & 0.701 \\
\hline Finger ext. & 0.14 & 0.07 & 0.22 & 0.10 & -0.08 & 0.09 & -2.21 & 5 & 0.078 \\
\hline Thumb ext. & 0.19 & 0.11 & 0.09 & 0.03 & 0.11 & 0.12 & 2.25 & 5 & 0.074 \\
\hline Wrist ext. & 0.29 & 0.08 & 0.19 & 0.04 & 0.10 & 0.10 & 2.49 & 5 & 0.055 \\
\hline Forearm ext. & 0.12 & 0.04 & 0.12 & 0.05 & 0.00 & 0.04 & -0.08 & 5 & 0.937 \\
\hline
\end{tabular}

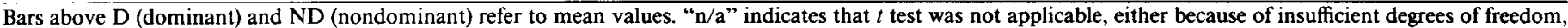
or nonsignificant ANOVA. $p$ values shown in bold italics indicate statistical significance.

example, within flexion/extension categories, seven significant $t$ tests were found for the complexity index alone.

Where significant interhemispheric differences occurred, they invariably resulted from larger areas, longer boundary lengths (perimeter), greater numbers of regions, and greater complexity indices in the dominant hemisphere (Fig. 13). For example, area and perimeter of wrist extension regions in the dominant hemisphere were each about 2 times the area and perimeter in the nondominant hemispherc, the number of finger extension regions in the dominant hemisphere was about 1.7 times the number in the nondominant hemisphere, and the thumb extension complexity index in the dominant hemisphere was about 1.4 times the index in the nondominant hemisphere. While thresholds were generally higher (sensitivity lower) in the nondominant hemisphere, a single significant $t$ test resulted from a higher threshold for thumb extension in the dominant hemisphere (Fig. 13). However, the absolute interhemispheric difference in threshold for thumb extension movements was only about 2 $\mu \mathrm{A}$. Finally, while size of the largest region did not display any bias for the dominant or nondominant hemisphere, the single significant $t$ test resulted from a greater wrist/forearm value in the dominant hemisphere.

Results for flexion/extension groups were similar and will not be described further.

Proximal movement representations embedded within distal forelimb fields. Proximal movement representations were often located well within the main distal forelimb representation. Comparison of the number of discrete proximal regions embedded within the main distal forelimb region revealed a statistically significant difference between dominant and nondom- 


\section{WRIST EXTENSION}

8727 (Left Hemisphere Dominant) LEFT HEMISPHERE

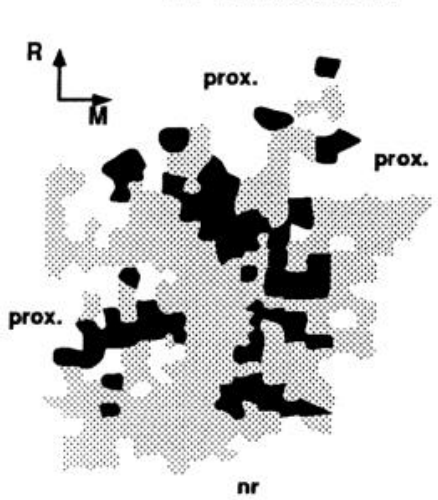

RIGHT HEMISPHERE

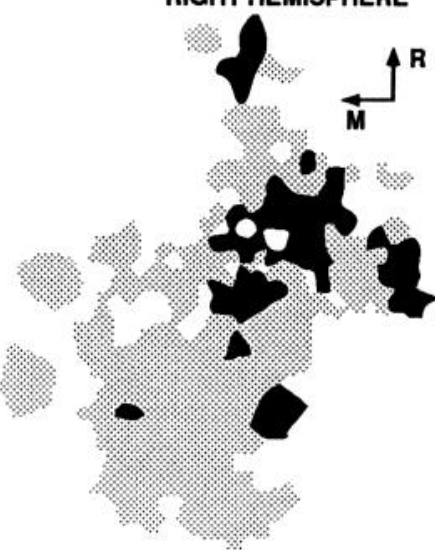

\section{4 (Right Hemisphere Dominant)}

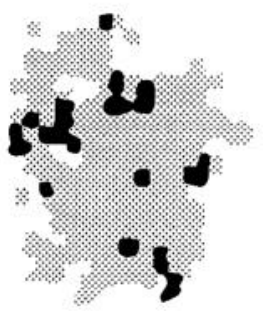

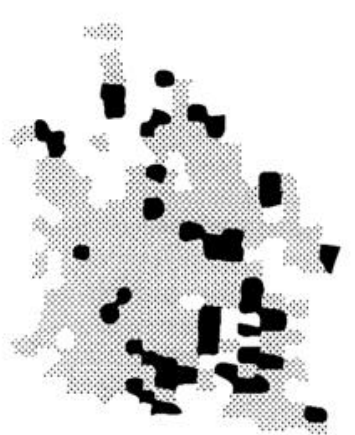

wrist extension

other distal forelimb

8905 (Right Hemisphere Dominant)
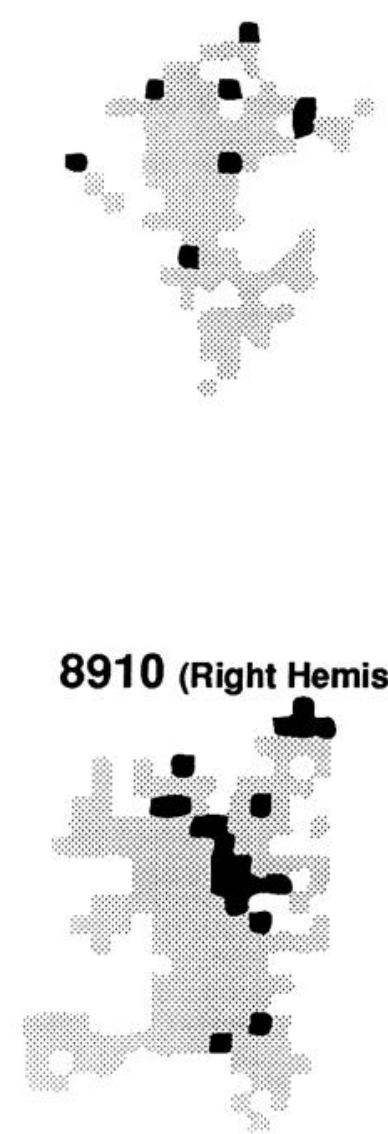

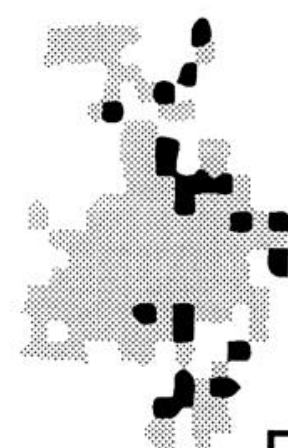

\begin{tabular}{|l|r|r|}
\hline \multicolumn{3}{|c|}{ Wrist extension } \\
\hline & \multicolumn{1}{|c|}{$d-n d$} & $p$ \\
\hline area & 1.358 & 0.017 \\
\hline perimeter & 14.258 & 0.008 \\
\hline complexity & 1.253 & 0.006 \\
\hline \% total area & 0.109 & 0.017 \\
\hline
\end{tabular}

8909 (Right Hemisphere Dominant)
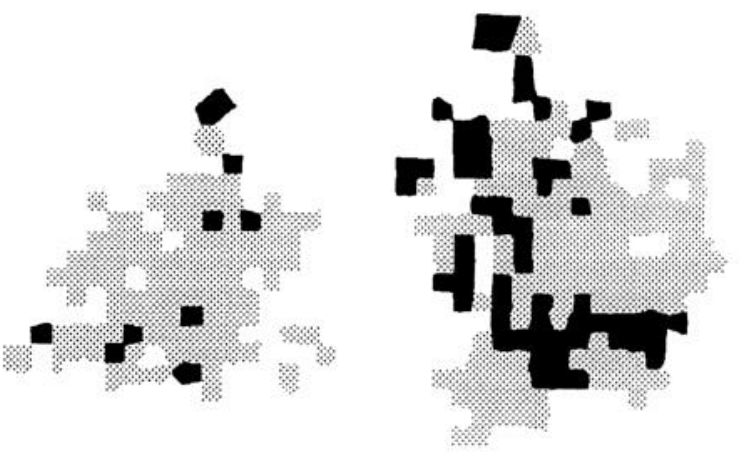

8911 (Right Hemisphere Dominant)
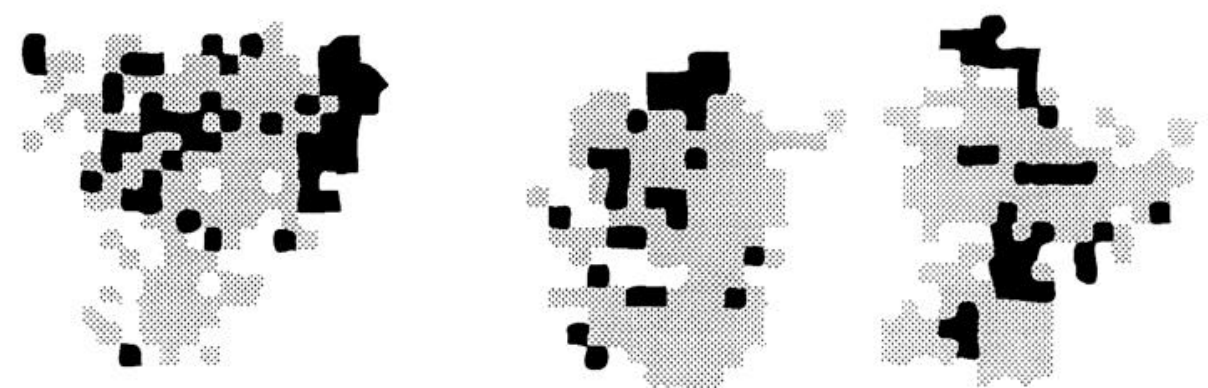

Figure 9. Representation of wrist extension fields in cortical area 4 in left and right hemispheres of each monkey. Wrist extension fields are displayed in black; other distal forelimb fields are displayed in shaded areas. Selected statistical results are shown in the inset. 


\begin{tabular}{|c|c|c|c|c|c|c|c|c|c|c|c|}
\hline Level & Source & $\mathrm{df}$ & MS & $F$ & $p$ & Level & Source & $\mathrm{df}$ & MS & $F$ & $p$ \\
\hline \multicolumn{6}{|c|}{ A. Digit/wrist-forearm categories } & 2 & Side (S) & 1 & 1.72 & 1.53 & 0.236 \\
\hline \multicolumn{6}{|l|}{ Area } & & Individual (I) & 5 & 3.60 & 3.20 & 0.037 \\
\hline \multirow[t]{4}{*}{1} & Side $(\mathbf{S})$ & 1 & 9.68 & 3.75 & 0.111 & & Movement (M) & 1 & 0.10 & 0.09 & 0.765 \\
\hline & Individual (I) & 5 & 9.97 & 3.86 & 0.082 & & $\mathbf{S} \times \mathbf{M}$ & 1 & 5.88 & 5.23 & 0.037 \\
\hline & Movement (M) & 0 & $\mathrm{n} / \mathrm{a}$ & $\mathrm{n} / \mathrm{a}$ & $\mathrm{n} / \mathrm{a}$ & 3 & Side (S) & 1 & 0.03 & 0.08 & 0.773 \\
\hline & $\mathbf{S} \times \mathbf{M}$ & 0 & $\mathrm{n} / \mathbf{a}$ & $\mathbf{n} / \mathbf{a}$ & $\mathbf{n} / \mathbf{a}$ & & Individual (I) & 5 & 0.82 & 2.34 & 0.062 \\
\hline \multirow[t]{4}{*}{2} & Side (S) & 1 & 4.29 & 4.14 & 0.060 & & Movement (M) & 3 & 4.34 & 12.42 & 0.000 \\
\hline & Individual (I) & 5 & 5.44 & 5.25 & 0.006 & & $\mathbf{S} \times \mathbf{M}$ & 3 & 1.30 & 3.71 & 0.020 \\
\hline & Movement (M) & 1 & 0.25 & 0.24 & 0.633 & 4 & Side (S) & 1 & 0.00 & 0.02 & 0.892 \\
\hline & $\mathrm{S} \times \mathrm{M}$ & 1 & 0.82 & 0.79 & 0.389 & & Individual (I) & 5 & 0.22 & 2.47 & 0.036 \\
\hline \multirow[t]{4}{*}{3} & Side (S) & 1 & 3.54 & 4.75 & 0.036 & & Movement (M) & 13 & 1.09 & 12.40 & 0.000 \\
\hline & Individual (I) & 5 & 2.57 & 3.45 & 0.012 & & $\mathbf{S} \times \mathbf{M}$ & 13 & 0.15 & 1.71 & 0.064 \\
\hline & Movement (M) & 3 & 15.26 & 20.45 & 0.000 & Comp & xity index & & & & \\
\hline & $\mathrm{S} \times \mathrm{M}$ & 3 & 2.13 & 2.86 & 0.051 & 1 & Side (S) & 1 & 0.08 & 0.55 & 0.490 \\
\hline \multirow[t]{4}{*}{4} & Side (S) & 1 & 0.74 & 2.58 & 0.111 & & Individual (I) & 5 & 0.35 & 2.53 & 0.166 \\
\hline & Individual (I) & 5 & 0.80 & 2.75 & 0.021 & & Movement (M) & $\mathbf{n} / \mathbf{a}$ & $\mathrm{n} / \mathrm{a}$ & $\mathbf{n} / \mathbf{a}$ & $\mathrm{n} / \mathrm{a}$ \\
\hline & Movement (M) & 13 & 5.42 & 18.88 & 0.000 & & $\mathbf{S} \times \mathbf{M}$ & $\mathrm{n} / \mathbf{a}$ & $\mathbf{n} / \mathbf{a}$ & $\mathrm{n} / \mathbf{a}$ & $\mathrm{n} / \mathrm{a}$ \\
\hline & $\mathbf{S} \times \mathbf{M}$ & 13 & 0.62 & 2.15 & 0.015 & 2 & Side (S) & 1 & 6.74 & 32.08 & 0.000 \\
\hline \multicolumn{6}{|c|}{ Number of regions } & & Individual (I) & 5 & 0.57 & 2.69 & 0.063 \\
\hline \multirow[t]{4}{*}{1} & Side (S) & 1 & 1.33 & 0.53 & 0.501 & & Movement (M) & 1 & 0.72 & 3.40 & 0.085 \\
\hline & Individual (I) & 5 & 0.93 & 0.37 & 0.851 & & $\mathbf{S} \times \mathbf{M}$ & 1 & 0.02 & 0.12 & 0.738 \\
\hline & Movement (M) & 0 & $\mathrm{n} / \mathrm{a}$ & $\mathrm{n} / \mathrm{a}$ & $\mathrm{n} / \mathrm{a}$ & 3 & Side $(\mathbf{S})$ & 1 & 7.62 & 22.44 & 0.000 \\
\hline & $\mathbf{S} \times \mathbf{M}$ & 0 & $\mathrm{n} / \mathrm{a}$ & $\mathrm{n} / \mathrm{a}$ & $\mathrm{n} / \mathrm{a}$ & & Individual (I) & 5 & 1.88 & 5.55 & 0.001 \\
\hline \multirow[t]{4}{*}{2} & Side (S) & 1 & 32.67 & 3.04 & 0.102 & & Movement (M) & 3 & 5.41 & 15.94 & 0.000 \\
\hline & Individual (I) & 5 & 13.70 & 1.28 & 0.325 & & $\mathbf{S} \times \mathbf{M}$ & 3 & 0.45 & 1.32 & 0.282 \\
\hline & Movement (M) & 1 & 0.67 & 0.06 & 0.807 & 4 & Side $(S)$ & 1 & 3.77 & 8.33 & 0.005 \\
\hline & $\mathbf{S} \times \mathbf{M}$ & 1 & 37.50 & 3.49 & 0.081 & & Individual (I) & 5 & 2.16 & 4.78 & 0.001 \\
\hline \multirow[t]{4}{*}{3} & Side (S) & 1 & 3.54 & 4.75 & 0.000 & & Movement (M) & 13 & 9.29 & 20.51 & 0.000 \\
\hline & Individual (I) & 5 & 2.57 & 3.45 & 0.001 & & $\mathbf{S} \times \mathbf{M}$ & 13 & 0.39 & 0.85 & 0.606 \\
\hline & Movement (M) & 3 & 15.26 & 20.45 & 0.022 & Threst & & & & & \\
\hline & $\mathrm{S} \times \mathbf{M}$ & 3 & 2.13 & 2.86 & 0.430 & 1 & Side (S) & 1 & 0.42 & 0.06 & 0.814 \\
\hline \multirow[t]{4}{*}{4} & Side (S) & 1 & 77.36 & 14.74 & 0.000 & & Individual (I) & 5 & 14.02 & 2.04 & 0.227 \\
\hline & Individual (I) & 5 & 33.48 & 6.38 & 0.000 & & Movement (M) & 0 & $\mathrm{n} / \mathrm{a}$ & $\mathrm{n} / \mathrm{a}$ & $\mathrm{n} / \mathrm{a}$ \\
\hline & Movement (M) & 13 & 114.83 & 21.88 & 0.000 & & $\mathbf{S} \times \mathbf{M}$ & 0 & $\mathrm{n} / \mathrm{a}$ & $\mathrm{n} / \mathrm{a}$ & $n / \mathbf{a}$ \\
\hline & $\mathrm{S} \times \mathrm{M}$ & 13 & 8.36 & 1.59 & 0.095 & 2 & Side (S) & 1 & 0.60 & 0.11 & 0.749 \\
\hline \multicolumn{3}{|c|}{ Perimeter } & & & & & Individual (I) & 5 & 36.89 & 6.52 & 0.002 \\
\hline \multirow[t]{4}{*}{1} & Side (S) & 1 & 85.12 & 2.79 & 0.156 & & Movement (M) & 1 & 6.98 & 1.23 & 0.284 \\
\hline & Individual (I) & 5 & 101.39 & 3.32 & 0.107 & & $\mathbf{S} \times \mathbf{M}$ & 1 & 0.45 & 0.08 & 0.782 \\
\hline & Movement (M) & 0 & $\mathrm{n} / \mathrm{a}$ & $\mathrm{n} / \mathrm{a}$ & $\mathrm{n} / \mathrm{a}$ & 3 & Side (S) & 1 & 3.70 & 0.59 & 0.446 \\
\hline & $\mathbf{S} \times \mathbf{M}$ & 0 & $\mathrm{n} / \mathrm{a}$ & $\mathrm{n} / \mathrm{a}$ & $\mathbf{n} / \mathbf{a}$ & & Individual (I) & 5 & 64.50 & 10.34 & 0.000 \\
\hline \multirow[t]{4}{*}{2} & Side (S) & 1 & 903.56 & 33.94 & 0.000 & & Movement (M) & 3 & 25.39 & 4.07 & 0.014 \\
\hline & Individual (I) & 5 & 198.75 & 7.47 & 0.001 & & $\mathbf{S} \times \mathbf{M}$ & 3 & 0.56 & 0.09 & 0.966 \\
\hline & Movement (M) & 1 & 7.46 & 0.28 & 0.604 & 4 & Side (S) & 1 & 252.40 & 12.56 & 0.001 \\
\hline & $\mathbf{S} \times \mathbf{M}$ & 1 & 21.55 & 0.81 & 0.383 & & Individual (I) & 5 & 216.00 & 10.75 & 0.000 \\
\hline 3 & Side (S) & 1 & 706.10 & 17.01 & 0.000 & & Movement (M) & 13 & 27.65 & 1.38 & 0.183 \\
\hline & Individual (I) & 5 & 197.20 & 4.75 & 0.002 & & $\mathrm{~S} \times \mathrm{M}$ & 13 & 42.43 & 2.11 & 0.019 \\
\hline & Movement (M) & 3 & 951.88 & 22.94 & 0.000 & Percen & ige total distal forel & $\mathrm{nb}$ area & & & \\
\hline & $\mathrm{S} \times \mathrm{M}$ & 3 & 136.23 & 3.28 & 0.032 & 1 & Side (S) & 1 & $\mathbf{n} / \mathbf{a}$ & $\mathrm{n} / \mathrm{a}$ & $\mathrm{n} / \mathrm{a}$ \\
\hline 4 & Side (S) & 1 & 208.06 & 9.62 & 0.002 & & Individual (I) & 5 & $\mathrm{n} / \mathrm{a}$ & $\mathrm{n} / \mathrm{a}$ & $\mathrm{n} / \mathrm{a}$ \\
\hline & Individual (I) & 5 & 72.72 & 3.36 & 0.007 & & Movement (M) & 0 & $\mathrm{n} / \mathrm{a}$ & $\mathrm{n} / \mathrm{a}$ & $\mathrm{n} / \mathrm{a}$ \\
\hline & Movement (M) & 13 & 590.91 & 27.32 & 0.000 & & $\mathbf{S} \times \mathbf{M}$ & 0 & $\mathrm{n} / \mathrm{a}$ & $\mathrm{n} / \mathrm{a}$ & $\mathrm{n} / \mathrm{a}$ \\
\hline & $\mathrm{S} \times \mathrm{M}$ & 13 & 55.28 & 2.56 & 0.004 & 2 & Side $(\mathbf{S})$ & 1 & 0.00 & 0.03 & 0.858 \\
\hline Larges & egion & & & & & & Individual (I) & 5 & 0.00 & 0.06 & 0.997 \\
\hline 1 & Side (S) & 1 & 7.99 & 3.65 & 0.114 & & Movement (M) & 1 & 0.00 & 0.45 & 0.511 \\
\hline & Individual (I) & 5 & 9.67 & 4.42 & 0.064 & & $\mathbf{S} \times \mathbf{M}$ & 1 & 0.01 & 1.37 & 0.260 \\
\hline & Movement (M) & 0 & $\mathrm{n} / \mathbf{a}$ & $\mathrm{n} / \mathrm{a}$ & $\mathbf{n} / \mathbf{a}$ & 3 & Side (S) & 1 & 0.00 & 0.17 & 0.681 \\
\hline & $\mathrm{S} \times \mathrm{M}$ & 0 & $\mathbf{n} / \mathbf{a}$ & $\mathrm{n} / \mathrm{a}$ & $\mathrm{n} / \mathrm{a}$ & & Individual (I) & 5 & 0.00 & 0.04 & 0.999 \\
\hline
\end{tabular}




\begin{tabular}{|c|c|c|c|c|c|}
\hline Level & Source & df & MS & $F$ & $p$ \\
\hline \multirow{6}{*}{4} & Movement (M) & 3 & 0.15 & 32.23 & 0.000 \\
\hline & $\mathbf{S} \times \mathbf{M}$ & 3 & 0.03 & 5.81 & 0.002 \\
\hline & Side (S) & 1 & 0.00 & 0.02 & 0.900 \\
\hline & Individual (I) & 5 & 0.00 & 0.02 & 1.000 \\
\hline & Movement (M) & 13 & 0.06 & 24.61 & 0.000 \\
\hline & $\mathbf{S} \times \mathbf{M}$ & 13 & 0.01 & 2.62 & 0.003 \\
\hline \multicolumn{6}{|c|}{$\begin{array}{l}\text { B. Flexion extension categories } \\
\text { Area }\end{array}$} \\
\hline \multirow[t]{4}{*}{1} & Side (S) & 1 & 9.68 & 3.75 & 0.111 \\
\hline & Individual (I) & 5 & 9.97 & 3.86 & 0.082 \\
\hline & Movement (M) & 0 & $\mathbf{n} / \mathbf{a}$ & $\mathrm{n} / \mathrm{a}$ & $\mathrm{n} / \mathrm{a}$ \\
\hline & $\mathbf{S} \times \mathbf{M}$ & 0 & $\mathrm{n} / \mathrm{a}$ & $n / a$ & $\mathrm{n} / \mathrm{a}$ \\
\hline \multirow[t]{4}{*}{2} & Side (S) & 1 & 4.19 & 2.67 & 0.123 \\
\hline & Individual (I) & 5 & 4.96 & 3.16 & 0.038 \\
\hline & Movement (M) & 1 & 60.96 & 38.76 & 0.000 \\
\hline & $\mathbf{S} \times \mathbf{M}$ & 1 & 8.37 & 5.32 & 0.036 \\
\hline \multirow[t]{4}{*}{3} & Side (S) & 1 & 2.49 & 2.83 & 0.101 \\
\hline & Individual (I) & 5 & 2.85 & 3.24 & 0.017 \\
\hline & Movement (M) & 3 & 14.08 & 16.01 & 0.000 \\
\hline & $\mathbf{S} \times \mathbf{M}$ & 3 & 2.19 & 2.49 & 0.076 \\
\hline \multirow[t]{4}{*}{4} & Side (S) & 1 & 1.76 & 3.28 & 0.074 \\
\hline & Individual (I) & 5 & 1.48 & 2.75 & 0.024 \\
\hline & Movement (M) & 7 & 7.24 & 13.48 & 0.000 \\
\hline & $S \times M$ & 7 & 1.53 & 2.85 & 0.011 \\
\hline \multicolumn{6}{|c|}{ Number of regions } \\
\hline \multirow[t]{4}{*}{1} & Side (S) & 1 & 1.33 & 0.53 & 0.501 \\
\hline & Individual (I) & 5 & 0.93 & 0.37 & 0.851 \\
\hline & Movement (M) & 0 & $\mathrm{n} / \mathrm{a}$ & $\mathrm{n} / \mathrm{a}$ & $\mathrm{n} / \mathrm{a}$ \\
\hline & $\mathbf{S} \times \mathbf{M}$ & 0 & $\mathrm{n} / \mathrm{a}$ & $\mathrm{n} / \mathrm{a}$ & $\mathrm{n} / \mathrm{a}$ \\
\hline \multirow[t]{4}{*}{2} & Side (S) & 1 & 15.04 & 2.19 & 0.160 \\
\hline & Individual (I) & 5 & 14.54 & 2.12 & 0.120 \\
\hline & Movement (M) & 1 & 40.04 & 5.82 & 0.029 \\
\hline & $\mathbf{S} \times \mathbf{M}$ & 1 & 0.04 & 0.01 & 0.939 \\
\hline \multirow[t]{4}{*}{3} & Side (S) & 1 & 133.33 & 18.43 & 0.000 \\
\hline & Individual (I) & 5 & 31.48 & 4.35 & 0.003 \\
\hline & Movement (M) & 3 & 54.14 & 7.48 & 0.001 \\
\hline & $\mathrm{S} \times \mathrm{M}$ & 3 & 42.50 & 5.87 & 0.002 \\
\hline \multirow[t]{4}{*}{4} & Side (S) & 1 & 119.26 & 18.24 & 0.000 \\
\hline & Individual (I) & 5 & 41.96 & 6.42 & 0.000 \\
\hline & Movement (M) & 7 & 114.86 & 17.57 & 0.000 \\
\hline & $\mathbf{S} \times \mathbf{M}$ & 7 & 11.05 & 1.69 & 0.124 \\
\hline \multicolumn{6}{|c|}{ Perimeter } \\
\hline \multirow[t]{4}{*}{1} & Side (S) & 1 & 85.12 & 2.79 & 0.156 \\
\hline & Individual (I) & 5 & 101.39 & 3.32 & 0.107 \\
\hline & Movement (M) & 0 & $\mathbf{n} / \mathbf{a}$ & $\mathrm{n} / \mathrm{a}$ & $\mathrm{n} / \mathrm{a}$ \\
\hline & $\mathbf{S} \times \mathbf{M}$ & 0 & $\mathrm{n} / \mathrm{a}$ & $\mathrm{n} / \mathbf{a}$ & $\mathbf{n} / \mathbf{a}$ \\
\hline \multirow[t]{4}{*}{2} & Side (S) & 1 & 282.63 & 10.15 & 0.006 \\
\hline & Individual (I) & 5 & 148.86 & 5.35 & 0.005 \\
\hline & Movement (M) & 1 & 282.47 & 46.07 & 0.000 \\
\hline & $\mathbf{S} \times \mathbf{M}$ & 1 & 137.00 & 4.92 & 0.042 \\
\hline \multirow[t]{4}{*}{3} & Side (S) & 1 & 609.54 & 15.18 & 0.000 \\
\hline & Individual (I) & 5 & 145.74 & 3.63 & 0.009 \\
\hline & Movement (M) & 3 & 1082.66 & 26.96 & 0.000 \\
\hline & $\mathrm{S} \times \mathrm{M}$ & 3 & 198.40 & 4.94 & 0.006 \\
\hline \multirow[t]{4}{*}{4} & Side (S) & 1 & 394.31 & 12.28 & 0.001 \\
\hline & Individual (I) & 5 & 121.55 & 3.78 & 0.004 \\
\hline & Movement (M) & 7 & 700.05 & 21.79 & 0.000 \\
\hline & $\mathbf{S} \times \mathbf{M}$ & 7 & 120.54 & 3.75 & 0.002 \\
\hline
\end{tabular}

Table 3. Continued

\begin{tabular}{|c|c|c|c|c|c|}
\hline I evel & Source & df & MS & $F$ & $p$ \\
\hline \multicolumn{6}{|c|}{ Largest region } \\
\hline \multirow[t]{4}{*}{1} & Side (S) & 1 & 7.99 & 3.65 & 0.114 \\
\hline & Individual (I) & 5 & 9.67 & 4.42 & 0.064 \\
\hline & Movement (M) & 0 & $\mathrm{n} / \mathrm{a}$ & $\mathrm{n} / \mathrm{a}$ & $\mathrm{n} / \mathrm{a}$ \\
\hline & $\mathbf{S} \times \mathbf{M}$ & 0 & $\mathrm{n} / \mathrm{a}$ & $\mathrm{n} / \mathrm{a}$ & $\mathrm{n} / \mathrm{a}$ \\
\hline \multirow[t]{4}{*}{2} & Side (S) & 1 & 2.33 & 1.00 & 0.334 \\
\hline & Individual (I) & 5 & 5.31 & 2.27 & 0.100 \\
\hline & Movement (M) & 1 & 68.21 & 29.20 & 0.000 \\
\hline & $\mathbf{S} \times \mathbf{M}$ & 1 & 6.06 & 2.59 & 0.128 \\
\hline \multirow[t]{4}{*}{3} & Side (S) & 1 & 0.00 & 0.00 & 0.986 \\
\hline & Individual (I) & 5 & 0.95 & 1.42 & 0.240 \\
\hline & Movement (M) & 3 & 3.89 & 5.87 & 0.002 \\
\hline & $\mathrm{S} \times \mathrm{M}$ & 3 & 0.73 & 1.11 & 0.360 \\
\hline \multirow[t]{4}{*}{4} & Side (S) & 1 & 0.01 & 0.03 & 0.869 \\
\hline & Individual (I) & 5 & 0.36 & 2.13 & 0.071 \\
\hline & Movement (M) & 7 & 1.34 & 7.87 & 0.000 \\
\hline & $\mathbf{S} \times \mathbf{M}$ & 7 & 0.32 & 1.88 & 0.0 \\
\hline
\end{tabular}

Complexity index

$1 \quad$ Side (S)

Individual (I)

Movement (M)

$\mathrm{S} \times \mathrm{M}$

$2 \quad$ Side $(\mathbf{S})$

Individual (I)

Movement (M)

$\mathrm{S} \times \mathrm{M}$

$3 \quad$ Side (S)

Individual (I)

Movement (M)

$\mathrm{S} \times \mathrm{M}$

$4 \quad$ Side (S)

Individual (I)

Movement (M)

$\mathbf{S} \times \mathbf{M}$

Threshold

1 Side (S)

Individual (I)

Movement (M)

$\mathrm{S} \times \mathrm{M}$

2 Side (S)

Individual (I)

Movement (M)

$\mathrm{S} \times \mathrm{M}$

3 Side (S)

Individual (I)

Movement (M)

$\mathbf{S} \times \mathbf{M}$

$4 \quad$ Side (S)

Individual (I)

Movement (M)

$\mathrm{S} \times \mathrm{M}$

1
5
$\mathbf{n} / \mathbf{a}$
$\mathbf{n} / \mathbf{a}$
1
5
1
1
1
5
3
3
1
5
7
7

$\begin{array}{rrl}0.08 & 0.55 & 0.490 \\ 0.35 & 2.53 & 0.166 \\ \mathrm{n} / \mathrm{a} & \mathrm{n} / \mathrm{a} & \mathrm{n} / \mathrm{a}\end{array}$

$\mathrm{n} / \mathrm{a}$

1.51

0.94

0.69

0.00

7.25

1.55

7.25

1.06

8.22

1.98

9.27

0.60

$\mathrm{n} / \mathbf{a}$

7.03

4.40

3.20

0.01

21.95

4.70

21.95

3.22

21.70

5.24

24.48

1.58

n/a

0.018

0.011

0.094

0.912

0.000

0.002

0.000

0.035

0.000

0.000

0.000

0.155

$\begin{array}{lll}0.42 & 0.06 & 0.814\end{array}$

$\begin{array}{lll}14.02 & 2.04 & 0.227\end{array}$

$\mathrm{n} / \mathbf{a} \quad \mathrm{n} / \mathrm{a} \quad \mathrm{n} / \mathrm{a}$

$\mathrm{n} / \mathrm{a}$

5.47

26.20

n/a

0.94

n/a

0.348

1.59

0.011

13.00

7.12

2.23

0.609

51.89

0.74

0.156

5.39

0.396

29.21

3.03

0.001

11.23

1.17

0.042

6.76

0.53

135.67

10.54

0.471

46.12

3.58

0.000

8.50

0.66

0.705

Percentage total distal forelimb area

1 Side (S)

Individual (I) $\quad 5 \quad \mathrm{n} / \mathrm{a}$

$\mathbf{n} / \mathbf{a} \quad \mathbf{n} / \mathbf{a}$

Movement (M)

$\mathrm{n} / \mathbf{a}$

$\mathbf{n} / \mathbf{a}$

$\mathrm{n} / \mathbf{a}$

$\mathrm{S} \times \mathrm{M}$

$2 \quad$ Side (S)

$\mathrm{n} / \mathrm{a}$

$\mathrm{n} / \mathrm{a}$

Individual (I) $\mathrm{n} / \mathrm{a} \quad \mathrm{n} / \mathrm{a}$

$0.02 \quad 0.890$

$0.12 \quad 0.986$ 


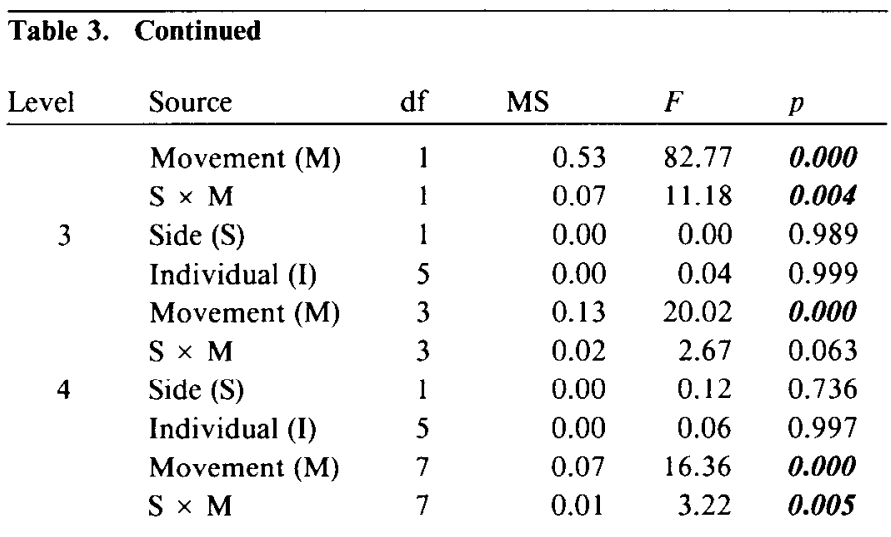

"n/a" indicates that $t$ test was not applicable because of insufficient degrees of freedom. $p$ values shown in bold italics indicate statistical significance.

inant hemispheres $(t=11.619 ; p=0.0001)$. In all cases, a larger number of proximal movement regions was found within the distal forelimb region of the dominant hemisphere (Figs. 4, 5). Comparison of distal forelimb regions embedded within proximal regions did not result in statistically significant differences between dominant and nondominant hemispheres $(t=0.725$; $p=0.5007)$, but it should be noted that the total representational extent of proximal movements was not completely mapped.

Examination of movements evoked at suprathreshold current levels. At each of the low-threshold sites (threshold current $\leq$ $18 \mu \mathrm{A}$ ) in four of the six animals, secondary responses were defined at a fixed suprathreshold current of $20 \mu \mathrm{A}$. In each hemisphere of each animal, we calculated the percentage of lowthreshold sites at which this modest suprathreshold stimulation evoked a secondary response in addition to the primary response. While the results that follow were not statistically reliable due to a relatively large variance for such a small number of subjects, pooled results across the four animals are presented.

Using a fixed suprathreshold current of $20 \mu \mathrm{A}$, the proportions of sites whose stimulation evoked secondary responses were similar in the two hemispheres. Secondary responses were evoked at $47.5 \%$ of low-threshold sites in the dominant hemisphere, compared to $40.8 \%$ in the nondominant hemisphere. However, when specific secondary responses associated with specific primary responses were examined, very large differences were found. For example, in the dominant hemisphere, $67.6 \%$ of low-threshold sites whose primary response was finger flexion resulted in a secondary wrist extension response. That is, at these sites, suprathreshold stimulation produced digit flexion and wrist extension in combination. By contrast, suprathreshold stimulation of only $26.1 \%$ of low-threshold finger flexion sites in the nondominant hemisphere resulted in finger flexion in combination with wrist extension (Fig. 14). These results suggest a difference in the degree and specificity of overlap in motor representations between the hemispheres, and will be addressed in the Discussion.

\section{Correlation of spatial parameters with degree of hand preference}

In order to determine if any of the spatial characteristics were correlated with the hand preference index, a correlation coefficient was determined within each hemisphere for each spatial parameter at each hierarchical level. A number of these relationships were statistically significant $(p \leq 0.05)$, as shown in
Table 4. Most (34 of 37) of these significant relationships between dominance scores and spatial representational features were found in the dominant hemisphere.

\section{Discussion}

Using conventional ICMS motor mapping techniques, we have found large interhemispheric differences in the representations of distal forelimb movements in primary motor cortex of the squirrel monkey. These differences appear to be related to the hand preferences of the individual animals in a task requiring skilled use of the digits. Before discussing the implications of these findings for the organization of motor cortex and their functional significance, we address other possible sources of variability that may have contributed to the individual and interhemispheric differences observed here.

\section{Reliability of ICMS-defined motor maps}

Large sources of variability in the movements evoked by ICMS (e.g., variability among individuals, with different levels of anesthesia, with different anesthetic agents, with different pulse train durations, as a function of previous stimulation, etc.) are not uncommon, as previous investigators have discussed (e.g., see Graham Brown and Sherrington, 1912; Lashley, 1923; Penfield and Boldrey, 1937; Stoney et al., 1968; Hall and Lindholrm, 1974; Neafsey et al., 1986; Nudo et al., 1990). In the present experiment, we have attempted to control, as closely as possible, several sources of variation contributed by the ICMS technique. First, we used an animal with a relatively flat, unfissured motor cortex. Since microelectrode penetrations were made perpendicular to the cortical surface, reliable two-dimensional maps of the distal forelimb representation were obtained with no error introduced by reconstructions from tangential penetrations. Further, highly detailed representations of movement topography were obtained from stimulation at closely spaced penetration sites, enabling strict quantitative comparisons. The large number of penetration sites provided a built-in reliability estimate of local topography.

Second, in a sample of $10 \%$ of the microelectrode penetration sites, a second experimenter independently determined the evoked movement and threshold current. The movement categories defined by the two experimenters rarely differed. Third, in order to isolate variations in motor maps contributed by differences between individual monkeys, we derived detailed motor maps in both hemispheres of each animal in the study. This allowed us to use a three-way ANOVA to assess statistically the relative contributions of individual, side (hemisphere), movement category, and side-by-movement interactions to the total variability in motor maps. Fourth, although it is somewhat difficult to maintain a completely stable anesthetic state using ketamine/acepromazine, we were able to lessen the magnitude of anesthetic peaks and troughs by continuous infusion of a diluted solution of these drugs. ICMS mapping was conducted only during stable periods of anesthesia and was temporarily halted during occasional periods of excessive muscle tone in forelimb muscles, or during occasional periods of deep narcosis marked by movement threshold elevation. Fifth, mapping was conducted in separate, limited sessions in each hemisphere, so that effects of extremely long-term anesthesia were minimized. Sixth, mapping was conducted in each hemisphere in random order. Seventh, we minimized the possibility of trauma to the cortex by using very fine, beveled glass micropipettes as stimulating microelectrodes. Mapping was conducted with the dura 


\section{THUMB EXTENSION}

\section{7 (Left Hemisphere Dominant)}

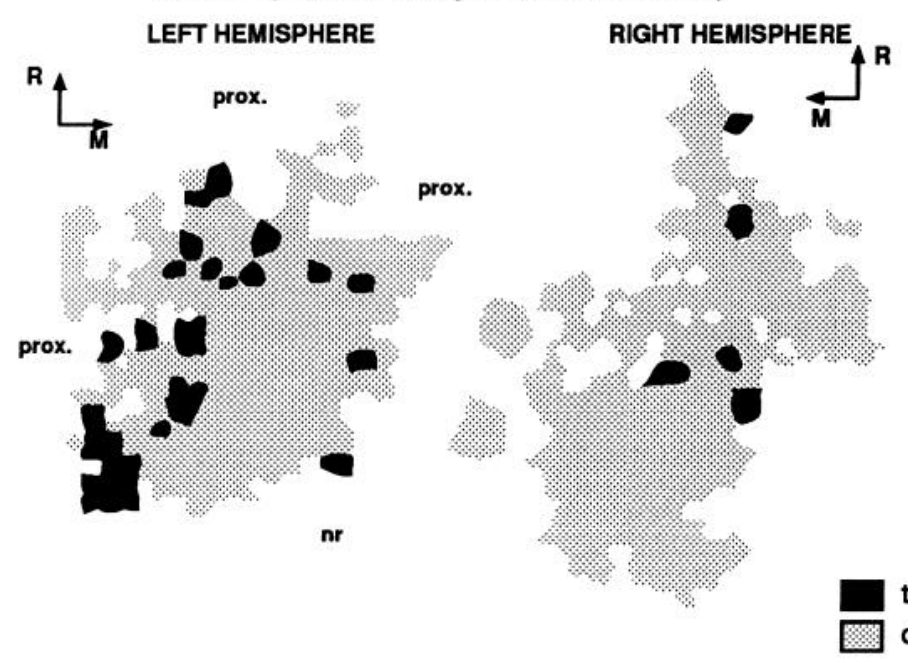

8734 (Right Hemisphere Dominant)

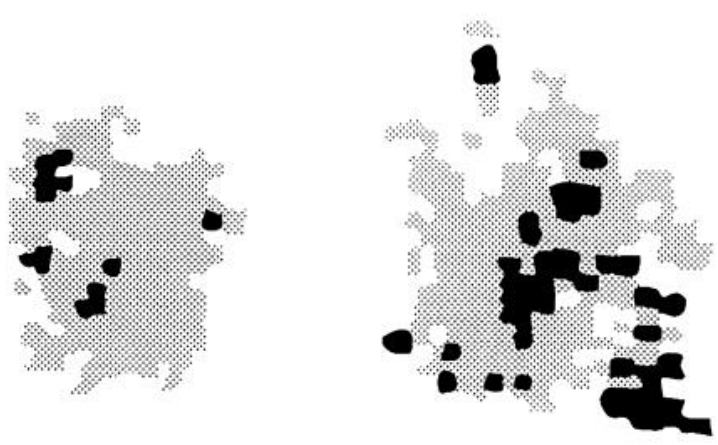

thumb extension

other distal forelimb

\section{9 (Right Hemisphere Dominant)}
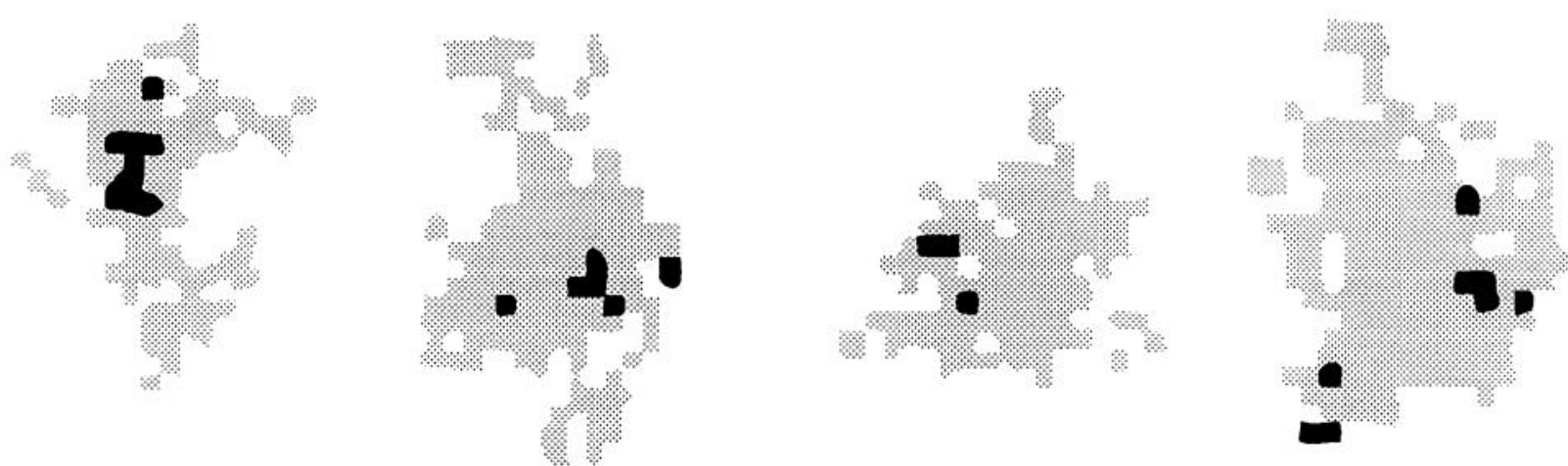

\begin{tabular}{|l|c|c|}
\hline \multicolumn{3}{|c|}{ Thumb extension } \\
\hline & d-nd & $P$ \\
\hline \# regions & 3.833 & 0.036 \\
\hline threshold & 2.592 & 0.012 \\
\hline complexity & 0.897 & 0.028 \\
\hline
\end{tabular}

\section{0 (Right Hemisphere Dominant)}

8911 (Right Hemisphere Dominant)
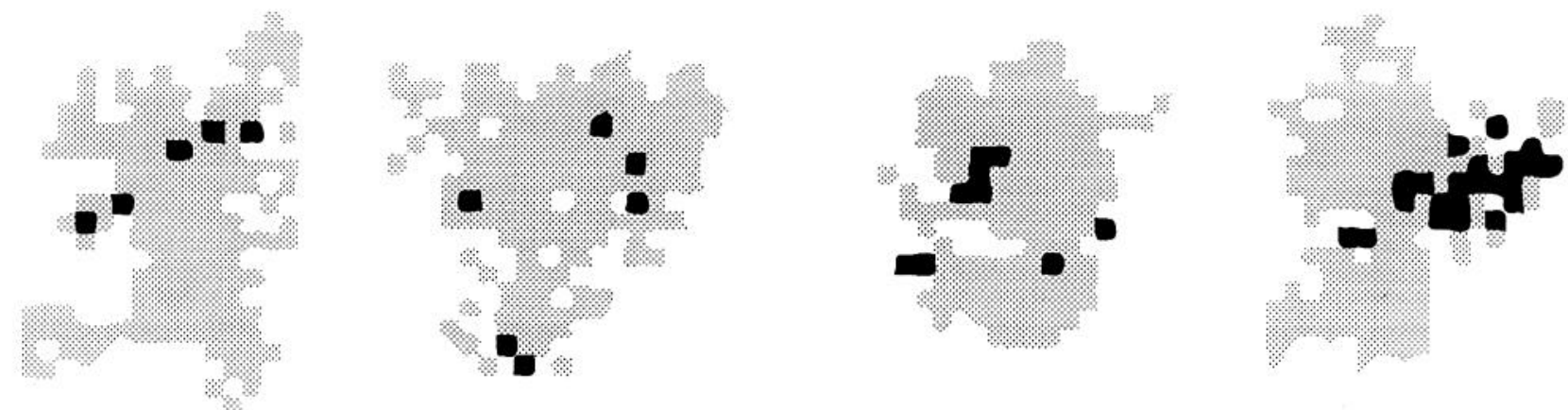

Figure 10. Representation of thumb extension fields in cortical area 4 in left and right hemispheres of each monkey. Thumb extension fields are displayed in black; other distal forelimb fields are displayed in shaded areas. Selected statistical results are shown in inset. 

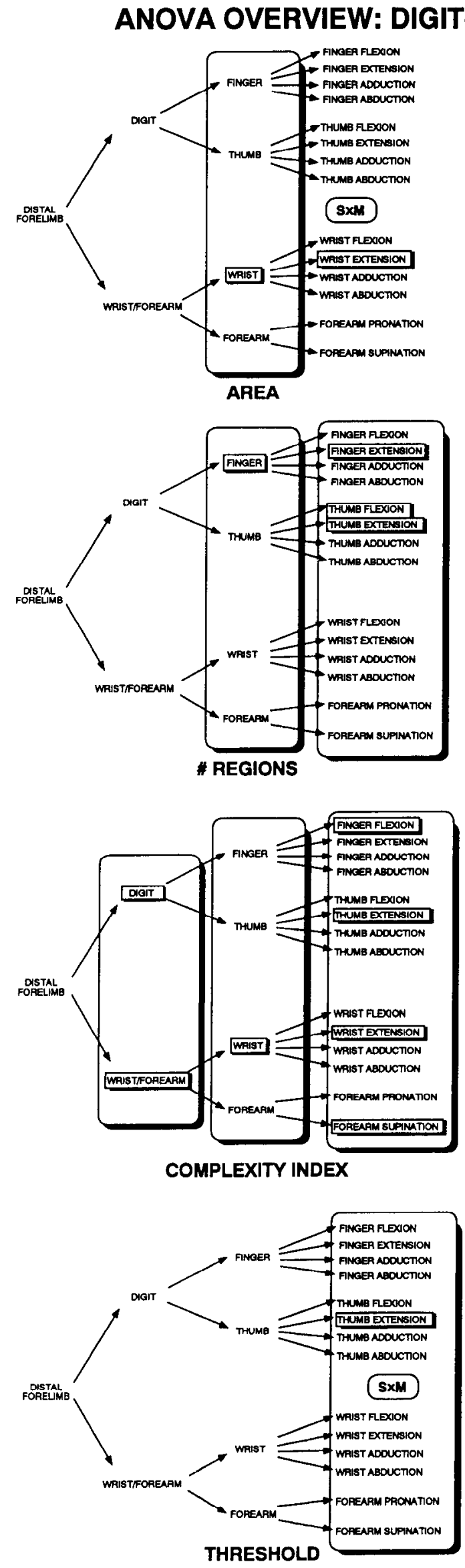
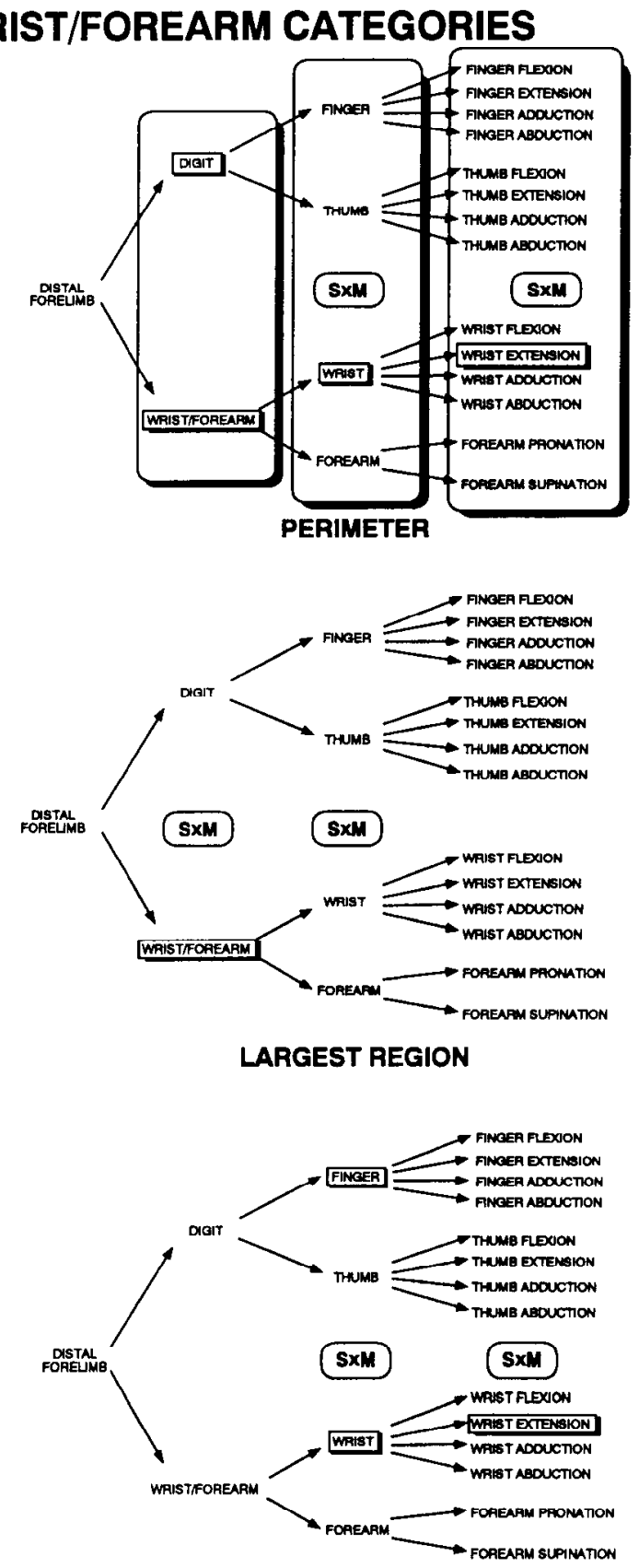

PERCENT TOTAL DISTAL FORELIMB AREA

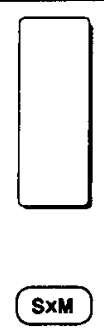

significant main effect of side

significant side $\mathrm{x}$ movement interaction

significant interhemispheric difference using $t$-test 
Table 4. Significant correlations of spatial characteristics with dominance scores

\begin{tabular}{|c|c|c|c|c|c|c|}
\hline \multirow[b]{2}{*}{ Level } & \multicolumn{3}{|l|}{$\underline{\text { Digit-wrist/forearm categories }}$} & \multicolumn{3}{|l|}{ Flexion-extension categories } \\
\hline & Movement & $r$ & $p$ & Movement & $r$ & $p$ \\
\hline \multicolumn{7}{|c|}{ Dominant hemisphere } \\
\hline 1 & Distal forelimb index & 0.895 & 0.016 & Distal forelimb index & 0.895 & 0.016 \\
\hline 2 & None & & & None & & \\
\hline \multirow[t]{6}{*}{3} & \# wrist regions & 0.872 & 0.023 & Digit flexion area & -0.849 & 0.033 \\
\hline & Wrist index & 0.889 & 0.018 & Digit extension \% area & -0.962 & 0.002 \\
\hline & Forearm area & 0.891 & 0.017 & Wrist/forearm flexion area & 0.835 & 0.039 \\
\hline & Forearm perimeter & 0.960 & 0.002 & Wrist/forearm flex. perim. & 0.871 & 0.024 \\
\hline & Forearni index & 0.919 & 0.009 & Wrist/forearm flexion index & 0.821 & 0.045 \\
\hline & Forearm \% total area & 0.819 & 0.046 & & & \\
\hline \multirow[t]{11}{*}{4} & Finger flexion area & -0.952 & 0.003 & Finger flexion area & -0.927 & 0.008 \\
\hline & Finger flexion $\%$ total area & -0.955 & 0.003 & Finger flexion $\%$ total area & -0.949 & 0.004 \\
\hline & \# Finger extension regions & 0.824 & 0.044 & \# Finger flexion regions & 0.912 & 0.011 \\
\hline & \# Finger adduction regions & 0.842 & 0.036 & Wrist flexion index & 0.948 & 0.014 \\
\hline & Finger adduction $\%$ tot. area & 0.829 & 0.041 & \# Wrist extension regions & 0.862 & 0.027 \\
\hline & Wrist adduction index & 0.986 & 0.002 & Forearm flexion area & 0.920 & 0.009 \\
\hline & Forearm supination perim. & 0.866 & 0.026 & Forearm flexion index & 0.902 & 0.014 \\
\hline & Forearm supination index & 0.891 & 0.017 & \# Forearm flexion regions & 0.882 & 0.020 \\
\hline & Forearm pronation area & 0.920 & 0.009 & Forearm extension perim. & 0.866 & 0.026 \\
\hline & Forearm pronation index & 0.907 & 0.012 & Forearm extension index & 0.927 & 0.008 \\
\hline & Forearm pron. \% tot. area & 0.859 & 0.028 & & & \\
\hline \multicolumn{7}{|c|}{ Nondominant hemisphere } \\
\hline 1 & None & & & None & & \\
\hline 2 & Wrist/forearm index & 0.637 & 0.045 & None & & \\
\hline 3 & None & & & None & & \\
\hline 4 & Thumb flexion largest area & 0.851 & 0.032 & \# Wrist/forearm flex. reg. & 0.843 & 0.035 \\
\hline
\end{tabular}

removed, and penetrations specifically avoided the surface vasculature, minimizing local ischemia caused by ruptured or temporarily occluded blood vessels.

Despite efforts to control each of these identifiable factors, some uncontrolled variability probably occurred. At a few sitcs, on a few occasions we observed changes in the response during the determination of the stimulus-evoked movement (Graham Brown and Sherrington, 1912; Nudo et al., 1990). These changes usually occurred at or near representational borders. When a site located well within representational boundaries was stimulated at different times during the same mapping session, the movement evoked at near-threshold current levels rarely varied. Based upon the observation that the variability between hemispheres within individuals was consistently smaller than the variability among individuals, the results suggest that the representational maps obtained in the present study are reliable for quantitative assessment. This result is evident both in the topography of individual movement representations (see Figs. 810) and in the quantitative results using ANOVA. Also, in the course of motor mapping experiments on squirrel monkeys in this and other studies, we have derived detailed maps on two different occasions by stimulation of virtually the same sites in the same hemisphere of the same individuals. While some differences were found in local topography, the general topography as well as several quantitative measurements of spatial characteristics (e.g., total area, percentage of total area occupied by particular movement representations, etc.) were constant (R. J. Nudo and M. M. Merzenich, unpublished observations; also see Craggs and Rushton, 1976). Therefore, for the purposes of the present study, using a statistical approach to describe interhemispheric differences quantitatively, the degree of variability was within an acceptable range.

It is important to note that ICMS-evoked movements may result from both direct excitation of local neurons and polysynaptic activation of more distant neurons. Since thresholds for evoking movements were low (as low as $1 \mu \mathrm{A}$, but more typically 10-15 $\mu \mathrm{A}$ ), the direct spread of current was limited to the immediate vicinity of the stimulating electrode (i.e., a diameter less than the interpenetration distance of $250 \mu \mathrm{m})$. However, more widespread polysynaptic effects cannot be ruled out. It is

\footnotetext{
Figure 11. Statistical summary illustrating interhemispheric differences for digit-wrist/forearm categories. ANOVA was performed for each spatial characteristic, at each hierarchical level, examining main effects of individual, side (hemisphere), and movement, as well as interactions between side and movement. Large boxes encompassing all movements within a given level denote significant main effects of side. For example, area was significantly different between the two hemispheres only at hierarchical level 3 (finger, thumb, wrist, forearm). $S \times M$ denotes a significant interaction effect between side and movement at a given hierarchical level. For example, a significant side-by-movement interaction was found for area at hierarchical level 4. Small boxes surrounding individual movements denote significant interhemispheric differences using paired $t$ tests. For example, $t$ tests demonstrated a significant difference between the two hemispheres in wrist extension area.
} 


\section{ANOVA OVERVIEW: FLEXION-EXTENSION CATEGORIES}

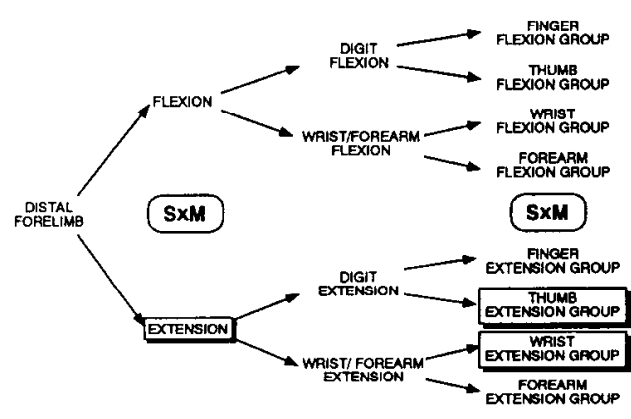

AREA

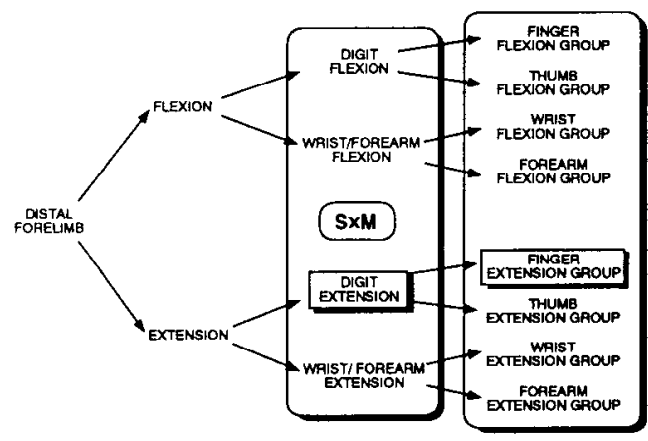

\# REGIONS

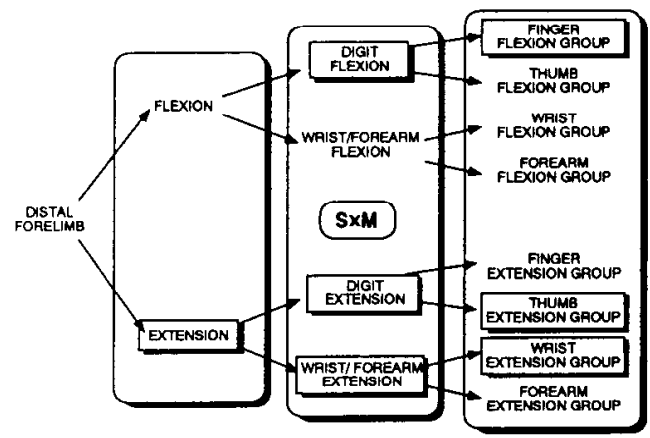

COMPLEXITY INDEX

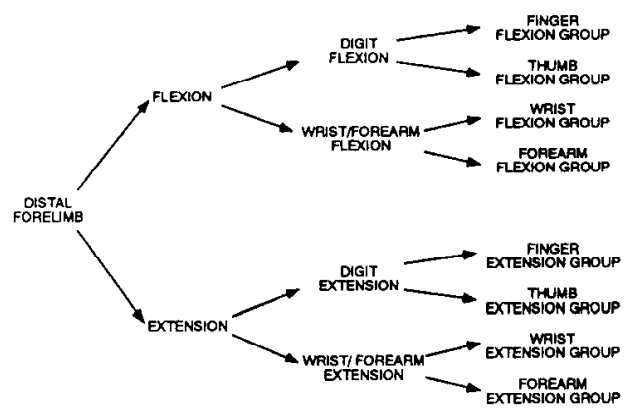

THRESHOLD

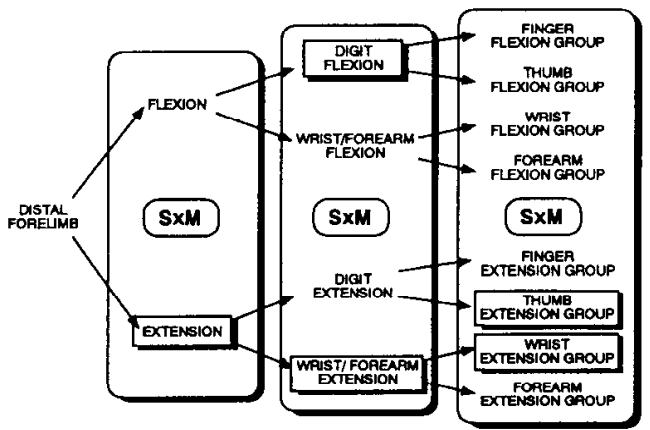

PERIMETER

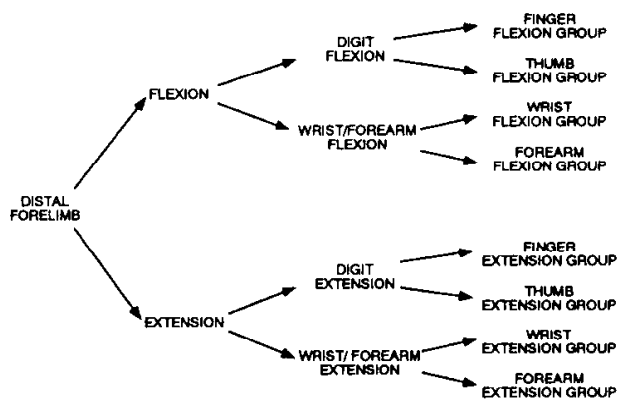

LARGEST REGION

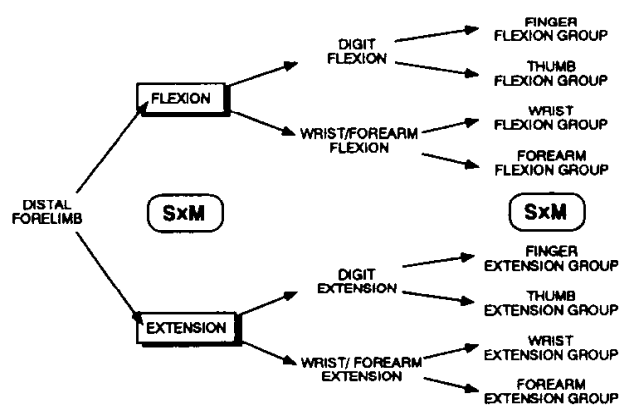

PERCENT TOTAL DISTAL FORELIMB HAND AREA

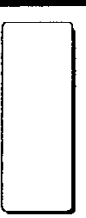

significant main effect of side

SxM

significant side $\mathrm{x}$ movement interaction

significant interhemispheric difference using $\mathrm{t}$-test

Figure 12. Statistical summary illustrating interhemispheric differences for flexion-extension categories. See Figure 11 for explanation. 
possible that the mosaic representations of movement as defined by the ICMS technique are at least partially a result of complex excitatory and inhibitory effects on spinal motoneurons arising from a relatively wide area of cortex. Nevertheless, the relative stability of the response at a given site, the striking differences in response between adjacent sites, and the correlation of ICMSdefined boundaries with cytoarchitectonic boundaries suggest that ICMS is a reliable technique for defining functional boundaries in motor cortex (see review by Huang et al., 1988; Nudo et al., 1990).

\section{Comparison of present results to previous investigations of primary motor cortex}

The location of the primary motor distal forelimb representation a few millimeters rostral to the lateral edge of the central sulcus in the squirrel monkey confirms the findings of Strick and Preston (1982a) using similar techniques. In addition, the total area occupied by distal forelimb movements is similar $\left(5.5-9 \mathrm{~mm}^{2}\right.$, Strick and Preston, 1982a; 5.86-14.26 $\mathrm{mm}^{2}$, present results). However, details of the representation of distal forelimb movements presented here differ substantially from previously published motor maps in squirrel monkey with respect to the total number of discrete digit and wrist/forearm regions. In an earlier study by Welker et al. (1957) using surface stimulation techniques, a single, continuous forelimb area was described in primary motor cortex. Later, using ICMS mapping techniques, Strick and Preston (1982a) described two spatially segregated representations of digit and wrist. In the present study, using unambiguous criteria to define boundaries between spatially segregated movement representations, we found an average of approximately $10 \mathrm{digit}$ and $10 \mathrm{wrist} /$ forearm representations. The principal reason for this discrepancy is likely due to substantial differences in the spatial resolution of the maps. The average number of sites explored with electrical stimulation in the distal forelimb area in the present study was at least 3.5 times that of previous investigations (Welker et al., 1957; Strick and Preston, 1982a). Even if locally segregated representations in the present study are grouped into larger clusters, the total number of digit or wrist/forearm clusters in an individual map is typically greater than two (Fig. 7). When individual movements arc examined, occasionally two clusters, onc located in the rostral portion of the distal forelimb representation, and one located in the caudal portion can be roughly delineated (e.g., finger flexion in monkey 8911 in Fig. 8), but this distinction was the exception rather than the rule. Even in these individuals, digit and wrist/forearm representations were interdigitated in complex ways.

The complex interdigitation of movement representations in primary motor cortex found in the present study is more similar to the results obtained by Gould et al. (1986) in owl monkeys using comparable techniques with a comparable density of electrode penetrations. Taken together with the present results, these studies suggest that when examined in detail, the two-dimensional topography of distal forelimb representations in primary motor cortex is organized into spatially complex, fractionated mosaical patterns containing multiple digit and wrist/forearm regions. Further, these fractionated mosaical patterns are highly variable in local topography among individuals and between the hemispheres of the same individual. The complex overlapping representations of movements (and presumably, muscles) underlying evoked-movement maps have been appreciated by each successive generation of motor cortex physiologists (e.g.,
Leyton and Sherrington, 1917; Murphy and Gellhorn, 1945; Penfield and Rasmussen, 1950; Woolsey, 1952; Welker et al., 1957; Hern et al., 1962; Asanuma and Rosén, 1972; Andersen et al., 1975; Jankowska et al., 1975; Phillips and Porter, 1977; Kwan et al., 1978; Fetz and Cheney, 1980; McGuinness et al., 1980; Tanji and Wise, 1981; Strick and Preston, 1982a; Gould et al., 1986; Humphrey, 1986; Lemon et al., 1987; Donoghue and Sanes, 1988; Huang et al., 1988; Rapisarda et al., 1990; Schmidt and McIntosh, 1990; Waters et al., 1990; Huntley and Jones, 1991). The present study extends these earlier findings by allowing a quantitative assessment of the degree of spatial complexity in motor maps.

It should be noted that in the present study, only area 4 motor outputs were examined. Primary motor cortex of both macaque monkey and squirrel monkey has also been divided into two zones, one caudal and one rostral, based on the distribution of cutaneous versus deep inputs (Tanji and Wise, 1981; Strick and Preston, 1982b). It is unclear how the multiple mosaical output representations of area 4 observed in the present study coincide with the cutaneous versus deep gradient described for inputs to area 4 (see also Asanuma et al., 1968; Doetsch and Gardner, 1972; Rosén and Asanuma, 1972; Lemon and Porter, 1976; Murphy et al., 1978; Armstrong and Drew, 1984; Wiesendanger et al., 1985; Huang et al., 1988, 1989).

In addition, the present data are based entirely upon evoked movements in area 4. EMG data were not obtained. Examination of EMG data at each site would add significant power to the results, by further elucidating differences in the overlap of individual muscle representations, and the total numbers of their separated representations. Future investigations should address this issue in more detail.

\section{Individual variability in motor maps}

The present results demonstrate statistically significant variation in motor topography across individuals. Only a few basic map features were relatively constant across animals. First, the distal forelimb representation was relatively discrete, forming a well-circumscribed zone a few millimeters rostral to the lateral edge of the central sulcus. Second, the distal forelimb representation was bounded rostrally, medially, and laterally by representations of more proximal body parts, typically elbow and shoulder. Third, the distal forelimb representation was bounded caudally by a nonresponsive zone, in which stimulation failed to evoke observable movements at the highest current levels used $(30 \mu \mathrm{A})$. Fourth, suprathreshold stimulation of low-threshold sites often evoked other movements. Beyond these broad generalizations, the local mosaic-like topography of individual distal forelimb representations was highly idiosyncratic. In terms of the location of individual movement representations within the distal forelimb zone, no two maps were similar between individuals.

These qualitative differences among individuals were confirmed and elaborated when each spatial parameter of distal forelimb movement maps was examined quantitatively. Using statistical procedures to determine the independent contributions of individual, side, and movement category to the total variation in motor maps, it was found that maps differed significantly across individuals along several spatial dimensions, such as areal extent, perimeter, number of discrete regions, size of the largest region, complexity index, and threshold. Only the percentage of the total distal forelimb area failed to display 
AREA

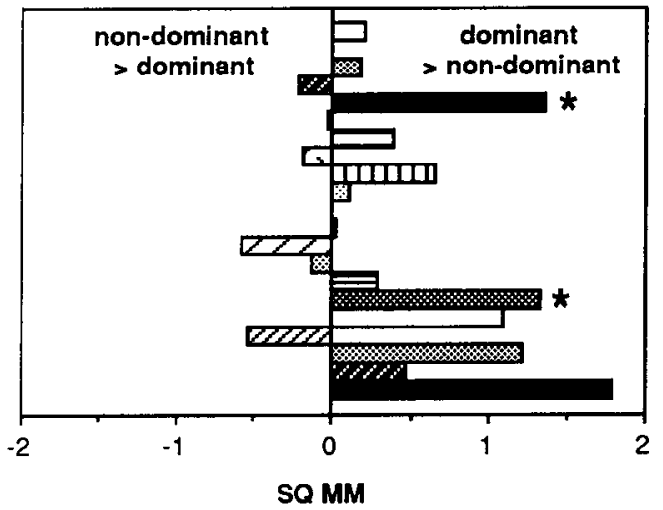

\section{LARGEST REGION}

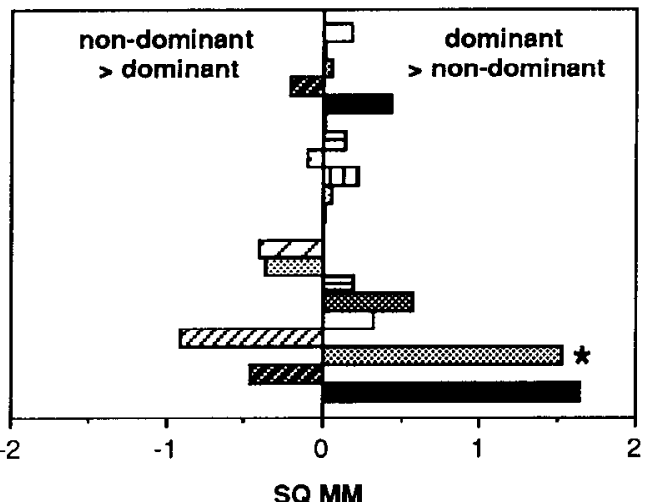

\section{COMPLEXITY INDEX}

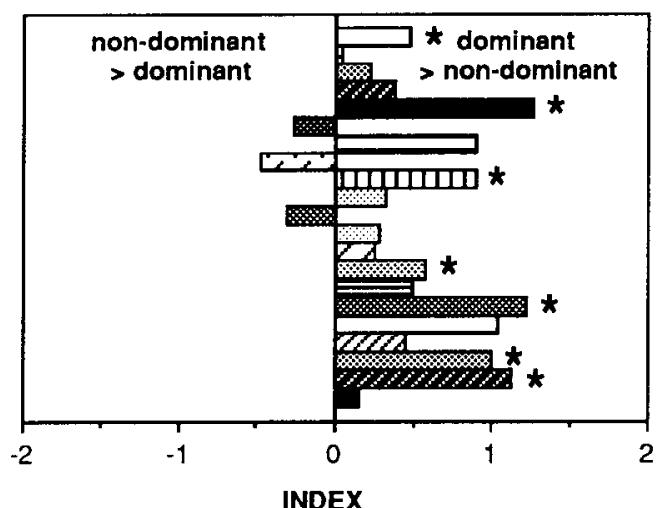

fa sup

fa pron

wrist abd

wrist add

wrist ext

wrist fl

thumb abd

thumb add

II thumb ext

thumb flex

finger abd

finger add

finger ext

finger fl

forearm

wrist

thumb

finger

$w / f a$

digit

distal fl
PERIMETER

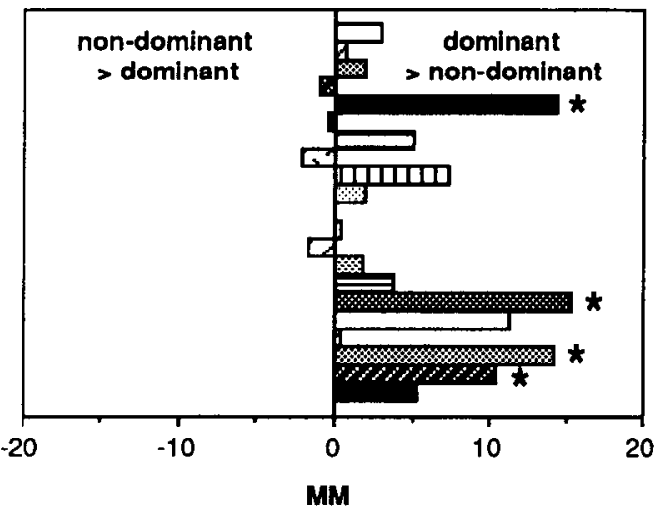

TOTAL NO. OF REGIONS

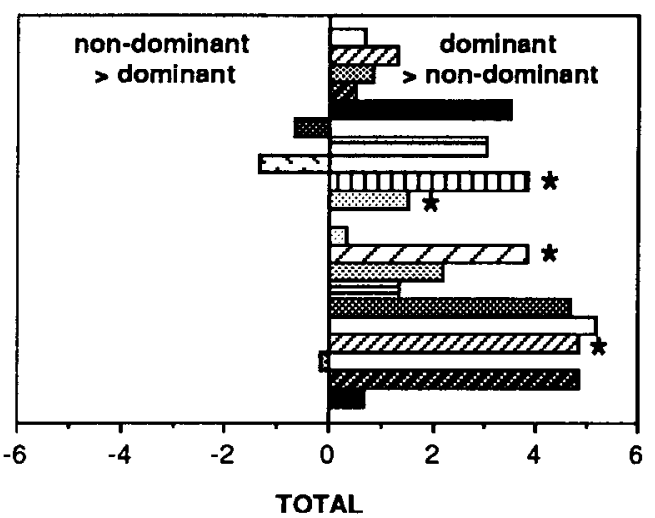

\% TOTAL DISTAL FORELIMB AREA

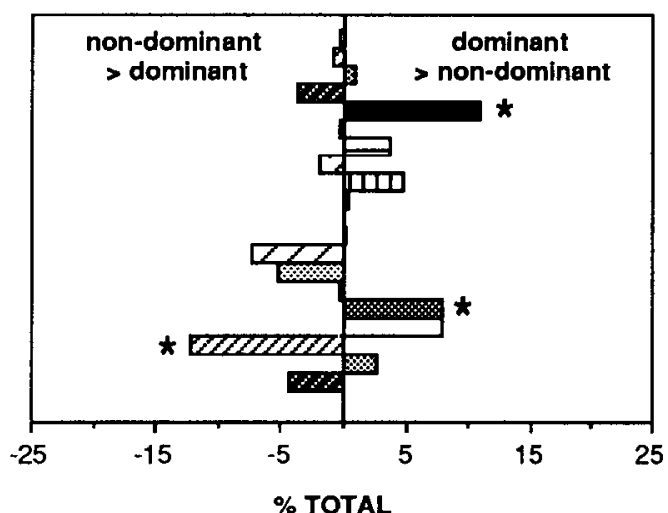

THRESHOLD

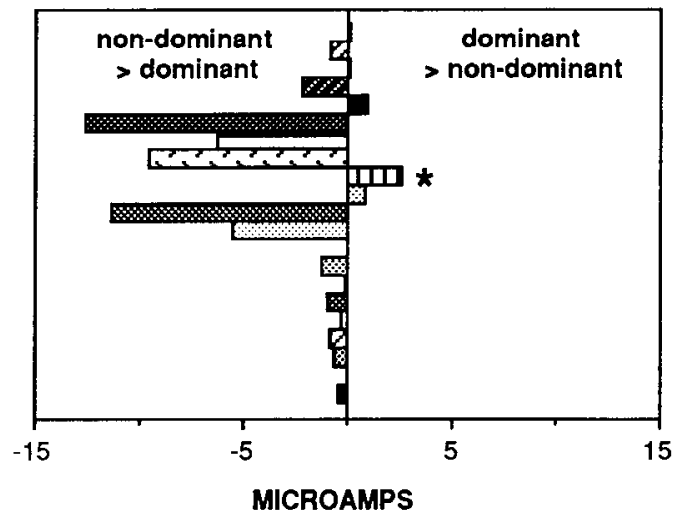


significant differences among individuals. The implications of individual variation in motor maps are discussed below.

\section{Hand preferences in nonhuman primates}

While asymmetries in hand preference are evident in humans, evidence for comparable population level asymmetries in nonhuman primates is mixed and conclusions are controversial (e.g., see Warren, 1977; MacNeilage et al., 1987; Lehman, 1989). MacNeilage has suggested that cerebral dominance for hand preference in nonhuman primates exists, but is task specific (MacNeilage et al., 1987). They have proposed that nonhuman primates might possess specialization for visually guided reaching in one hand, and a specialization for manipulative tasks in the other. In fact, some evidence for task-specific lateralization of manual function has been found. King has reported that squirrel monkeys display a strict left-hand preference when reaching for moving targets, but a strict right-hand preference when reaching for a food reward while clinging to their cage bars (King et al., 1987; J. E. King, personal communication). A left-hand preference for reaching for food has also been demonstrated in lemurs and in bushbaby (Forsythe and Ward, 1988; Forsythe et al., 1988; Larson et al., 1989; Milliken et al., 1989; Ward et al., 1990). Capuchins picking up food show right-hand preferences (Masataka, 1990), and most (66\%) are right-handed for acts of prehensive grip (Costello and Fragaszy, 1988). The relevant tasks underlying this dichotomy are not yet clear, but these recent studies suggest that hand preferences in nonhuman primates may have been dismissed in the past because investigators expected or required uniform hand preferences across all manual tasks (MacNeilage et al., 1987).

The use of a single task to assess hand preference in the present study was a compromise between two conflicting goals. On the one hand, we wanted to provide a reliable estimate of hand preference on a task requiring skilled use of digits (see below). On the other hand, we wanted to avoid possible effects of training on electrophysiologically defined maps. Ideally, estimates of hand preference should be conducted using a battery of motor tasks, requiring various degrees of axial and distal muscle control, eye-hand coordination, and bimanual coordination. However, because of the possibility that motor experience may affect both the anatomical and physiological organization of cerebral cortex, including motor cortex (e.g., Diamond et al., 1972, 1985; Woody and Engel, 1972; Greenough et al., 1973, 1985; Stamm et al., 1975; G. W. Milliken, R. J. Nudo, R. Grenda, W. M. Jenkins, and $M$. M. Merzenich, unpublished observations), we chose to limit our assessment to a single task that was readily executed without extensive training. In any event, the fact that more elaborate or complex representations were found for the preferred hand for retrieving food pellets in this experimental series should be interpreted with the provision that the definition of "hand preference" in individuals may be task specific (e.g., see MacNeilage et al., 1987).

We chose for our assessment of hand preference a task using a modified form of a device commonly known as a Klüver board (Glees, 1961; Lawrence and Kuypers, 1968). Since we were interested in interhemispheric comparisons of distal forclimb

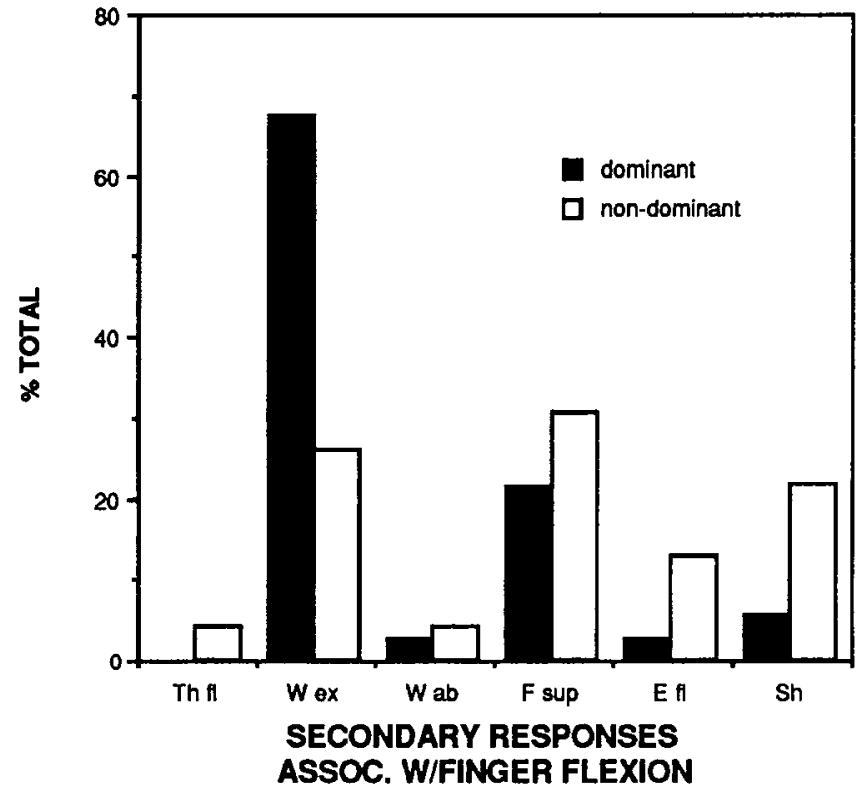

Figure 14. Distribution of secondary (higher-threshold) responses associated with primary (near-threshold) finger flexion responses in the left and right hemispheres of four squirrel monkeys. Th, thumb; $S h$, shoulder. Other abbreviations as in Figure 4.

representations, this device possessed two specific advantages. (1) Bilateral asymmetries in motor abilities of primates are demonstrated quickly, with minimal training. (2) Using a similar device, it has been argued that primates suffer a permanent loss of independent digit control following pyramidal tract section (Lawrence and Kuypers, 1968). Such a lesion approximates isolated destruction of the corticospinal tract, the most direct pathway from cerebral cortex to spinal cord motoneurons. While we cannot assume that results from this single task generalize to other tasks, it seemed a reasonable compromise for achieving the goal of comparing behavioral asymmetries without introducing significant training effects.

In our design, we first assessed hand preference using the Klüver board, and then several days later derived representational maps of the distal forelimb. It is entirely possible that the behavioral testing procedure, while brief, directly caused changes in the organization of motor maps. However, these effects were probably minimal due to the brief exposure to the task and the relatively long interval between behavioral testing and physiological mapping. An alternative approach would be to derive electrophysiological maps first, and then test animals on a battery of motor tasks. While results from four animals who were tested on the Klüver board both before and well after the mapping procedure suggest that hand preference were not significantly affected by intracortical microstimulation mapping techniques and associated surgical intervention, we cannot rule out possible traumatic effects of the ICMS mapping procedure on both physiological and behavioral measures. Therefore, the procedure adopted for this study seemed a reasonable compromisc. 
Hand preferences, as defined here, appear to be remarkably stable. Though not reported here in detail, results from the present study as well as results from over 20 other squirrel monkeys tested in our laboratory (R. J. Nudo, W. M. Jenkins, M. M. Merzenich, T. Prejean, and R. Grenda, unpublished observations) suggest that hand preference on the Klüver board is stable throughout at least much of an individual's adult life. We have tracked hand preference in individual monkeys for up to 2 years and found little if any variability in the hand used for initial reach or for retrieval of pellets from the Klüver board. In addition hand preference was unaffected by changing the position of the Klüver board on the animal's cage, such as reversing the board, so that the smallest well was on the animal's left instead of the right, or shifting the vertical or horizontal position of the board relative to the cage bars.

It should be noted that five of the six squirrel monkeys in this study were predominantly left-handed on the Klüver board task. Only one was predominantly right-handed. Still, generalizations of handedness to squirrel monkey populations at large should be made with great caution for several reasons. First, assessment of handedness using tasks requiring skilled digit use should be performed on much larger sample sizes before broader generalizations can safely be made. Second, all monkeys in this study were caught wild, and information about their relatedness and rearing conditions is unavailable. Third, it is not yet clear how other studies of hand preference in squirrel monkey, using tasks possibly requiring different sets of motor skills, can be integrated with the present results (King et al., 1987; Costello and Fragaszy, 1988). Therefore, at this point the present results are useful for describing relationships between interhemispheric differences and hand preference on a single task requiring skilled digit use. Implications for hand preference and cerebral dominance in the population at large are left for future studies.

\section{Interhemispheric differences in motor cortex}

Comparable electrophysiological studies of neurophysiological correlates of handedness have not been previously reported. Most human studies of cerebral asymmetry have been concerned with lateralization of language and are beyond the scope of the present discussion (e.g., see review by Geschwind and Galaburda, 1985). However, cortical asymmetry in forelimb motor cortex has been inferred indirectly from several lines of evidence. In 1915, Shepherd Ivory Franz, using surface stimulation techniques, found interhemispheric variability in the size of the hand representation in macaque motor cortex (Franz, 1915). Considering the techniques available at the time, the results and conclusions are remarkably similar to those found here. However, interpretation of Franz's early work is complicated (1) because of the use of surface stimulation techniques requiring high current levels for evoking movement; (2) by the difficulty in reconstructing accurate detailed maps of distal forelimb topography in the macaque, whose primary motor cortex is largely buried in the central sulcus; and (3) because hand preferences of the individual animals were not reported.

Electrophysiological demonstrations of hemispheric asymmetries in somatic sensorimotor cortex have been few and somewhat indirect. For example, differential training of the two forelimbs in monkeys results in differential changes in evoked potential activity in the prefrontal and precentral cortex (Stamm et al., 1975). Other studies employing evoked-potential techniques have reported hemispheric asymmetries in human so- matosensory cortex in either normal or brain-damaged subjects (e.g., Goff et al., 1962; Semmes, 1968). Physiological asymmetries related to hand preference have also been demonstrated in subcortical motor structures. For example, Caliskan and Tan (1990) have reported that the excitability of motoneurons innervating foreleg flexors in cat is related to paw preference (see also Tan, 1984, 1985).

Measurements of cerebral blood flow in humans also suggest functional interhemispheric asymmetry in primary motor cortex. These studies reveal in right-handed subjects a greater blood flow increase in the right hemisphere during left-hand use than in the left hemisphere during right-hand use (Halsey et al., 1979). Along these same lines, magnetic resonance imaging studies in humans have demonstrated a larger left frontal lobe in lefthanders, and a larger right frontal lobe in right-handers (Kertesz et al., 1990). In the present studies, movements of the dominant hand are consistently represented in more separated islands in a relatively diffused, complex pattern. Perhaps that explains the paradoxical findings of apparently greater cerebral blood flow with hand use in the nondominant hemisphere.

Indirect evidence for neurophysiological differences between the two hemispheres in sensorimotor cortex can also be gleaned from ablation-behavior studies. While it is clear that unilateral ablation of motor cortex induces preferential use of the limb ipsilateral to the lesion (e.g., Passingham et al., 1983, in macaque monkey; Burgess and Villablanca, 1986, in cat; Castro, 1977, and Whishaw and Kolb, 1988, in rat), few studies have examined differential effects of lesions in the two hemispheres. However, unilateral removal of SII contralateral to a monkey's preferred hand resulted in bilateral deficits on a tactile discrimination task, while removal of SII ipsilateral to the preferred hand resulted in little or no impairment (Garcha et al., 1982; Hörster and Ettlinger, 1985).

Anatomical asymmetries related to hand dominance have also been reported in nonhuman mammals. For example, in the rat, the sensorimotor cortex may be larger in the right hemisphere, especially in males (Diamond et al., 1981; Sherman and Galaburda, 1984). In addition, it has been demonstrated that after differential experience of the two forelimbs in rat, anatomical differences (larger dendritic fields) are evident in motor cortex opposite the highly trained limb (Greenough et al., 1985).

In summary, the present results provide evidence for neurophysiological correlates of hand preference in motor cortex of squirrel monkey. We found significant quantitative differences in the detailed spatial topography of distal forelimb representations, and these quantitative differences were related to the hand preferred by the animal on a task requiring skilled use of the digits. In the dominant hemisphere, that is, the hemisphere contralateral to the preferred hand, digit and wrist representations were generally greater in number and larger in total area and displayed a longer total boundary length and a greater index of spatial complexity. These quantitative differences between the dominant and nondominant hemisphere were statistically reliable, and were obtained using different classification schemes for dividing the distal forelimb map into movement categories. It is interesting that many of the largest and most consistent quantitative differences were found for the most predominant movements used in the task, that is, digit flexion, wrist extension, and forearm supination.

Also, differences were found in the movement categories of "secondary," higher-threshold movements evoked in the two hemispheres. While this analysis was performed in only four of 
the six animals and statistical significance was not achicved, differences were found in the specific secondary responses associated with a given primary movement. For example, in the dominant hemisphere, sites that displayed finger flexion at threshold usually displayed wrist extension at suprathreshold current levels. By contrast, in the nondominant hemisphere, sites that displayed finger flexion at threshold usually displayed elbow or shoulder movements at suprathreshold current levels.

\section{Implications for the organization of motor cortex}

These results extend other recent studies of motor cortex topography revealing that primary motor cortex of primates is composed of multiple representations of distal forelimb movements (Kwan et al., 1978; Murphy et al., 1978; Strick and Preston, 1978, 1982a; Gould et al., 1986; Humphrey, 1986). It suggests that at least in terms of output representations, it is difficult to describe the organization of digit and wrist representations as arranged in a single or a double representation. Instead, a variable number of discrete representations of any given movement class can be delineated in a spatially complex, fractionated mosaical pattern. It should be pointed out that multiple sites that evoke the same movement do not necessarily imply that the same muscles are represented at these sites; the same movement may sometimes be accomplished using different muscle combinations. However, in several other investigations in which EMG recordings were obtained during ICMS in motor cortex, it has been demonstrated that there are multiple, discrete representations of individual muscles as well as movements (e.g., Kwan et al., 1978; Strick and Preston, 1982a; Humphrey, 1986)

Furthermore, it is now clear that multiple muscles may be represented at a single site in the primary motor distal forelimb representation. Using spike-triggered averaging tcchniqucs in macaque monkeys, Fetz and Cheney (1980) have demonstrated that the output of a single cortical neuron typically facilitates multiple muscles. Using anatomical techniques in cats, Shinoda et al. (1981) have identified individual corticospinal neurons that project to multiple spinal cord segments, suggesting that some corticospinal neurons may project to multiple motoneuron pools.

Taken together with the present results, these studies suggest that multiple representations of distal forelimb movements overlap in spatially complex ways. The number of re-representations as well as the types of movements that overlap are highly variable, both between individuals and between hemispheres of the same individuals. Because of the relationship between interhemispheric asymmetry and behavioral asymmetry, we hypothesize that a large source of variability found in the topography of motor maps in this and other studies derives from differences in the way the use of particular muscles and/or muscle combinations develop ontogenetically in each animal. That suggestion follows the lead of Karl Lashley, who invoked the concepts of cortical "equipotentiality" and experience-induced representational changes to explain the individual variability of movement maps recorded in the studies of Franz (Lashley, 1923; see also Stout, 1917).

The apparent differences between the dominant and nondominant hemispheres in the complexity of interwoven movements and in the types of movements or muscles that overlap in these representations in motor cortex are consistent with the reasonable conclusion that muscles or movements used in combination or in close temporal contiguity are spatially represented together, cither in adjacent cortical tissue and/or overlapping in the same cortical territory. Muscles that are used in close temporal contiguity (e.g., muscles that are coactivated or are used in sequence) may require a high level of intracortical interaction. Greater interaction would most likely be achieved with overlapping or adjacent representations of those muscles. A similar mechanism has been proposed by Semmes (1968) to explain hemispheric specialization in humans. By that interpretation, the greater complexities of movement representations in the dominant hemispheres would manifest a greater repertoire of more refined movement combinations.

\section{References}

Andersen P, Hagan P, Phillips C, Powell T (1975) Mapping by microstimulation of overlapping projections from area 4 to motor units of the baboon's hand. Proc R Soc Lond [Biol] 188:31-60.

Armstrong DM, Drcw T (1984) Topographic localization in the motor cortex of the cat for somatic afferent responses and evoked movements. J Physiol (Lond) 350:33-54.

Asanuma H, Rosén I (1972) Topographical organization of cortical efferent zones projecting to distal forelimb muscles in the monkey. Exp Brain Res 14:243-256.

Asanuma H, Stoney SD Jr, Abzug C (1968) Relationship between afferent input and motor outflow in cat motorsensory cortex. J Neurophysiol 31:670-681.

Beck CH, Barton RL (1972) Deviation and laterality of hand preference in monkeys. Cortex 8:339-363.

Broca $P$ (1865) Sur le siège de la faculté du langage articulé. Bull Soc Anthropol 6:377-393.

Burgess JW, Villablanca JR (1986) Recovery of function after neonatal or adult hemispherectomy in cats. II. Limb bias and development, paw usage, locomotion and rehabilitative effects of exercise. Behav Brain Res 20:1-18.

Caliskan S, Tan U (1990) The relationship between the degree of paw preference and excitability of motor neurons innervating foreleg flexors in right- and left-preferent cats. Int $\mathbf{J}$ Neurosci 53:173-178.

Castro AJ (1977) Limb preference after lesions of the cerebral hemisphere in adult and neonatal rats. Physiol Behav 18:605-608.

Corballis MC (1989) Laterality and human evolution. Psychol Rev 96:492-505.

Costello MB, Fragaszy DM (1988) Prehension in Cebus and Saimiri I. Grip type and hand preference. Am J Primatol 15:235-245.

Craggs MD, Rushton DN (1976) The stability of the electrical stimulation map of the motor cortex of the anaesthetized baboon. Brain 99:575-600.

Denenberg VH, Yutzey DA (1985) Hemispheric laterality, behavioral asymmetry, and the effects of early experience in rats. In: Cerebral lateralization in nonhuman species (Glick SD, ed), pp 109-133. New York: Academic.

Diamond MC, Rosenzweig MR, Bennett EL, Lindner B, Lyon L (1972) Effects of environmental enrichment and impoverishment on rat cerebral cortex. J Neurobiol 3:47-64.

Diamond MC, Dowling GA, Johnson RE (1981) Morphological cerebral cortical asymmetry in male and female rats. Exp Neurol 71: 261-268.

Diamond MC, Johnson RE, Protti AM, Ott C, Kajisa L (1985) Plasticity in the 904-day-old male rat cerebral cortex. Exp Neurol 87: 309-317.

Doetsch GS, Gardner EB (1972) Relationship between afferent input and motor output in sensorimotor cortex of the monkey. Exp Neurol 35:78-97.

Donoghue JP, Sanes JN (1988) Organization of adult motor cortex representation patterns following neonatal forelimb nerve injury in rats. J Neurosci 8:3221-3232.

Fagot J, Vauclair J (1991) Manual laterality in nonhuman primates: a distinction between handedness and manual specialization. Psychol Bull 109:76-89.

Fetz EE, Cheney PD (1980) Postspike facilitation of forelimb muscle activity by primate corticomotoneuronal cells. J Neurophysiol 44: $751-772$.

Forsythe C, Ward JP (1988) Black lemur (Lemur macaco) hand preference in food reaching. Primates 29:369-374. 
Forsythe C, Milliken GW, Stafford DK, Ward JP (1988) Posturally related variations in the hand preferences of the ruffed lemur (Varecia variegata variegata). J Comp Psychol 102:248-250.

Franz SI (1915) Variations in distribution of the motor centers. Psychol Monogr 19:80-162.

Galaburda AM, Aboitiz F, Rosen GD, Sherman GF (1986) Histological asymmetry in the primary visual cortex of the rat: implications for mechanisms of cerebral asymmetry. Cortex 22:151-160.

Garcha HS, Ettlinger G, MacCabe JJ (1982) Unilateral removal of the second somatosensory projection cortex in the monkey: evidence for cerebral predominance? Brain 105:787-810.

Geschwind N, Galaburda AM (1985) Cerebral lateralization. Biological mechanisms, associations, and pathology. I. A hypothesis and a program for research. Arch Neurol 42:428-459.

Geschwind N, Galaburda AM (1987) Cerebral lateralization. Cambridge, MA: MIT Press

Glees P (1961) Experimental neurology. Oxford: Clarendon.

Goff WR, Rosner BS, Allison T (1962) Distribution of cerebral somatosensory evoked responses in normal man. Electroencephalogr Clin Neurophysiol 14:697-713.

Gould HJI, Cusick CG, Pons TP, Kaas JH (1986) The relationship of corpus callosum connections to electrical stimulation maps of motor, supplementary motor, and the frontal eye fields in owl monkeys. J Comp Neurol 247:297-325.

Graham Brown T, Sherrington CS (1912) On the instability of a cortical point. Proc R Soc Lond [Biol] 85:250-277.

Greenough WT, Volkmar FR, Juraska JM (1973) Effects of rearing complexity on dendritic branching in frontolateral and temporal cortex of the rat. Exp Neurol 41:371-378.

Greenough WT, Larson JR, Withers GS (1985) Effects of unilateral and bilateral training in a reaching task on dendritic branching of neurons in the rat motor-sensory forelimb cortex. Behav Neurol Biol 44:301-314

Hall RD, Lindholm EP (1974) Organization of motor and somatosensory neocortex in the albino rat. Brain Res 66:23-38.

Halsey JH Jr, Blauenstein UW, Wilson EM, Wills EH (1979) Regional cerebral blood flow comparison of right and left hand movement. Neurology 29:21-28.

Hern J, Landgren S, Phillips C, Porter R (1962) Selective excitation of corticofugal neurones by surface-anodal stimulation of the baboon's motor cortex. J Physiol (Lond) 161:73-90.

Hörster W, Ettlinger G (1985) An association between hand preference and tactile discrimination performance in the rhesus monkey. Neuropsychologia 23:411-413.

Huang C, Sirisko M, Hiraba H, Murray G, Sessle B (1988) Organization of the primate face motor cortex as revealed by intracortical microstimulation and electrophysiological identification of afferent inputs and corticobulbar projections. J Neurophysiol 59:796-818.

Huang C-S, Hiraba H, Sessle BJ (1989) Input-output relationships of the primary face motor cortex in the monkey (Macaca fascicularis). J Neurophysiol 61:350-362.

Humphrey DR (1986) Representation of movements and muscles within the primate precentral motor cortex: historical and current perspectives. Fed Proc 45:2687-2699

Huntley GW, Jones EG (1991) Relationship of intrinsic connections to forelimb movement representations in monkey motor cortex: a correlative anatomic and physiological study. J Neurophysiol 66:390413.

Jankowska E, Padel Y, Tanaka R (1975) The mode of activation of pyramidal tract cells by intracortical stimuli. J Physiol (Lond) 249: $617-636$

Jones EG (1975) Lamination and differential distribution of thalamic afferents within the sensory-motor cortex of the squirrel monkey. J Comp Neurol 160:167-204.

Jones EG, Porter R (1980) What is area 3a? Brain Res Rev 2:1-43.

Kertesz A, Polk M, Black SE, Howell J (1990) Sex, handedness, and the morphometry of cerebral asymmetries on magnetic resonance imaging. Brain Res 530:40-48.

Kimura D (1977) Acquisition of a motor skill after left hemisphere damage. Brain 100:527-542.

King JE, Landau VI, Scott A (1987) Hand preference during capture of live fish by squirrel monkeys. Int J Primatol 8:540.

Kolb B, Sutherland RJ, Nonneman AJ, Whishaw IQ (1982) Asymmetry in the cerebral hemispheres of the rat, mouse, rabbit and cat: the right hemisphere is larger. Exp Neurol 78:348-359.
Kwan HC, MacKay WA, Murphy JT, Wong YC. (1978) Spatial organization of precentral cortex in awake primates. II. Motor outputs J Neurophysiol 41:1120-1131.

Larson CF, Dodson DL, Ward JP (1989) Hand preferences and wholebody turning biases of lesser bushbabies (Galago senegalensis). Brain Behav Evol 33:261-267.

Lashley KS (1923) Temporal variation in the function of the gyrus precentralis in primates. Am J Physiol 65:585-602.

Lawrence DG, Kuypers HGJM (1968) The functional organization of the motor system in the monkey. I. The effects of bilateral pyramidal lesions. Brain 91:1-33.

Lehman RA (1989) Hand preferences of rhesus monkeys on differing tasks. Neuropsychologia 27:1193-1196.

Lemon R, Muir R, Mantel G (1987) The effects upon the activity of hand and forearm muscles of intracortical stimulation in the vicinity of corticomotor neurones in the conscious monkey. Exp Brain Res 66:621-637.

Lemon RN, Porter R (1976) Afferent input to movement-related precentral neurones in conscious monkeys. Proc R Soc Lond [Biol] 194: 313-339

Leyton ASF, Sherrington CS (1917) Observations on the excitable cortex of the chimpanzee, orang-utan and gorilla. Q J Exp Physiol $11: 135-222$.

MacNeilage PF, Studdert-Kennedy MG, Lindblom B (1987) Primate handedness reconsidered. Behav Brain Sci 10:247-303.

Masataka N (1990) Handedness of capuchin monkeys. Folia Primatol (Basel) 55:189-192.

McGuinness E, Sivertsen D, Allman J (1980) Organization of the face representation in macaque motor cortex. J Comp Neurol 193:591608

Milliken GW, Forsythe C, Ward JP (1989) Multiple measures of handuse lateralization in the ring-tailed lemur (Lemur catta). J Comp Psychol 103:262-268.

Murphy JP, Gellhorn E (1945) Multiplicity of representation versus punctate localization in the motor cortex. Arch Neurol Psychiatry 54 256-273.

Murphy JT, Kwan HC, MacKay WA, Wong YC (1978) Spatial organization of precentral cortex in awake primates. III. Input-output coupling. J Neurophysiol 41:1132-1139.

Napier JR, Napier PH (1985) The natural history of the primates. Cambridge, MA: MIT Press.

Neafsey EJ, Bold EL, Haas G, Hurley-Gius KM, Quirk G, Sievert CF, Terreberry RR (1986) The organization of rat motor cortex: a microstimulation mapping study. Brain Res Rev 1 1:77-96.

Nudo RJ, Jenkins WM, Merzenich MM (1990) Repetitive microstimulation alters the cortical representation of movements in adult rats. Somatosens Motor Res 7:463-483.

Oldfield RC (1971) The assessment and analysis of handedness: the Edinburgh inventory. Neuropsychologia 9:97-113.

Passingham RE, Perry VH, Wilkinson F (1983) The long-term effects of removal of sensorimotor cortex in infant and adult rhesus monkeys. Brain 106:675-705

Penfield W, Boldrey E (1937) Somatic motor and sensory representation in the cerebral cortex of man as studied by electrical stimulation. Brain 60:389-443.

Penfield W, Rasmussen T (1950) The cerebral cortex of man. New York: Macmillan.

Phillips CG, Porter R (1977) Corticospinal neurones: their role in movement. New York: Academic.

Rapisarda C, Palmeri A, Aicardi G, Sapienza S (1990) Multiple representations of the body and input-output relationships in the agranular and granular cortex of the chronic awake guinea pig. Somatosens Motor Res 7:289-314.

Robinson RG (1979) Differential behavior and biochemical effects of right and left hemispheric cerebral infarction in the rat. Science 205 : $707-710$.

Rosén I, Asanuma H (1972) Peripheral afferent inputs to the forelimb area of the monkey motor cortex: input-output relations. Exp Brain Res 14:257-273.

Sanides F (1968) The architecture of the cortical taste nerve areas in squirrcl monkcy (Saimiri sciureus) and their relationships to insular, sensorimotor and prefrontal regions. Brain Res 8:97-124.

Schmidt EM, McIntosh JS (1990) Microstimulation mapping of precentral cortex during trained movements. J Neurophysiol 64:16681682 . 
Semmes I (1968) Hemispheric specialization: a possible clue to mechanism. Neuropsychologia 6:11-26.

Sherman GF, Galaburda AM (1984) Neocortical asymmetry and openfield behavior in the rat. Exp Neurol 86:473-482.

Shinoda Y, Yokota JI, Futami T (1981) Divergent projection of individual corticospinal axons to motoneurons of multiple muscles in the monkey. Neurosci Lett 23:7-12.

Springer SP, Deutsch G (1989) Left brain, right brain. New York: Freeman.

Stamm JS, Gadotti A, Rosen SC (1975) Interhemispheric functional differences in prefrontal cortex of monkeys. J Neurobiol 6:39-49.

Stoney SD Jr, Thompson WD, Asanuma H (1968) Excitation of pyramidal cells by intracortical microstimulation: effective extent of stimulating current. J Neurophysiol 31:659-669.

Stout JD (1917) On the motor functions of the cerebral cortex of the cat. Psychobiology 1:177-229.

Strick PL, Preston JB (1978) Multiple representation in the primate motor cortex. Brain Res 154:366-370.

Strick PL, Preston JB (1982a) Two representations of the hand in area 4 of a primate. I. Motor output organization. J Neurophysiol 48:139149.

Strick PL, Preston JB (1982b) Two representations of the hand in area 4 of a primate. II. Somatosensory input organization. J Neurophysiol 48:150-159.

Tan U (1984) Lateral asymmetry of H-reflex recovery curves in cat: evidence for a spinal motor asymmetry. Int J Neurosci 24:45-52.

Tan U (1985) Relationships between hand skill and the excitability of motoneurons innervating the postural soleus muscle in human subjects. Int J Neurosci 26:289-300.

Tanji J, Wise SP (1981) Submodality distribution in sensorimotor cortex of the unanesthetized monkey. J Neurophysiol 45:467-481.
Ward JP, Milliken GW, Dodson DL, Stafford DK, Wallace M (1990) Handedness as a function of sex and age in a large population of lemur. J Comp Psychol 104:169-176.

Warren JM (1977) Handedness and cerebral dominance in monkeys. In: Lateralization in the nervous system (Harnad S, Doty RW, Goldstein L, Jaynes J, Krauthamer G, eds), pp 151-172. New York: Academic.

Waters RS, Samulack DD, Dykes RW, McKinley PA (1990) Topographic organization of baboon primary motor cortex: face, hand, forelimb, and shoulder representation. Somatosens Motor Res 7:485514.

Webster WG, Webster IH (1975) Anatomical asymmetry of the cerebral hemispheres of the cat brain. Physiol Behav 14:876-869.

Welker WI, Benjamin RM, Miles RC, Woolsey CN (1957) Motor effects of stimulation of cerebral cortex of squirrel monkey (Saimiri sciureus). J Neurophysiol 20:347-364.

Whishaw IQ, Kolb B (1988) Sparing of skilled forelimb reaching and corticospinal projections after neonatal motor cortex removal or hemidecortication in the rat: support for the Kennard doctrine. Brain Res 451:97-114.

Wiesendanger $M$, Hummelsheim $H$, Bianchetti $M$ (1985) Sensory input to the motor fields of the agranular frontal cortex: a comparison of the precentral, supplementary motor and premotor cortex. Behav Brain Res 18:89-94.

Woody CD, Engel J Jr (1972) Changes in unit activity and thresholds to electrical microstimulation at coronal-pericruciate cortex of cat with classical conditioning of different facial movements. J Neurophysiol 35:230-241.

Woolsey CN (1952) Patterns of localization in sensory and motor areas of the cerebral cortex. In: Milbank symposium, The biology of mental health and disease, pp 193-206. New York: Hoeber. 